•生物编目・

\title{
安徽省苔藓植物名录
}

师雪芹 $1^{*}$, 王健 ${ }^{2}$

1. 安徽师范大学生命科学学院, 安徽芜湖 241000; 2. 华东师范大学生命科学学院, 上海 200241

摘要: 物种名录是一个地区生物多样性的本底性资料, 及时更新生物物种名录对生物多样性的保护及促进基础数据共享都 具有重要意义。为了及时总结安徽省苔藓植物的分类学研究成果, 本文通过对文献的收集和分析, 整理出安徽省苔藓植物名 录。结果显示, 安徽省共有苔藓植物95科253属777种, 其中角苔类3科3属3种, 苔类36科62属185种, 藓类56科188属589种。种 数多于 25 的科为青藓科、细鳞苔科、从藓科、真藓科、灰藓科、提灯藓科、白发藓科、绢藓科和蔓藓科。种数多于15的属为 青藓属(Brachythecium)、真藓属(Bryum)、绢藓属(Entodon)、光蕶苔属(Porella)、羽苔属(Plagiochila)、灰藓属(Hypnum)、凤 尾藓属(Fissidens)、棉藓属(Plagiothecium)和耳叶苔属(Frullania)。区系成分组成上, 安徽苔藓植物以东亚成分占优势, 达到 $44.40 \%$ ，温带成分占31.53\% (其中以北温带型最多，占 $25.61 \%$ ), 热带成分占 $18.92 \%$ (其中以热带亚洲成分最多，达到 10.30\%)。安徽省共有中国特有苔藓55种, 濒危种 1 个, 易危种 8 个。安徽苔藓植物调查呈现出地区不均衡性, 建议在广泛调查 的同时加强名录修订和专科专属研究, 对有条件的地区开展时空变化下物种多样性比较研究。

关键词: 物种多样性; 苔藓植物; 物种编目; 安徽省

师雪芹，王健 (2021) 安徽省苔藓植物名录. 生物多样性, 29, 798-804. doi: 10.17520/biods.2020314.

Shi XQ, Wang J (2021) Bryophyte checklist of Anhui Province, China. Biodiversity Science, 29, 798-804. doi: 10.17520/biods.2020314.

\section{Bryophyte checklist of Anhui Province, China}

\author{
Xueqin $\mathrm{Shi}^{{ }^{*}}$, Jian Wang ${ }^{2}$
}

1 School of Life Sciences, Anhui Normal University, Wuhu, Anhui 241000

2 School of Life Sciences, East China Normal University, Shanghai 200241

\section{ABSTRACT}

Aims: Species checklist is the background data of the biodiversity of a region. A timely update of the list plays an important role in the protection of biodiversity and the promotion of basic data sharing. In order to summarize the research results of the taxonomy of bryophytes in Anhui Province in time, it is necessary to revise the list of bryophytes in the province.

Method: Based on the collection and analysis of the published records, we updated the checklist of bryophytes in Anhui Province.

Results: In total, the present checklist includes 777 species belonging to 253 genera in 95 families, with three hornwort species in three genera and three families, 185 liverwort species in 62 genera and 36 families, and 589 moss species in 188 genera and 56 families. Families with more than 25 species are Brachytheciaceae, Lejeuneaceae, Pottiaceae, Bryaceae, Hypnaceae, Mniaceae, Leucobryaceae, Entodontaceae and Meteoriaceae. Genera with more than 15 species are Brachythecium, Bryum, Entodon, Porella, Plagiochila, Hypnum, Fissidens, Plagiothecium and Frullania. East Asian geographical element (44.40\%) is the largest component of the bryophyte flora of Anhui Province, while temperate element is $31.53 \%$ (of which the northern temperate element is the most, accounting for 25.61\%), and tropical element is $18.92 \%$ (of which the tropical Asia element is 10.30\%). There are 55 species of China's endemic species, one endangered species, and eight vulnerable species in Anhui Province. The survey of bryophytes in Anhui Province shows regional imbalances.

Conclusions: Our results suggests that, while extensive surveys are carried out, the revision of the checklist and

收稿日期: 2020-08-05; 接受日期: 2020-09-28

基金项目: 国家自然科学基金(31600167)、安徽省自然科学基金(1608085MC61)和安徽高校自然科学研究项目(KJ2016A850)

* 通讯作者 Author for correspondence. E-mail: baiyunsxq@163.com 
specialized studies should be strengthened in Anhui Province. Furthemore, comparative studies of species diversity under temporal and spatial changes should be carried out in areas where conditions permit.

Key words: species diversity; bryophytes; biodiversity inventory; Anhui Province

生物物种名录是一个自然地理区域或行政单 位的生物区系本底性基础资料, 及时更新生物物种 名录是生物多样性保护研究、管理和监测的重要基 础(马克平, 2015)。随着各地区调查的深入及专科专 属类群修订的不断开展, 新物种被不断发现和描述, 已知物种的地理分布数据也得以不断更新。发表物 种分布信息共享的论文大大促进了研究者之间的 数据交流与共享。因此, 为了及时总结分类学研究 成果, 依据最新分类学文献更新生物物种名录, 对 生物多样性的保护及促进基础数据共享都具有重 要意义。

苔藓植物是最原始的一类高等植物, 其多样性 在高等植物中仅次于被子植物, 是生物多样性的重 要组成部分。随着人类活动的加剧、经济的快速发 展和环境的变化, 对环境变化极其敏感的苔藓植物 正面临着比其他植物更大的威胁。但由于其个体细 小、种类繁多、野外采集及分类鉴定困难等原因, 使 得苔藓植物的保护成为整个生物多样性保护中较 为薄弱的一环。

安徽省位于我国东部, 地理位置 $114^{\circ} 54^{\prime}-119^{\circ} 37^{\prime}$ E, $29^{\circ} 41^{\prime}-34^{\circ} 38^{\prime} \mathrm{N}$, 地跨长江、淮 河、钱塘江三大水系, 具有优越而独特的自然环境 和地理位置。境内地形地貌多样, 山地、丘陵、台 地、平原兼有。从北到南可将安徽省分为 5 个地理 单元: 淮河中游平原、江淮丘陵台地、皖西丘陵山 地、沿江平原和皖南丘陵山地。黄山为安徽省最高 峰, 海拔1,848 m。大致以淮河为界, 北部属暖温带 半湿润季风气候, 南部属亚热带湿润季风气候。植 被在淮河以北属暖温带落叶阔叶林带, 淮河以南属 北亚热带落叶阔叶与常绿阔叶混交林带。气候和植 被从南到北均呈现明显的过渡性。全省年平均气温 在 $14-17^{\circ} \mathrm{C}$ 之间, 平均日照 $1,800-2,500 \mathrm{~h}$, 平均无霜 期200-250 d, 平均降水量800-1,800 mm (闵显铭等, 1991; http://www.ah.gov.cn/hfwy/index.html)。

安徽省的苔藓调查和研究始于 20 世纪初期。最 早开展研究的是法国植物学家 P. Courtois, 他于 1907-1909年在安徽省(Ngan Hoei)的徽州府(Hoei
Tcheou Fou)、芜湖(Wu Hu) 等地采集了少量苔藓植 物, 后交给Paris进行研究并发表(Paris, 1908, 1909, 1911)。安徽省首次记录的苔藓植物是采自徽州府的

Trematodon tonkinensis Besch. (=Trematodon longicollis Michx.)。20世纪60年代, 陈邦杰教授及其 学生对黄山苔藓植物做了全面调查, 发表了《黄山 苔藓植物的初步研究》(陈邦杰和吴鹏程, 1965), 正 式揭开了安徽苔藓植物研究的篇章。到目前为止, 安徽苔藓研究的主要区域集中在皖南(陈邦杰和吴 鹏程, 1965; 郑维发, 1993; 吴明开等, 2008; 师雪芹 等, 2009)和皖西山区(Cai，2002; 师雪芹和陈家伟, 2012)。根据对 Annotated catalogue of Chinese Hepaticae and Anthocerotae (Piippo, 1990)和A newly updated and annotated checklist of Chinese mosses (Redfearn et al, 1996)两篇有关中国苔藓植物多样性 文献的统计, 分别记载安徽苔类和角苔类植物 114 种, 藓类植物457种。此外, 1993年《华东五省一市 植物名录》记录了安徽苔藓558种(张美珍和赖明洲, 1993)。

近些年, 随着苔藓植物分子系统学和专科专属 研究的进展, 苔藓植物分类系统发生了较大的变 化。一些属和种的系统位置变动, 一些科和属的概 念也发生了变化, 导致出现了大量的新组合和异 名。同时也由于苔藓植物调查的不断深入和范围扩 大, 出现了一些新种和新记录。本文在原有名录的 基础上, 收集了近些年安徽省苔藓研究相关的文献, 对安徽省的苔藓植物名录进行了整理更新, 以期为 后续工作提供基础资料, 同时为接下来的调查指明 方向。

\section{材料与方法}

物种名录的依据主要来源于正式发表的文献, 包括《中国苔藓志》(1-10卷), Moss Flora of China (Vol. 1-8), 涉及到安徽苔藓植物的名录, 以及已出 版的苔藓专著和期刊文献等, 硕士和博士论文未包 括在内。详见附录1后的文献引用。

苔类和角苔类的分类系统和学名主要参考 
Söderström等(2016); 藓类植物的分类系统和学名 则主要参考《中国生物物种名录》(第一卷)(贾渝和 何思, 2013)。每个种给出参考文献出处和分布地点 (附录1)。存疑种和排除出安徽的种在名录后单独列 出, 存疑种主要是一些文献和名录中记载安徽有分 布，但是没有引用凭证标本(如：吴鹏程等，2012; 贾渝和何思, 2013)或者无法追溯到凭证标本的种 (如: 张美珍和赖明洲, 1993), 也包括个别没有注明 采集号和馆藏地点的种(赵传海和张朝晖, 2006)。区 系成分组成参考吴征镒(1991)对中国种子植物属的 划分，每个种的分布范围主要参考贾渝和何思 (2013)以及 《中国苔藓志》, 将安徽苔藓植物划分为 13种分布型3种亚型。特有种的统计参考《中国生 物物种名录》(第一卷)(贾渝和何思, 2013)确定。受 威胁苔藓植物参照《中国高等植物受威胁物种名 录》(覃海宁等, 2017)进行确定。

\section{2 结果}

\section{1 安徽苔藓种类的组成及特点}

根据以上原则和方法统计的结果表明, 安徽省 共有苔藓植物 95科 253属777种(含9亚种19变种), 科、属、种分别占中国苔藓植物的 $63.33 \%$ 、 $42.81 \%$ 和 $25.72 \%$ 。其中角苔类3科3属3种，苔类36科 62 属 185种(含5亚种6变种), 藓类56科188属589种(含4亚 种13变种), 种数分别占我国角苔类的 $11.54 \%$, 苔类 的 $17.62 \%$, 藓类的 $30.28 \%$ 。存疑种 78 种, 排除出安 徽的18种。

科的组成上(表1), 含 1 种的科最多, 其次是含 2-4种的科, 这两类共 57 个科, 占总科数的 $60 \%$, 但 仅占安徽苔藓总种数的 $13.38 \%$ 。种数多于 25 的科分 别是青藓科(13属63种)、细鳞苔科(12属43种)、从藓
科(15属42种)、真藓 科(4属33种)、灰藓科 (8属32种)、 提灯藓科(6属28种)、白发藓科(4属26种)、绢藓科 (4 属26种)和蔓藓科(14属25种)。这 9 个科 1 个是苔类, 8 个为藓类, 共包含 80 属 318 种, 分别占安徽苔藓总 属数和总种数的 $31.62 \%$ 和 $40.93 \%$ 。

属的组成上(表1), 含1种的属最多，共125个， 占总属数的 $49.41 \%$, 其种数仅占安徽苔藓总种数的 $16.09 \%$ 。种数多于 15 的属分别是青藓属 (Brachythecium) (32种)、真藓属(Bryum) (23种)、绢 藓属(Entodon) (23种)、光葶苔属(Porella) (17种)、 羽苔属(Plagiochila) (16种)、灰藓属(Hypnum) (16 种)、凤尾藓属 (Fissidens) (15 种)、棉藓属 (Plagiothecium) (15种)和耳叶苔属(Frullania) (15 种)。这 9 个属中 3 个为苔类, 6 个为藓类, 共包含 172 个种，占安徽苔藓总种数的 $22.14 \%$ 。

\section{2 安徽苔藓区系的基本特征}

安徽省苔藓植物中, 热带分布种(147种)、温带 分布种(245种)和东亚分布种(345种), 分别占总种 数的 $18.92 \% 、 31.53 \%$ 和 $44.40 \%$ (表2)。热带成分以 热带亚洲型为主(10.30\%), 温带成分以北温带型为 主(25.61\%), 东亚成分以中国-日本分布亚型为主 (24.20\%)。在苔类、角苔类以及藓类中，东亚成分 均最多，在苔类和角苔中，热带成分 $(23.40 \%)$ 略多 于温带成分 (22.34\%); 而在藓类中，温带成分 (34.47\%)多于热带成分 (17.49\%), 这与前人的研究 结果(陈邦杰和吴鹏程, 1965; 吴明开等, 2008; 师雪 芹等, 2009)比较一致。总体上安徽苔藓植物区系表 现出温带成分高于热带成分，东亚成分占据优势的 特点。

\section{3 特有种和濒危种}

安徽省共有中国特有种 55 种，其中苔类6种，

\section{表1 安徽省苔藓植物区系科和属的分级统计}

Table 1 Statistics on families and genera of bryophytes in Anhui Province

\begin{tabular}{llll||lll}
\hline $\begin{array}{l}\text { 科的大小 } \\
\text { Size of family }\end{array}$ & $\begin{array}{l}\text { 科数 } \\
\text { No. family (\%) }\end{array}$ & $\begin{array}{l}\text { 所含属数 } \\
\text { No. genera (\%) }\end{array}$ & $\begin{array}{l}\text { 所含种数 } \\
\text { No. species (\%) }\end{array}$ & $\begin{array}{l}\text { 属的大小 } \\
\text { Size of genus }\end{array}$ & $\begin{array}{l}\text { 属数 } \\
\text { No. genus (\%) }\end{array}$ & $\begin{array}{l}\text { 所含种数 } \\
\text { No. species (\%) }\end{array}$ \\
\hline$\geq 25$ 种 $\geq 25$ species & $9(9.47)$ & $80(31.62)$ & $318(40.93)$ & $\geq 15$ 种 $\geq 15$ species & $9(3.56)$ & $172(22.14)$ \\
$15-24$ 种 $15-24$ species & $12(12.63)$ & $50(19.76)$ & $210(27.03)$ & $10-14$ 种 $10-14$ species & $5(1.98)$ & $54(6.95)$ \\
5-14 种 5-14 species & $17(17.89)$ & $48(18.97)$ & $145(18.66)$ & 5-9 种 5-9 species & $30(11.86)$ & $202(26.00)$ \\
2-4 种 2-4 species & $27(28.42)$ & $45(17.79)$ & $74(9.52)$ & 2-4 种 2-4 species & $84(33.20)$ & $224(28.83)$ \\
1 种 1 species & $30(31.58)$ & $30(11.86)$ & $30(3.86)$ & 1 种 1 species & $125(49.41)$ & $125(16.09)$ \\
\hline
\end{tabular}


表2 安徽苔藓植物分布区类型统计

Table 2 Areal types of bryophyte species in Anhui Province

\begin{tabular}{|c|c|c|c|c|c|c|}
\hline \multirow{2}{*}{ 分布区类型 Areal type } & \multicolumn{2}{|c|}{ 苔和角苔 Liverwort \& hornwort } & \multicolumn{2}{|l|}{ 蘚 Moss } & \multicolumn{2}{|c|}{ 苔藓 Bryophyte } \\
\hline & 数量 Number & $\%$ & 数量 Number & $\%$ & 数量 & Number \% \\
\hline 1. 世界分布 Cosmopolitan & 9 & 4.79 & 31 & 5.26 & 40 & 5.15 \\
\hline 2. 泛热带 Pantropic & 3 & 1.60 & 8 & 1.36 & 11 & 1.42 \\
\hline 3. 热带亚洲和热带美洲 Trop. Asia \& Trop. Amer. Disjuncted & 0 & 0.00 & 8 & 1.36 & 8 & 1.03 \\
\hline 4. 旧世界热带 Old World Tropics & 6 & 3.19 & 5 & 0.85 & 11 & 1.42 \\
\hline 5. 热带亚洲至热带大洋洲 Trop. Asia \& Trop. Australasia & 6 & 3.19 & 16 & 2.72 & 22 & 2.83 \\
\hline 6. 热带亚洲至热带非洲 Trop. Asia \& Trop. Africa & 4 & 2.13 & 11 & 1.87 & 15 & 1.93 \\
\hline 7. 热带亚洲 Trop. Asia & 25 & 13.30 & 55 & 9.34 & 80 & 10.30 \\
\hline 热带成分小计 Subtotal & 44 & 23.40 & 103 & 17.49 & 147 & 18.92 \\
\hline 8. 北温带 North Temperate & 30 & 15.96 & 169 & 28.69 & 199 & 25.61 \\
\hline 9. 东亚北美 E. Asia \& N. Amer. Disjuncted & 8 & 4.26 & 19 & 3.23 & 27 & 3.47 \\
\hline 10. 旧世界温带 Old World Temperate & 3 & 1.60 & 13 & 2.21 & 16 & 2.06 \\
\hline 11. 温带亚洲 Temperate Asia & 1 & 0.53 & 2 & 0.34 & 3 & 0.39 \\
\hline 温带成分小计 Subtotal & 42 & 22.34 & 203 & 34.47 & 245 & 31.53 \\
\hline 12. 东亚分布 E. Asia & (87) & $(46.28)$ & (203) & $(34.47)$ & (290) & $(37.32)$ \\
\hline 12-1. 东亚广布 Himalaya-Sino-Japan & 32 & 17.02 & 39 & 6.62 & 71 & 9.14 \\
\hline 12-2. 中国-喜马拉雅 Sino-Himalaya & 7 & 3.72 & 24 & 4.07 & 31 & 3.99 \\
\hline 12-3. 中国-日本 Sino-Japan & 48 & 25.53 & 140 & 23.77 & 188 & 24.20 \\
\hline 13. 中国特有 Endemic to China & 6 & 3.19 & 49 & 8.32 & 55 & 7.08 \\
\hline 东亚成分小计 Subtotal & 93 & 49.47 & 252 & 42.78 & 345 & 44.40 \\
\hline 总计 Total & 188 & 100.00 & 589 & 100.00 & 777 & 100.00 \\
\hline
\end{tabular}

藓类 49 种, 占安徽苔藓的 $7.08 \%$ 。根据覃海宁等 (2017), 安徽省有濒危种 (EN) 1个: 短柄卷叶藓 (Ulota perbreviseta); 易危种(VU) 8个: 白绿细鳞苔 (Lejeunea pallidevirens) 、苏氏冠鳞苔 (Lopholejeunea soae)、新线苔 (Neotrichocolea bissetii)、华东蓑藓(Macromitrium courtoisii)、粗柄 木灵藓 (Orthotrichum subpumilum) 、毛尖棉藓 (Plagiothecium piliferum)、树形蕨藓 (Pterobryon arbuscula) 和顶胞藓粗枝变种 (Acroporium stramineum var. turgidum)。

\section{4 存疑种和排除种}

名录中包括了 78 个存疑种, 它们多数是出现在 一些名录和苔藓志中, 但没有引用凭证标本。这些 物种引用的硕士学位论文(Redfearn et al, 1996)或者 未正式发表的文献(张美珍和赖明洲, 1993), 或者每 个种后无明确的文献引证(如: 张美珍和赖明洲, 1993; 吴鹏程等, 2012; 贾渝和何思, 2013), 无法追 溯到凭证标本, 故作为存疑处理。部分种没有注明 采集号和馆藏地点(赵传海和张朝晖, 2006)也作为 存疑处理。其中有少部分种, 根据我们的调查已确
定安徽有分布, 如地钱 (Marchantia polymorpha) 和 粗裂地钱风自亚种 (Marchantia paleacea ssp. diptera)。名录中还包括了18个排除出安徽的种, 有 些是原始鉴定错误, 如Cheilolejeunea mariana、 Cololejeunea floccosa 等; 有些是错误引用, 如 Homaliodendron flabellatum 、 Trichosteleum mammosum等。

\section{3 今后工作的建议}

\section{1 加大苔藓调查的广度和深度}

安徽省的地形地貌多样, 从北到南由平原到丘 陵到山区, 也决定了苔藓调查的不均衡。淮北平原 地势平坦, 地形地貌单一, 植被主要为人工植被和 农作物, 几乎未见苔藓记录。江淮丘陵台地为大别 山余脉向东的延伸部分, 多数海拔在 $200 \mathrm{~m}$ 以下, 少数丘陵达到 $500 \mathrm{~m}$, 仅滁州琅哪山有少量的苔藓 记载。沿江平原区以冲积平原为主, 地势低洼, 河 湖众多, 水网交织, 其间有少量低丘分布, 仅芜湖、 铜陵等地有零散苔蘚记载。

安徽苔藓调查的主要区域集中在皖西和皖南 
的丘陵山地, 皖南黄山和皖西大别山也被《中国生 物多样性保护行动计划(2011-2030年)》列为生物多 样性保护优先区域。这两个区域保存了较为完整的 亚热带森林生态系统，地形地貌多样、植被茂盛、 小生境多样; 同时大量的国家级和省级自然保护 区、森林公园和风景名胜区, 为苔藓植物生长提供 了良好的条件, 一直以来都是植物学家调查的首选 地区。皖南山区早在20世纪20年代就有苔藓采集活 动, 1965年出版的《黄山苔蘚植物的初步研究》(陈 邦杰和吴鹏程, 1965)是安徽省最早的系统性区域苔 藓植物调查。黄山也是迄今安徽省苔蘚调查次数最 多、苔藓记载种类最多的山脉。此外, 皖南的牯牛 降、九华山、浙皖交界的清凉峰也都有苔藓调查。 皖西的调查最早见于 1985 年胡人亮教授带领学生 刘仲苓、蔡空辉、钱琳和赵建成等对大别山主峰白 马尖的系统考察和采集(Cai, 2002), 此后是天马自 然保护区(师雪芹和陈家伟, 2012), 安徽省境内的䍃 落坪、古井园、天柱山等尚未见有系统的调查报告。 基于此, 此后应该加强对安徽苔藓调查比较薄弱的 地区的工作，同时对皖南和皖西山区的调查应该继 续深入。

\section{2 加快名录和科属的修订}

从目前统计数量上来看, 安徽的苔藓数量比较 丰富, 但是文献来源呈现出原始调查数据年代久远 的特点, 许多种自从发表后一直是文献引用, 而在 近些年的调查并未发现。如一些仅出现在《华东五 省一市植物名录》的种：日本网藓(Syrrhopodon japonicus)、拟木毛藓(Pseudospiridentopsis horrida)、 滇蒴蘚(Pseudopterobryum tenuicuspisa)等(张美珍和 赖明洲，1993), 因为每个种后没有文献引用, 现在 难以回溯具体的文献引证和标本引证, 且在随后的 文献中均未记载, 这些种在安徽的真实分布值得商 榷。再如镰蔩苔(Harpanthus flotovianus), 该种在中 国首次记录地点在安徽大别山的白马尖(钱琳和蔡 空辉, 1989), 《中国苔藓志》(第十卷) (高谦和吴玉 环, 2008)中在该种后面也只引用这份标本, 此后国 内其他省份再未见有该种的分布报道。刘氏同叶藓 (Isopterygium lioui)是1938年基于安徽黄山的采集 发表的种，陈邦杰和吴鹏程(1965)对黄山苔藓的研 究也记录了该种, 但是《中国苔藓志》和Moss Flora of China均未记录该种, 《中国生物物种名录》(第 一卷) (贾渝和何思, 2013)记载该种在中国仅安徽省
有分布。我们对这些“文献种”认识很少, 因此建议 在全面采集标本的基础上, 逐步开展专科专属的研 究，这项工作将有助于我们对这些“文献种”的确认， 厘清一些形近种和近缘种的关系, 排除一些错误鉴 定, 同时发现一些新种和新记录(师雪芹等, 2018)。

\section{3 苔藓物种多样性的时空变化}

一个地区的物种多样性随着该地区外部环境 的变化而发生变化, 在野外调查的基础上, 要对不 同地区的物种多样性进行空间上的比较以知晓不 同区域物种的差异，并探究产生差异的原因。同时 对一些本底调查工作比较完善的地区还要进行时 间上的比较以了解同一地区不同时间段的物种组 成变化, 可以研究环境变化以及人类活动对物种多 样性的影响, 进而为地区物种保护提供指导性建 议。大别山位于鄂皖豫交界处, 这一区域与邻近区 域苔藓植物的区系比较研究, 将为中国苔藓植物分 区中华东区和华中区的划分合理性提供重要的依 据(吴鹏程和贾渝, 2006)。目前我国有少量研究用定 点复查方法对苔藓多样性变化进行研究, 如西天目 山(汪岱华等, 2013)和上海徐家汇(刘艳等, 2008)。黄 山作为安徽省首个苔藓调查全面的地区(陈邦杰和 吴鹏程, 1965), 半个世纪以来, 一方面是旅游开发 和基础设施建设带来的环境变化和部分小生境丧 失, 另一方面是随着调查深入新记录不断出现, 因 此可以将这些因素考虑进去, 进行苔藓植物时空多 样性变化的研究。

\section{参考文献}

Cai KH (2002) A list of the bryophytes of Mt. Baimajian Houshan County, Anhui Province, SE China. Chenia, 7, 149-159.

Chen PC, Wu PC (1965) The preliminary study of the bryophytes of Mt. Hwangshan. In: Observationes ad Florulam Hwangshanicum (eds Chen PC, Wu PC, Qiu PX, $\mathrm{Xu}$ BS, Zhou JL), pp. 1-59. Shanghai Scientific \& Technical Publishers, Shanghai. (in Chinese) [陈邦杰, 吴鹏 程 (1965) 黄山苔藓植物的初步研究. 见: 黄山植物的研 究(陈邦杰, 吴鹏程, 雸佩喜, 徐炳声, 周纪纶主编), 1-59 页. 上海科学技术出版社, 上海.]

Gao C, Wu YH (2008) Flora Bryophytarum Sinicorum, Vol. 10. Science Press, Beijing. (in Chinese) [高谦, 吴玉环 (2008) 中国苔藓志(第10卷). 科学出版社, 北京.]

Jia Y, He S (2013) Species Catalogue of China, Vol. 1. Plants: Bryophytes. Science Press, Beijing. (in Chinese) [贾渝, 何 思 (2013) 中国生物物种名录(第一卷): 植物・苔藓植物. 
科学出版社, 北京.]

Liu Y, Cao T, Lou YX (2008) Effect of environmental change on species diversity of bryophytes: A case study in Xujiahui (Zi ka Wei) area, Shanghai. Biodiversity Science, 16, 181-184. (in Chinese with English abstract) [刘艳, 曹同, 娄玉霞 (2008) 环境变化对苔藓植物物种多样性的影响: 以上海徐家汇地区为例. 生物多样性, 16, 181-184.]

Ma KP (2015) Species Catalogue of China: A remarkable achievement in the field of biodiversity science in China. Biodiversity Science, 23, 137-138. (in Chinese) [马克平 (2015) 中国生物多样性编目取得重要进展. 生物多样性, 23, 137-138.]

Min YM, Cao ST, Fang JS, Yang JS, Guo BX (1991) Anhui Geography. Anhui People's Publishing House, Hefei. (in Chinese) [闵煜铭, 曹松涛, 方觉曙, 杨积述, 过宝兴 (1991) 安徽省地理. 安徽人民出版社, 合肥.]

Paris EG (1908) Muscinées de l'Asie orientale. 7. Revue Bryologique, 35, 40-55.

Paris EG (1909) Muscinées de l'Asie Orientale. 9. Revue Bryologique, 36, 8-13.

Paris EG (1911) Mousses de l'Asie orientale. 12. Revue Bryologique, 38, 53-60.

Piippo S (1990) Annotated catalogue of Chinese Hepaticae and Anthocerotae. Journal of the Hattori Botanical Laboratory, 68, 1-192.

Qian L, Tsai KH (1989) Some bryophytes new to China found in Anhui, China. Bulletin of Botanical Research, 9(1), 81-84. (in Chinese with English abstract) [钱琳, 蔡空辉 (1989) 安徽产苔蘚植物新记录种. 植物研究, 9(1), 81-84.]

Qin HN, Yang Y, Dong SY, He Q, Jia Y, Zhao LN, Yu SX, Liu HY, Liu B, Yan YH, Xiang JY, Xia NH, Peng H, Li ZY, Zhang ZX, He XJ, Yin LK, Lin YL, Liu QR, Hou YT, Liu Y, Liu QX, Cao W, Li JQ, Chen SL, Jin XH, Gao TG, Chen WL, Ma HY, Geng YY, Jin XF, Chang CY, Jiang H, Cai L, Zang CX, Wu JY, Ye JF, Lai YJ, Liu B, Lin QW, Xue NX (2017) Threatened Species List of China's Higher Plants. Biodiversity Science, 25, 696-744. (in Chinese and in English) [覃海宁, 杨永, 董仕勇, 何强, 贾渝, 赵莉娜, 于胜祥, 刘慧圆, 刘博, 严岳鸿, 向建英, 夏念和, 彭华, 李振宇, 张志翔, 何兴金, 尹林克, 林余霖, 刘全儒, 侯 元同, 刘演, 刘启新, 曹伟, 李建强, 陈世龙, 金效华, 高 天刚, 陈文俐, 马海英, 耿玉英, 金孝锋, 常朝阳, 蒋宏, 蔡蕾, 藏春金鍂, 武建勇, 叶建飞, 赖阳均, 刘冰, 林秦文, 薛纳新 (2017) 中国高等植物受威胁物种名录. 生物多 样性, 25, 696-744.]

Redfearn PL Jr, Tan BC, He S (1996) A newly updated and annotated checklist of Chinese mosses. Journal of the Hattori Botanical Laboratory, 79, 163-357.

Shi XQ, Chen JW (2012) Study on bryophytes flora in Tianma Nature Reserve of Anhui Province, China. Journal of Anhui Normal University (Natural Science), 35, 158-162. (in Chinese with English abstract) [师雪芹, 陈家伟 (2012) 天
马自然保护区苔藓植物区系研究. 安徽师范大学学报(自 然科学版), 35, 158-162.]

Shi XQ, Tang X, Wei YM, Wang J (2018) Study and investigation of Lejeuneaceae species diversity in Anhui Province. Journal of East China Normal University (Natural Science), (4), 138-146. (in Chinese with English abstract) [师雪芹, 唐霞, 韦玉梅, 王健 (2018) 安徽省细鳞苔科植 物物种多样性调查与研究. 华东师范大学学报(自然科学 版), (4), 138-146.]

Shi XQ, Wu MK, Zhang XP (2009) Studies on liverwort flora in Huangshan Mountain. Journal of Wuhan Botanical Research, 27, 368-372. (in Chinese with English abstract) [师雪芹, 吴明开, 张小平 (2009) 黄山苔类植物区系研 究. 武汉植物学研究, 27, 368-372.]

Söderström L, Hagborg A, von Konrat M, Bartholomew-Began SE, Bell D, Briscoe L, Brown EA, Cargill DC, Costa DP, Crandall-Stotler BJ, Cooper ED, Dauphin López AG, Engel JJ, Feldberg K, Glenny D, Gradstein SR, He XL, Heinrichs J, Hentschel J, Ilkiu-Borges AL, Katagiri T, Konstantinova NA, Larraín J, Long DG, Nebel M, Pócs T, Puche F, Reiner-Drehwald ME, Renner MAM, Gyarmati AA, Schäfer-Verwimp A, Segarra-Moragues JG, Stotler RE, Sukkharak P, Thiers BM, Uribe J, Váňa J, Villarreal A JC, Wigginton MJ, Zhang L, Zhu RL (2016) World checklist of hornworts and liverworts. PhytoKeys, 59(1-2), 1-828.

Wang DH, Wang YF, Zuo Q, Li M, Wei QQ, Li XQ, Zhao MS (2013) Comparison of bryophyte diversity in West Tianmu Mountain from 1977 to 2011. Biodiversity Science, 21, 170-179. (in Chinese with English abstract) [汪岱华, 王幼 芳, 左勤, 李敏, 魏倩倩, 李晓芹, 赵明水 (2013) 浙江 西天目山30年来苔藓物种多样性变化. 生物多样性, 21 , 170-179.]

Wu MK, Cao T, Zhang XP (2008) Study on moss flora of Anhui Province, China. Acta Botanica Yunnanica, 30, 645-654. (in Chinese with English abstract) [吴明开, 曹同, 张小平 (2008) 安徽藓类植物区系. 云南植物研究, 30, 645-654.]

Wu PC, Jia Y (2006) The regionalization and distribution types of the bryophytes in China. Journal of Plant Resources and Environment, 15(1), 1-8. (in Chinese with English abstract) [吴鹏程, 贾渝 (2006) 中国苔藓植物的地理分区及分布 类型. 植物资源与环境学报, 15(1), 1-8.]

Wu PC, Jia Y, Zhang L (2012) Higher Plants of China, (Vol. 1.): Bryophyta. Qingdao Press, Qingdao. (in Chinese) [吴鹏 程, 贾渝, 张力 (2012) 中国高等植物(第一卷): 苔藓植 物门. 青岛出版社, 青岛.]

Wu ZY (1991) The areal-types of Chinese genera of seed plants. Acta Batanica Yunnanica, 13(IV), 1-139. (in Chinese) [吴征镒 (1991) 中国种子植物属的分布区类型. 云南植物研究, 13(IV), 1-139.]

Zhang MZ, Lai MZ (1993) Checklist of Plants of Five Provinces and One City in Eastern China. Shanghai Popular Science Press, Shanghai. (in Chinese) [张美珍, 赖明洲 
(1993) 华东五省一市植物名录. 上海科学普及出版社, 上海.]

Zhao CH, Zhang ZH (2006) Studies on bryophytes in the Shizishan copper mine of Tongling City, Anhui. Journal of Guizhou Normal University (Natural Sciences), 24(2), 7-12. (in Chinese with English abstract) [赵传海, 张朝晖 (2006) 安徽铜陵狮子山铜矿苔藓植物研究. 贵州师范大学学报 (自然科学版), 24(2), 7-12.]

Zheng WF (1993) A floristic study on bryophytes of
Qingliangfeng natural preserve of Shexian County, Anhui Province. Journal of Xuzhou Normal University (Natural Science Edition), 11, 39-43. (in Chinese with English abstract) [郑维发 (1993) 安徽檀县清凉峰自然保护区苔 藓植物区系研究. 徐州师范学院学报(自然科学版), 11, 39-43.]

(责任编委: 朱瑞良 责任编辑: 时意专)

\section{附录 Supplementary Material}

\section{附录1 安徽省苔藓植物名录}

Appendix 1 Bryophyte checklist of Anhui Province

http://www.biodiversity-science.net/fileup/PDF/2020314-1.pdf 


\section{附录 1 安徽省苔蘚植物名录}

Appendix 1 Bryophyte checklist of Anhui Province

\section{角苔科 Anthocerotaceae}

\section{角苔植物门 Anthocerotophyta}

\section{角苔属 Anthoceros}

1. 角苔 Anthoceros punctatus $\mathrm{L}$.

安徽(Piippo, 1990; 张美珍和赖明洲, 1993; 贾渝和何思, 2013); 黄山市(陈邦杰和吴鹏 程, 1965 as A. crispulus)。

\section{大角苔科 Dendrocerotaceae}

大角苔属 Megaceros

2. 东亚大角苔 Megaceros flagellaris (Mitt.) Steph.

祁门县(彭涛等, 2018)。

\section{短角苔科 Notothyladaceae}

黄角苔属 Phaeoceros

3. 黄角苔 Phaeoceros laevis (L.) Prosk.

安徽(张美珍和赖明洲, 1993); 霍山县(Cai, 2002)。

\section{裸蒴苔科 Haplomitriaceae}

\section{苔类植物门 Marchantiophyta}

\section{裸蒴苔属 Haplomitrium}

4. 圆叶裸龩苔 Haplomitrium mnioides (Lindb.) R. M. Schust.

祁门县(程前和师雪芹, 2019)。

\section{隐葫苔科 Adelanthaceae}

\section{对耳苔属 Syzygiella}

5. 东亚对耳苔 Syzygiella nipponica (S. Hatt.) K. Feldberg, Váňa, Hentschel et Heinrichs 安徽(贾渝和何思, 2013); 黄山市(Gao \& Bai, 2001 as Jamesoniella verrucosa；高谦, 2003 as J. nipponica); 檁县(Gao \& Bai, 2001 as J. verrucosa; 高谦, 2003 as J. nipponica)。

\section{挺叶苔科 Anastrophyllaceae}

\section{圆瓣苔属 Biantheridion}

6. 波叶圆瓣苔 Biantheridion undulifolium (Nees) Konstant. et Vilnet

霍山县(Gao \& Bai, 2001 as Jamesoniella undulifolia; 高谦, 2003 as J. undulifolia)。

\section{服部苔属 Hattoria}

7. 服部苔 Hattoria yakushimensis (Horik.) R. M. Schust.

黄山市(程前等, 2020)。

\section{褶葶苔属 Plicanthus}

8. 全缘褶萼苔 Plicanthus birmensis (Steph.) R. M. Schust.

安徽(张美珍和赖明洲, 1993 as Chandonanthus birmensis); 霍山县(Cai, 2002 as $C$. birmensis)。 
9. 齿边褶萝苔 Plicanthus hirtellus (F. Weber) R. M. Schust.

安徽(Piippo, 1990 as Chandonanthus hirtellus; 张美珍和赖明洲, 1993 as C. hirtellus); 黄 山市(陈邦杰和吴鹏程, 1965 as C. hirtellus); 石台县(郭新弧等, 1990 as C. hirtellus)。

\section{大蕶苔科 Cephaloziaceae}

\section{Fuscocephaloziopsis}

10. Fuscocephaloziopsis pleniceps (Austin) Váňa et L. Söderstr.

安徽(Piippo, 1990 as Cephalozia pleniceps); 祁门县(郭新弧等, 1990 as C. pleniceps)。

\section{拳叶苔属 Nowellia}

11. 无毛拳叶苔 Nowellia aciliata (P. C. Chen et P. C. Wu) Mizut.

安徽(Piippo, 1990; 贾渝和何思, 2013); 黄山市(陈邦杰和吴鹏程, 1965 as N. curvifolia var. aciliata；高谦, 2003)。

12. 拳叶苔 Nowellia curvifolia (Dicks.) Mitt.

安徽(Piippo, 1990; 张美珍和赖明洲, 1993; 贾渝和何思, 2013); 黄山市(陈邦杰和吴鹏 程, 1965; 高谦, 2003); 石台县(郭新弧等, 1990)。

\section{裂齿苔属 Odontoschisma}

13. 合叶裂齿苔 Odontoschisma denudatum (Mart.) Dumort.

安徽(Piippo, 1990; 张美珍和赖明洲, 1993); 黄山市(陈邦杰和吴鹏程, 1965); 霍山县 (Cai, 2002)。

\section{拟大蕶苔科 Cephaloziellaceae 拟大蕶苔属 Cephaloziella}

14. 刺茎拟大莺苔 Cephaloziella spinicaulis Douin 繁昌县(程前和师雪芹, 2018); 宁国市(程前和师雪芹, 2018); 歇县(程前和师雪芹, 2018)。

\section{筒蕓苔属 Cylindrocolea}

15. 弯叶筒蕶苔 Cylindrocolea recurvifolia (Steph.) Inoue 安徽(张美珍和赖明洲, 1993 as Cephaloziella recurvifolia); 石台县(郭新弧等, 1990 as $C$. recurvifolia)。

\section{折叶苔科 Scapaniaceae}

\section{折叶苔属 Diplophyllum}

16. 尖瓣折叶苔 Diplophyllum apiculatum (A. Evans) Steph. 安徽(贾渝和何思, 2013); 黄山市(高谦和吴玉环, 2008)。

\section{合叶苔属 Scapania}

17. 刺边合叶苔 Scapania ciliata Sande Lac.

安徽(Piippo, 1990; 张美珍和赖明洲, 1993; 贾渝和何思, 2013); 黄山市(陈邦杰和吴鹏 程, 1965 as S. spinosa；高谦和吴玉环, 2008); 霍山县(Cai, 2002)。

18. 舌叶合叶苔多齿变种 Scapania ligulata ssp. stephanii (Müll. Frib.) Potemkin 安徽(Piippo, 1990 as S. stephanii; 张美珍和赖明洲, 1993 as S. stephanii; 贾渝和何思, 2013); 黄山市(陈邦杰和吴鹏程, 1965 as S. stephanii; 高谦和吴玉环, 2008 as $S$. stephanii); 霍山县(Cai, 2002 as S. stephanii)。

19. 细齿合叶苔 Scapania parvidens Steph. 
安徽(Piippo, 1990); 黄山市(陈邦杰和吴鹏程, 1965; 高谦和吴玉环, 2008)。

20. 弯瓣合叶苔 Scapania parvitexta Steph.

安徽(张美珍和赖明洲, 1993; 贾渝和何思, 2013); 黄山市(高谦和吴玉环, 2008); 石台县 (郭新弧等, 1990)。

21. 合叶苔 Scapania undulata (L.) Dumort.

安徽(张美珍和赖明洲, 1993; 贾渝和何思, 2013); 黄山市(高谦和吴玉环, 2008); 霍山县 (Cai, 2002)。

22. 粗疮合叶苔 Scapania verrucosa Heeg

安徽(Piippo, 1990 as S. parva；张美珍和赖明洲, 1993 as S. parva；贾渝和何思, 2013); 黄 山市(陈邦杰和吴鹏程, 1965 as S. verrucifera；高谦和吴玉环, 2008)。

\section{顶苞苔科 Acrobolbaceae}

\section{顶苞苔属 Acrobolbus}

23. 针角顶苍苔 Acrobolbus ciliatus (Mitt.) Schiffn.

黄山市(程前和师雪芹, 2018)。

\section{护薪苔科 Calypogeiaceae}

\section{护秙苔属 Calypogeia}

24. 刺叶护蒴苔 Calypogeia arguta Nees et Mont. 安徽(张美珍和赖明洲, 1993); 霍山县(Cai, 2002)。

25. 三角护龩苔 Calypogeia azurea Stotler et Crotz 安徽(Piippo, 1990 as C. trichomanis; 张美珍和赖明洲, 1993 as C. trichomanis); 石台县 (郭新弧等, 1990 as C. trichomanis)。

26. 针叶护蒴苔 Calypogeia neesiana (C. Massal. et Carestia) Müll. Frib. 安徽(Piippo, 1990; 张美珍和赖明洲, 1993); 黄山市(陈邦杰和吴鹏程, 1965)。

27. 双齿护蒴苔 Calypogeia tosana (Steph.) Steph. 安徽(Piippo, 1990; 张美珍和赖明洲, 1993); 黄山市(陈邦杰和吴鹏程, 1965); 霍山县 (Cai, 2002); 石台县(郭新弧等, 1990)。

\section{全蕓苔科 Gymnomitriaceae}

\section{钱袋苔属 Marsupella}

28. 钱袋苔(缺刻钱袋苔)Marsupella emarginata (Ehrh.) Dumort. 安徽(张美珍和赖明洲, 1993; 贾渝和何思, 2013); 黄山市(高谦和吴玉环, 2008)。

29. 钱袋苔小亚种 Marsupella emarginata ssp. tubulosa (Steph.) N. Kitag. 安徽(Piippo, 1990); 黄山市(陈邦杰和吴鹏程, 1965 as M. tubulosa); 石台县(郭新弧等, 1990)。

30. 东亚钱袋苔 Marsupella yakushimensis (Horik.) S. Hatt. 安徽(Piippo, 1990; 张美珍和赖明洲, 1993; 贾渝和何思, 2013); 黄山市(陈邦杰和吴鹏 程, 1965; 高谦和吴玉环, 2008)。

\section{被蒴苔属 Nardia}

31. 南亚被蒴苔 Nardia assamica (Mitt.) Amakawa 安徽(Piippo, 1990; 张美珍和赖明洲, 1993; 贾渝和何思, 2013); 黄山市(陈邦杰和吴鹏 程, 1965 as N. grandistipula); 霍山县(Gao \& Bai, 2001; Cai, 2002 as N. sieboldii; 高谦, 
2003); 石台县(郭新弧等, 1990 as N. sieboldii)。

\section{镰票苔科 Harpanthaceae \\ 镰蕓苔属 Harpanthus}

32. 镰蓦苔 Harpanthus flotovianus (Nees) Nees

安徽(张美珍和赖明洲, 1993; 贾渝和何思, 2013); 霍山县(钱琳和蔡空辉, 1989; Cai, 2002; 高谦和吴玉环, 2008)。

\section{叶苔科 Jungermanniaceae}

\section{叶苔属 Jungermannia}

33. 深绿叶苔 Jungermannia atrovirens Dumort.

安徽(张美珍和赖明洲, 1993); 霍山县(Cai, 2002 as J. lanceolata)。

\section{管口苔科 Solenostomataceae \\ 管口苔属 Solenostoma}

34. 圆叶管口苔 Solenostoma appressifolium (Mitt.) Váňa et D. G. Long

安徽(贾渝和何思, 2013); 黄山市(Gao \& Bai, 2001 as Jungermannia appressifolia; 高谦, 2003 as J. appressifolia)。

35. 偏叶管口苔 Solenostoma comatum (Nees) C. Gao

安徽(张美珍和赖明洲, 1993 as Jungermannia comata; 贾渝和何思, 2013); 黄山市(Gao \&

Bai, 2001 as J. comata; 高谦, 2003 as J. comata); 霍山县(Cai, 2002 as J. comata)。

36. 褐绿管口苔 Solenostoma infuscum (Mitt.) Hentschel

安徽(贾渝和何思, 2013); 黄山市(Gao \& Bai, 2001 as Jungermannia infusca; 高谦, 2003 as $J$. infusca)。

37. 倒卵叶管口苔 Solenostoma obovatum (Nees) C. Massal.

安徽(Piippo, 1990 as Jungermannia obovata; 张美珍和赖明洲, 1993 as J. obovata; 贾渝 和何思, 2013); 黄山市(Gao \& Bai, 2001 as J. obovata；高谦, 2003 as J. obovata); 石台县 (郭新弧等, 1990)。

\section{蛽毛苔科 Blepharostomataceae}

\section{睫毛苔属 Blepharostoma}

38. 小睫毛苔 Blepharostoma minor Horik.

安徽(Piippo, 1990; 张美珍和赖明洲, 1993); 黄山市(陈邦杰和吴鹏程, 1965); 霍山县 (Cai, 2002); 石台县(郭新弧等, 1990)。

39. 睫毛苔 Blepharostoma trichophyllum (L.) Dumort.

安徽(Piippo, 1990; 张美珍和赖明洲, 1993); 黄山市(陈邦杰和吴鹏程, 1965); 霍山县 (Cai, 2002)。

\section{剪叶苔科 Herbertaceae}

\section{剪叶苔属 Herbertus}

40. 剪叶苔 Herbertus aduncus (Dicks.) Gray

安徽(Piippo, 1990; 张美珍和赖明洲, 1993 as H. fragilis; 贾渝和何思, 2013 as H. fragilis); 黄山市(高谦, 2003 as H. fragilis); 霍山县(Cai, 2002); 石台县(郭新弧等, 1990)。 
41. 长角剪叶苔 Herbertus dicranus (Gottsche, Lindenb. et Nees) Trevis.

安徽(Piippo, 1990 also as H. sakuraii; 张美珍和赖明洲, 1993 also as H. sakuraii; 贾渝和 何思, 2013); 黄山市(陈邦杰和吴鹏程, 1965 also as H. sakuraii); 石台县(郭新弧等, 1990 as H. chinensis)。

42. 长肋剪叶苔 Herbertus longifissus Steph. 安徽(Piippo, 1990; 张美珍和赖明洲, 1993); 黄山市(陈邦杰和吴鹏程, 1965)。

\section{指叶荅科 Lepidoziaceae}

\section{鞭苔属 Bazzania}

43. 厚角鞭苔 Bazzania fauriana (Steph.) S. Hatt.

安徽(Piippo, 1990; 张美珍和赖明洲, 1993; 贾渝和何思, 2013); 黄山市(Mizutani \& Chang, 1986); 石台县(郭新弧等, 1990)。

44. 日本鞭苔 Bazzania japonica (Sande Lac.) Lindb.

安徽(Piippo, 1990; 张美珍和赖明洲, 1993; 贾渝和何思, 2013); 黄山市(陈邦杰和吴鹏

程, 1965; Mizutani \& Chang, 1986; 高谦, 2003; 周兰平等, 2012); 石台县(郭新弧等, 1990)。

45. 小叶鞭苔 Bazzania ovistipula (Steph.) Abeyw.

安徽(Piippo, 1990; 张美珍和赖明洲, 1993; 贾渝和何思, 2013); 黄山市(陈邦杰和吴鹏 程, 1965 as B. kanemarui); 撮县(周兰平等, 2012)。

46. 弯叶鞭苔 Bazzania pearsonii Steph.

安徽(Piippo, 1990; 张美珍和赖明洲, 1993; 贾渝和何思, 2013); 黄山市(陈邦杰和吴鹏 程, 1965)。

47. 三裂鞭苔 Bazzania tridens (Reinw., Blume et Nees) Trevis.

安徽(Piippo, 1990; 张美珍和赖明洲, 1993; 贾渝和何思, 2013); 黄山市(陈邦杰和吴鹏 程, 1965 as B. albicans; 周兰平等, 2012); 祁门县(郭新弧等, 1990); 石台县(郭新弧等, 1990)。

48. 鞭苔 Bazzania trilobata (L.) Gray 安徽(Piippo, 1990; 张美珍和赖明洲, 1993; 贾渝和何思, 2013); 黄山市(陈邦杰和吴鹏 程, 1965; Mizutani \& Chang, 1986; 高谦, 2003)。

49. 卷叶鞭苔 Bazzania yoshinagana (Steph.) Yasuda 黄山市(周兰平等, 2012)。

\section{齿蘦苔科 Lophocoleaceae}

\section{裂蕶苔属 Chiloscyphus}

50. 裂苧苔 Chiloscyphus polyanthos (L.) Corda 安徽(张美珍和赖明洲, 1993); 霍山县(Cai, 2002)。

\section{齿蕓苔属 Lophocolea}

51. 异叶齿募苔 Lophocolea heterophylla (Schrad.) Dumort.

安徽(Piippo, 1990 as Chiloscyphus profundus; 张美珍和赖明洲, 1993 as C. profundus); 霍 山县(Cai, 2002); 石台县(郭新弧等, 1990)。

52. 芽胞齿䒓苔 Lophocolea minor Nees 安徽(Piippo, 1990 as Chiloscyphus minor; 张美珍和赖明洲, 1993 as C. minor); 霍山县 (Cai, 2002); 祁门县(郭新弧等, 1990)。 


\section{异蕶苔属 Heteroscyphus}

53. 四齿异募苔 Heteroscyphus argutus (Reinw., Blume et Nees) Schiffn. 安徽(Piippo, 1990; 张美珍和赖明洲, 1993); 黄山市(陈邦杰和吴鹏程, 1965)。

54. 双齿异墓苔 Heteroscyphus coalitus (Hook.) Schiffn. 安徽(Piippo, 1990; 张美珍和赖明洲, 1993); 黄山市(陈邦杰和吴鹏程, 1965 as $H$. bescherellei)。

55. 脆叶异蓦苔 Heteroscyphus flaccidus (Mitt.) A. Srivast. et S. C. Srivast. 安徽(贾渝和何思, 2013); 黄山市(高谦和吴玉环, 2008)。

56. 叉齿异荌苔 Heteroscyphus lophocoleoides S. Hatt. 安徽(Piippo, 1990); 霍山县(Cai, 2002); 石台县(郭新弧等, 1990)。

57. 平叶异募苔 Heteroscyphus planus (Mitt.) Schiffn. 安徽(Piippo, 1990; 张美珍和赖明洲, 1993; Zhu \& So, 2001; 高谦和吴玉环, 2008); 霍山 县(Cai, 2002); 石台县(郭新弧等, 1990)。

58. 全缘异荌苔 Heteroscyphus saccogynoides Herzog 安徽(张美珍和赖明洲, 1993); 霍山县(Cai, 2002)。

59. 柔叶异募苔 Heteroscyphus tener (Steph.) Schiffn. 安徽(Piippo, 1990; 张美珍和赖明洲, 1993); 黄山市(陈邦杰和吴鹏程, 1965)。

60. 南亚异蔩苔 Heteroscyphus zollingeri (Gottsche) Schiffn. 安徽(贾渝和何思, 2013); 歌县(高谦和吴玉环, 2008)。

\section{羽苔科 Plagiochilaceae}

\section{鞭羽苔属 Chiastocaulon}

61. 羽状鞭羽苔 Chiastocaulon dendroides (Nees) Carl 安徽(Piippo, 1990 as Plagiochila dendroides); 石台县(郭新弧等, 1990 as P. dendroides)。

\section{羽苔属 Plagiochila}

62. 树形羽苔 Plagiochila arbuscula (Brid. ex Lehm. et Lindenb.) Lindenb. 霍山县(Cai, 2002 as P. belangeriana)。

63. 陈氏羽苔 Plagiochila chenii Grolle et M. L. So 安徽(贾渝和何思, 2013); 黄山市(So, 2001; 高谦和吴玉环, 2008)。

64. 小叶羽苔 Plagiochila devexa Steph. 安徽(贾渝和何思, 2013); 黄山市(So, 2001; 高谦和吴玉环, 2008)。

65. 密鳞羽苔 Plagiochila durelii Schiffn. 安徽(贾渝和何思, 2013); 黄山市(So, 2001; 高谦和吴玉环, 2008)。

66. 大叶羽苔 Plagiochila elegans Mitt. 霍山县(So, 2001)。

67. 长叶羽苔 Plagiochila flexuosa Mitt. 安徽(Piippo, 1990; 张美珍和赖明洲, 1993; 贾渝和何思, 2013); 黄山市(陈邦杰和吴鹏 程, 1965 as P. titibuensis; So, 2001; 高谦和吴玉环, 2008)。

68. 纤细羽苔 Plagiochila gracilis Lindenb. et Gottsche 安徽(张美珍和赖明洲, 1993; 贾渝和何思, 2013); 黄山市(So, 2001); 霍山县(Cai, 2002 as P. firma)。

69. 齿苛羽苔 Plagiochila hakkodensis Steph. 安徽(Piippo, 1990; 张美珍和赖明洲, 1993; So, 2001); 黄山市(陈邦杰和吴鹏程, 1965)。 
70. 尼泊尔羽苔 Plagiochila nepalensis Lindenb. 安徽(Zhu \& So, 2001); 霍山县(So, 2001); 檁县(So, 2001)。

71. 卵叶羽苔 Plagiochila ovalifolia Mitt. 安徽(张美珍和赖明洲, 1993; 贾渝和何思, 2013); 黄山市(So, 2001; 高谦和吴玉环, 2008); 霍山县(So, 2001; Cai, 2002; 高谦和吴玉环, 2008); 青阳县(So, 2001)。

72. 圆头羽苔 Plagiochila parvifolia Lindenb.

安徽(贾渝和何思, 2013); 霍山县(Cai, 2002 as P. yokogurensis); 檁县(So, 2001; 高谦和吴 玉环, 2008)。

73. 刺叶羽苔 Plagiochila sciophila Nees 安徽(Piippo, 1990; 张美珍和赖明洲, 1993); 黄山市(陈邦杰和吴鹏程, 1965 as $P$. japonica); 霍山县(So, 2001; Cai, 2002 as P. japonica)。

74. 延叶羽苔 Plagiochila semidecurrens (Lehm. et Lindenb.) Lindenb. 安徽(Piippo, 1990; 张美珍和赖明洲, 1993; 贾渝和何思, 2013); 黄山市(陈邦杰和吴鹏 程, 1965 also as P. semidecurrens var. grossidens; So, 2001; 高谦和吴玉环, 2008); 檁县 (So, 2001); 石台县(郭新弧等, 1990)。

75. 上海羽苔 Plagiochila shangaica Steph. 宁国市(程前和师雪芹, 2018)。

76. 狭叶羽苔 Plagiochila trabeculata Steph. 㵊县(So, 2001)。

77. 短齿羽苔 Plagiochila vexans Schiffn. ex Steph. 安徽(贾渝和何思, 2013); 黄山市(So, 2001; 高谦和吴玉环, 2008)。

\section{对羽苔属 Plagiochilion}

78. 稀齿对羽苔 Plagiochilion mayebarae S. Hatt. 安徽(Piippo, 1990; 张美珍和赖明洲, 1993); 黄山市(陈邦杰和吴鹏程, 1965); 霍山县 (Cai, 2002)。

\section{黄羽苔属 Xenochila}

79. 黄羽苔 Xenochila integrifolia (Mitt.) Inoue 绩溪县(程前等, 2020)。

\section{线苔科 Trichocoleaceae}

\section{线苔属 Trichocolea}

80. 线苔 Trichocolea tomentella (Ehrh.) Dumort. 安徽(张美珍和赖明洲, 1993); 霍山县(Cai, 2002)。

\section{耳叶苔科 Frullaniaceae \\ 耳叶苔属 Frullania}

81. 青山耳叶苔 Frullania aoshimensis Horik.

安徽(Piippo, 1990; 张美珍和赖明洲, 1993; 贾渝和何思, 2013); 祁门县(刘仲苓等, 1988)。

82. 尖叶耳叶苔 Frullania apiculata (Reinw., Blume et Nees) Nees 安徽(Piippo, 1990; 张美珍和赖明洲, 1993; 贾渝和何思, 2013); 黄山市(陈邦杰和吴鹏 程, 1965)。

83. 达呼里耳叶苔 Frullania davurica Hampe ex Gottsche, Lindenb. et Nees 
安徽(Piippo, 1990; 张美珍和赖明洲, 1993); 霍山县(Cai, 2002 as F. jackii ssp. japonica); 黄山市(陈邦杰和吴鹏程, 1965 as F. jackii ssp. japonica)。

84. 筒瓣耳叶苔 Frullania diversitexta Steph. 安徽(Piippo, 1990; 贾渝和何思, 2013); 石台县(郭新弧等, 1990)。

85. 皱叶耳叶苔 Frullania ericoides (Nees) Mont. 安徽(张美珍和赖明洲, 1993); 霍山县(Cai, 2002 as F. squarrosa)。

86. 钩瓣耳叶苔 Frullania hamatiloba Steph. 安徽(Piippo, 1990; 张美珍和赖明洲, 1993; 贾渝和何思, 2013); 石台县(郭新弧等, 1990)。

87. 石生耳叶苔内弯变种 Frullania inflata var. mayebarae (S. Hatt.) K. Yamada 安徽(Piippo, 1990); 石台县(郭新弧等, 1990 as F. mayebarae)。

88. 列胞耳叶苔 Frullania moniliata (Reinw., Blume et Nees) Mont. 安徽(Piippo, 1990; 张美珍和赖明洲, 1993; 贾渝和何思, 2013); 黄山市(陈邦杰和吴鹏 程, 1965); 霍山县(Cai, 2002 as F. tamarisci ssp. moniliata); 祁门县(Zhu \& So, 2001)。

89. 羊角耳叶苔 Frullania monocera (Hook. f. et Taylor) Gottsche, Lindenb. et Nees 安徽(Piippo, 1990; 张美珍和赖明洲, 1993; 贾渝和何思, 2013); 石台县(郭新弧等, 1990 as F. hampeana)。

90. 盔瓣耳叶苔 Frullania muscicola Steph. 安徽(Piippo, 1990; 张美珍和赖明洲, 1993); 霍山县(Cai, 2002); 祁门县(郭新弧等, 1990; 刘仲苓等, 1988); 石台县(郭新弧等, 1990)。

91. 尼泊尔耳叶苔 Frullania nepalensis (Spreng.) Lehm. et Lindenb. 安徽(Piippo, 1990; 张美珍和赖明洲, 1993; 贾渝和何思, 2013); 黄山市(陈邦杰和吴鹏 程, 1965 also as F. nishiyamensis); 霍山县(Cai, 2002 also as F. nishiyamensis)。

92. 点胞耳叶苔 Frullania punctate Reimers 安徽(Piippo, 1990); 黄山市(陈邦杰和吴鹏程, 1965 as F. densiloba; Hattori \& Lin, 1985)。

93. 陕西耳叶苔 Frullania schensiana C. Massal. 安徽(Piippo, 1990; 贾渝和何思, 2013); 石台县(郭新弧等, 1990)。

94. 欧耳叶苔 Frullania tamarisci (L.) Dumort. 安徽(Piippo, 1990; 贾渝和何思, 2013); 霍山县(Cai, 2002); 石台县(郭新弧等, 1990)。

95. 硬叶耳叶苔 Frullania valida Steph.

安徽(Piippo, 1990; 贾渝和何思, 2013); 石台县(郭新弧等, 1990)。

\section{毛耳苔科 Jubulaceae}

\section{毛耳苔属 Jubula}

96. 日本毛耳苔 Jubula hutchinsiae ssp. japonica (Steph.) Horik. et Ando 安徽(Piippo, 1990 as J. japonica; 张美珍和赖明洲, 1993 as J. japonica); 黄山市(陈邦杰 和吴鹏程, 1965 as J. japonica)。

97. 爪哇毛耳苔Jubula hutchinsiae ssp.javanica (Steph.) Verd. 安徽(Piippo, 1990; 张美珍和赖明洲, 1993; 贾渝和何思, 2013 as J. javanica); 石台县(郭 新弧等, 1990 as J. javanica)。 
98. 东亚刺鳞苔 Acanthocoleus yoshinaganus (S. Hatt.) Kruijt 安徽(贾渝和何思, 2013); 㵊县(Zhu \& Grolle, 2001)。

\section{顶鳞苔属 Acrolejeunea}

99. 浅棕顶鳞苔 Acrolejeunea infuscata (Mitt.) Jian Wang bis et Gradst. 撮县(师雪芹等, 2018)。

100. 密枝顶鳞苔 Acrolejeunea pycnoclada (Taylor) Schiffn. 安徽(贾渝和何思, 2013); 撮县(Wang et al, 2016)。

101. 锡金顶鳞苔 Acrolejeunea sikkimensis (Mizut.) Gradst. 安徽(贾渝和何思, 2013); 黄山市(Wang et al, 2016); 潜山市(Wang et al, 2016)。

102. 中华顶鳞苔 Acrolejeunea sinensis (Jian Wang bis, R. L. Zhu et Gradst.) Jian Wang bis et Gradst.

绩溪县(师雪芹等, 2018); 休宁县(师雪芹等, 2018)。

103. 南亚顶鳞苔 Acrolejeunea sandvicensis (Gottsche) Steph.

安徽(Piippo, 1990 as Trocholejeunea sandvicensis; 张美珍和赖明洲, 1993 as T. sandvicensis); 黄山市(陈邦杰和吴鹏程, 1965 as Brachiolejeunea sandvicensis; Wang et al, 2016; 师雪芹等, 2018); 霍山县(Cai, 2002 as T. sandvicensis); 绩溪县(师雪芹等, 2018); 祁门县(郭新弧等, 1990 as T. sandvicensis); 青阳县(Wang et al, 2016); 石台县(郭新弧等, 1990 as T. sandvicensis)。

\section{唇鳞苔属 Cheilolejeunea}

104. 亚洲唇鳞苔 Cheilolejeunea krakakammae (Lindenb.) R. M. Schust. 黄山市(师雪芹等, 2018)。

105. 针叶唇鳞苔 Cheilolejeunea obtusifolia (Steph.) S. Hatt. 黄山市(师雪芹等, 2018)。

106. 针瓣唇鳞苔 Cheilolejeunea obtusilobula (S. Hatt.) S. Hatt. 祁门县(师雪芹等, 2018)。

107. 尖叶唇鳞苔 Cheilolejeunea subopaca (Mitt.) Mizut. 安徽(贾渝和何思, 2013); 黄山市(Zhu \& So, 2001; Zhu et al, 2002；师雪芹等, 2018)。

108. 粗茎唇鳞苔 Cheilolejeunea trapezia (Nees) Kachroo et R. M. Schust. 安徽(Piippo, 1990 as Cheilolejeunea imbricata; 张美珍和赖明洲, 1993 as C. imbricata; 贾 渝和何思, 2013); 黄山市(陈邦杰和吴鹏程, 1965 as C. imbricata; Zhu et al, 2002 as $C$. imbricata；师雪芹等, 2018); 祁门县(刘仲苓等, 1988 as C. imbricata)。

\section{疮鳞苔属 Cololejeunea}

109. 白边疮鳞苔 Cololejeunea inflata Steph. 安徽(Piippo, 1990 as Cololejeunea oshimensis; 张美珍和赖明洲, 1993 as C. oshimensis; 贾渝和何思, 2013); 祁门县(刘仲苓等, 1988 as C. oshimensis; Zhu, 1995; Zhu \& So, 2001)。

110. 鳞叶疮鳞苔 Cololejeunea longifolia (Mitt.) Benedix ex Mizut. 安徽(Piippo, 1990; 张美珍和赖明洲, 1993; 贾渝和何思, 2013); 祁门县(吴鹏程和郭新 弧, 1986 as Leptocolea minuta; 刘仲苓等, 1988 as L. oblonga; Zhu \& So, 2001; 师雪芹等, 2018); 石台县(师雪芹等, 2018)。

111. 距齿疮鳞苔 Cololejeunea macounii (Spruce) A. Evans 安徽(Piippo, 1990; 张美珍和赖明洲, 1993); 黄山市(陈邦杰和吴鹏程, 1965)。

112. 粗柱疮鳞苔 Cololejeunea ornata A. Evans 
安徽(Piippo, 1990; 贾渝和何思, 2013); 祁门县(刘仲苓等, 1988)。

113. 粗病鳞苔 Cololejeunea peraffinis (Schiffn.) Schiffn.

安徽(Piippo, 1990; 贾渝和何思, 2013); 祁门县(刘仲苓等, 1988; Zhu, 1995; Zhu \& So, 2001；师雪芹等，2018）。

114. 粗齿病鳞苔 Cololejeunea planissima (Mitt.) Abeyw. 安徽(张美珍和赖明洲, 1993; 贾渝和何思, 2013); 祁门县(吴鹏程和郭新弧, 1986 as Pedinolejeunea planissima; 刘仲苓等, 1988 as P. planissima, also as P. aoshimensis; Zhu \& So, 2001; 师雪芹等, 2018)。

115. 拟病鳞苔 Cololejeunea raduliloba Steph. 祁门县(师雪芹等, 2018); 黄山市(师雪芹等, 2018); 石台县(师雪芹等, 2018)。

116. 刺病鳞苔 Cololejeunea spinosa (Horik.) Pandé et R. N. Misra 安徽(张美珍和赖明洲, 1993; 贾渝和何思, 2013); 霍山县(Cai, 2002); 祁门县(Zhu \& So, 2001); 石台县(师雪芹等, 2018)。

117. 短肋疮鳞苔 Cololejeunea subfloccosa Mizut. 安徽(贾渝和何思, 2013); 祁门县(Zhu, 1995; Zhu \& So, 2001)。

118. 南亚疮鳞苔 Cololejeunea tenella Benedix 安徽(贾渝和何思, 2013); 祁门县(Zhu \& So, 2001)。

\section{角鳞苔属 Drepanolejeunea}

119. 狭叶角鳞苔 Drepanolejeunea angustifolia (Mitt.) Grolle 安徽(Piippo, 1990; 张美珍和赖明洲, 1993; 贾渝和何思, 2013); 黄山市(陈邦杰和吴鹏 程, 1965 as D. tenuis; 师雪芹等, 2018); 石台县(郭新弧等, 1990)。

120. 日本角鳞苔 Drepanolejeunea erecta (Steph.) Mizut. 黄山市(师雪芹等, 2018)。

121. 单齿角鳞苔 Drepanolejeunea ternatensis (Gottsche) Schiffn. 黄山市(师雪芹等, 2018)。

\section{细鳞苔属 Lejeunea}

122. 狭瓣细鳞苔 Lejeunea anisophylla Mont. 安徽(Piippo, 1990 as L. catanduana; 张美珍和赖明洲, 1993 as L. catanduana; 贾渝和何 思, 2013); 黄山市(师雪芹等, 2018); 祁门县(刘仲苓等, 1988 as L. borneensis; Zhu \& So, 2001)。

123. 耳瓣细鳞苔 Lejeunea compacta (Steph.) Steph. 安徽(贾渝和何思, 2013); 黄山市(师雪芹等, 2018); 青阳县(Zhu \& So, 1999)。

124. 弯叶细鳞苔 Lejeunea curviloba Steph. 安徽(Zhu \& So, 2001；贾渝和何思, 2013); 黄山市(师雪芹等, 2018)。

125. 黄色细鳞苔 Lejeunea flava (Sw.) Nees 安徽(张美珍和赖明洲, 1993; 贾渝和何思, 2013); 黄山市(师雪芹等, 2018); 霍山县(Cai, 2002)。

126. 日本细鳞苔 Lejeunea japonica Mitt. 安徽(贾渝和何思, 2013); 黄山市(师雪芹等, 2018)。

127. 三重细鳞苔 Lejeunea magohukui Mizut. 安徽(贾渝和何思, 2013); 祁门县(Zhu \& So, 2001)。

128. 尖叶细鳞苔 Lejeunea neelgherriana Gottsche 安徽(Zhu \& So, 2001; 贾渝和何思, 2013); 黄山市(师雪芹等, 2018)。 
129. 暗绿细鳞苔 Lejeunea obscura Mitt.

黄山市(师雪芹等, 2018); 石台县(师雪芹等, 2018)。

130. 淡绿细鳞苔 Lejeunea pallidevirens S. Hatt.

黄山市(师雪芹等, 2018)。

131. 小叶细鳞苔 Lejeunea parva (S. Hatt.) Mizut.

安徽(张美珍和赖明洲, 1993); 黄山市(师雪芹等, 2018); 歌县(So \& Zhu, 1998); 石台县 (郭新弧等, 1990 as L. rotundistipula)。

\section{薄鳞苔属 Leptolejeunea}

132. 尖叶薄鳞苔 Leptolejeunea elliptica (Lehm. et Lindenb.) Besch. 安徽(Piippo, 1990; 张美珍和赖明洲, 1993; 贾渝和何思, 2013); 祁门县(吴鹏程和郭新 弧, 1986; 刘仲苓等, 1988; Zhu \& So, 2001)。

\section{冠鳞苔属 Lopholejeunea}

133. 黑冠鳞苔 Lopholejeunea nigricans (Lindenb.) Schiffn. 安徽(贾渝和何思, 2013); 黄山市(Wang et al, 2016; 师雪芹等, 2018); 绩溪县(师雪芹等, 2018); 潜山市(Zhu \& Gradstein, 2005)。

134. 褐冠鳞苔Lopholejeunea subfusca (Nees) Schiffn. 安徽(Piippo, 1990; 张美珍和赖明洲, 1993; 贾渝和何思, 2013); 黄山市(陈邦杰和吴鹏 程, 1965; 师雪芹等, 2018); 祁门县(郭新弧等, 1990); 歇县(Wang et al, 2016)。

135. 苏氏冠鳞苔 Lopholejeunea soae R. L. Zhu et Gradst. 黄山市(Wang et al, 2016)。

\section{纤鳞苔属 Microlejeunea}

136. 斑叶纤鳞苔 Microlejeunea punctiformis (Taylor) Steph. 安徽(贾渝和何思, 2013 as Lejeunea punctiformis); 黄山市(陈邦杰和吴鹏程, 1965); 绩溪 县(师雪芹等, 2018)。

\section{拟多果苔属 Myriocoleopsis}

137. 圆叶拟多果苔 Myriocoleopsis minutissima (Sm.) R. L. Zhu, Y. Yu et Pócs 黄山市(师雪芹等, 2018); 岳西县(师雪芹等, 2018)。

\section{皱蕶苔属 Ptychanthus}

138. 皱荅苔 Ptychanthus striatus (Lehm. et Lindenb.) Nees 安徽(Piippo, 1990; 张美珍和赖明洲, 1993; 贾渝和何思, 2013); 黄山市(陈邦杰和吴鹏 程, 1965); 祁门县(刘仲苓等, 1988; 郭新弧等, 1990; Zhu \& So, 2001; Wang et al, 2016; 师雪芹等, 2018)。

\section{多褶苔属 Spruceanthus}

139. 弯叶多褶苔（新拟）Spruceanthus falcatus X. Q. Shi, R. L. Zhu et Gradst. ${ }^{1}$ 安徽(贾渝和何思, 2013 as Archilejeunea amakawana); 黄山市(师雪芹等, 2018); 祁门县 (Wang et al, 2016); 石台县(Zhu \& So, 2000 as A. amakawana)。

140. 多褶苔 Spruceanthus semirepandus (Nees) Verd. 安徽(Piippo, 1990; 张美珍和赖明洲, 1993; 贾渝和何思, 2013); 黄山市(陈邦杰和吴鹏 程, 1965；师雪芹等, 2018); 青阳县(Wang et al, 2016)。

\footnotetext{
1 该种的处理参照: Shi XQ, Gradstein SR, Zhu RL (2015) Phylogeny and taxonomy of Archilejeunea
} (Marchantiophyta: Lejeuneaceae) based on molecular markers and morphology. Taxon, 64, 881-892. 


\section{光蕶苔科 Porellaceae}

\section{光蕶苔属 Porella}

141. 尖瓣光萝苔东亚亚种 Porella acutifolia $\mathrm{ssp}$. tosana (Steph.) S. Hatt.

安徽(Piippo, 1990; 张美珍和赖明洲, 1993); 黄山市(陈邦杰和吴鹏程, 1965 as $P$. tosana)。

142. 丛生光葶苔 Porella caespitans (Steph.) S. Hatt. 安徽(张美珍和赖明洲, 1993); 霍山县(Cai, 2002)。

143. 从生光葶苔心叶变种 Porella caespitans var. cordifolia (Steph.) S. Hatt. ex T. Katag. et T. Yamag.

安徽(Piippo, 1990; 贾渝和何思, 2013 as P. caespitans var. setigera); 黄山市(陈邦杰和吴 鹏程, 1965 as P. setigera; Hattori, 1969 as P. setigera; Hattori, 1970 as P. caespitans var. setigera); 霍山县(Cai, 2002 as $P$. setigera)。

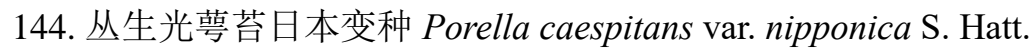

安徽(Piippo, 1990; 张美珍和赖明洲, 1993); 石台县(郭新弧等, 1990)。

145. 中华光颌苔 Porella chinensis (Steph.) S. Hatt. 安徽(张美珍和赖明洲, 1993); 霍山县(Cai, 2002)。

146. 中华光䓯苔延叶变种 Porella chinensis var. decurrens (Steph.) S. Hatt. 霍山县(Cai, 2002 as P. decurrens)。

147. 密叶光苛苔 Porella densifolia (Steph.) S. Hatt. 安徽(Piippo, 1990; 张美珍和赖明洲, 1993; 贾渝和何思, 2013); 石台县(郭新弧等, 1990); 黄山市(陈邦杰和吴鹏程, 1965; Hattori, 1969 as P. densifolia var. fallax); 霍山县 (Cai, 2002)。

148. 密叶光苛苔细尖叶变种 Porella densifolia var. paraphyllina (P. C. Chen) Pócs 安徽(Piippo, 1990; 贾渝和何思, 2013); 黄山市(陈邦杰和吴鹏程, 1965 as P. apiculata; Hattori, 1967 as P. paraphyllina)。

149. 细光莒苔 Porella gracillima Mitt. 安徽(张美珍和赖明洲, 1993); 霍山县(Cai, 2002)。

150. 尾尖光蔩苔 Porella handelii S. Hatt. 霍山县(Cai, 2002)。

151. 日本光募苔 Porella japonica (Sande Lac.) Mitt. 安徽(Piippo, 1990; 张美珍和赖明洲, 1993; 贾渝和何思, 2013); 黄山市(陈邦杰和吴鹏 程, 1965; Hattori, 1967); 霍山县(Cai, 2002)。

152. 全缘光颌苔 Porella javanica (Gottsche) Inoue 霍山县(Cai, 2002)。

153. 亮叶光蔩苔 Porella nitens (Steph.) S. Hatt. 霍山县(Cai, 2002)。

154. 毛边光募苔 Porella perrottetiana (Mont.) Trevis. 安徽(Piippo, 1990; 张美珍和赖明洲, 1993; 贾渝和何思, 2013); 黄山市(陈邦杰和吴鹏 程, 1965); 霍山县(Cai, 2002)。

155. 毛边光颌苔齿叶变种 Porella perrottetiana var. ciliatodentata (P. C. Chen et P. C. Wu) S. Hatt.

安徽(Piippo, 1990; 张美珍和赖明洲, 1993); 黄山市(陈邦杰和吴鹏程, 1965 as $P$. 
ciliatodentata; Hattori, 1967)。

156. 多瓣光蕶苔 Porella ulophylla (Steph.) S. Hatt.

安徽(Piippo, 1990 as Macvicaria ulophylla; 张美珍和赖明洲, 1993; 贾渝和何思, 2013 as M. ulophylla); 黄山市(陈邦杰和吴鹏程, 1965 as M. ulophylla); 祁门县(郭新弧等, 1990 as M. ulophylla)。

157. 细枝光蔩苔 Porella urogea (C. Massal.) S. Hatt. 安徽(张美珍和赖明洲, 1993 as P. gracillima ssp. urogea); 黄山市(陈邦杰和吴鹏程, 1965)。

\section{扁贯苔科 Radulaceae \\ 扁萝苔属 Radula}

158. 尖舌扁荳苔 Radula acuminata Steph. 安徽(Piippo, 1990; 张美珍和赖明洲, 1993; 贾渝和何思, 2013); 祁门县(刘仲苓等, 1988; Zhu \& So, 2001)。

159. Radula acuta Mitt.

安徽(Piippo, 1990 as R. apiculata; 张美珍和赖明洲, 1993 as R. apiculata; 贾渝和何思, 2013 as R. apiculata); 黄山市(高谦和吴玉环, 2008 as R. apiculata); 霍山县(Cai, 2002 as R. apiculata); 石台县(郭新弧等, 1990 as R. apiculata)。

160. 大瓣扁葶苔 Radula cavifolia Hampe ex Gottsche, Lindenb. et Nees 安徽(Piippo, 1990; 张美珍和赖明洲, 1993; 贾渝和何思, 2013); 黄山市(陈邦杰和吴鹏 程, 1965; 高谦和吴玉环, 2008); 霍山县(Cai, 2002); 石台县(郭新弧等, 1990)。

161. 中华扁荌苔 Radula chinensis Steph. 安徽(Piippo, 1990; 贾渝和何思, 2013); 黄山市(Yamada, 1982；高谦和吴玉环, 2008)。

162. 芽孢扁蓉苔 Radula constricta Steph. ${ }^{2}$ 安徽(Piippo, 1990；张美珍和赖明洲, 1993; 贾渝和何思, 2013 as R. lindenbergiana); 黄 山市(陈邦杰和吴鹏程, 1965 as R. lindenbergiana; 高谦和吴玉环, 2008 as $R$. lindenbergiana); 霍山县(Cai, 2002); 祁门县(刘仲苓等, 1988)。

163. 日本扁荳苔 Radula japonica Gottsche 安徽(张美珍和赖明洲, 1993); 霍山县(Cai, 2002)。

164. 尖叶扁蕓苔 Radula kojana Steph. 安徽(Piippo, 1990; 张美珍和赖明洲, 1993; 贾渝和何思, 2013); 黄山市(陈邦杰和吴鹏 程, 1965; Yamada, 1982; 高谦和吴玉环, 2008)。

165. 直瓣扁颌苔 Radula perrottetii Gottsche 安徽(张美珍和赖明洲, 1993); 霍山县(Cai, 2002 as R. valida)。

166. 东京扁䓵苔 Radula tokiensis Steph. 安徽(张美珍和赖明洲, 1993); 霍山县(Cai, 2002)。

\section{新线苔科 Neotrichocoleaceae}

\section{新线苔属 Neotrichocolea}

167. 新线苔 Neotrichocolea bissetii (Mitt.) S. Hatt. 安徽(Piippo, 1990; 张美珍和赖明洲, 1993; 贾渝和何思, 2013); 黄山市(陈邦杰和吴鹏 程, 1965; 高谦和吴玉环, 2008)。

2 此处将 Radula lindenbergiana Gottsche ex C. Hartm.作为 Radula constricta Steph. 的异名来处理。 


\section{囊线苔属 Trichocoleopsis}

168. 囊线苔 Trichocoleopsis sacculata (Mitt.) S. Okamura

安徽(Piippo, 1990; 张美珍和赖明洲, 1993; 贾渝和何思, 2013); 黄山市(陈邦杰和吴鹏 程, 1965; 高谦和吴玉环, 2008)。

\section{绿片苔科 Aneuraceae}

\section{绿片苔属 Aneura}

169. 绿片苔 Aneura pinguis (L.) Dumort. 安徽(张美珍和赖明洲, 1993); 霍山县(Cai, 2002)。

\section{片叶苔属 Riccardia}

170. 宽片叶苔 Riccardia latifrons (Lindb.) Lindb. 安徽(张美珍和赖明洲, 1993); 霍山县(Cai, 2002 “Riccia latifrons”)。

171. 片叶苔 Riccardia multifida (L.) Gray 安徽(张美珍和赖明洲, 1993); 霍山县(Cai, 2002 “Riccia latifrons”)。

\section{叉苔科 Metzgeriaceae}

\section{叉苔属 Metzgeria}

172. 平叉苔 Metzgeria conjugata Lindb. 安徽(张美珍和赖明洲, 1993); 霍山县(Cai, 2002)。

173. 叉苔 Metzgeria furcata (L.) Corda 安徽(Piippo, 1990 also as M. decipiens; 张美珍和赖明洲, 1993 also as M. decipiens; 贾渝 和何思, 2013); 黄山市(陈邦杰和吴鹏程, 1965 as M. quadriseriata); 祁门县(刘仲苓等, 1988)。

174. 钩毛叉苔 Metzgeria leptoneura Spruce 安徽(Piippo, 1990; 张美珍和赖明洲, 1993; 贾渝和何思, 2013); 霍山县(Cai, 2002 as $M$. hamata); 黄山市(陈邦杰和吴鹏程, 1965 as M. hamata)。

175. 毛叉苔 Metzgeria pubescens (Schrank) Raddi 安徽(Piippo, 1990 as Apometzgeria pubescens; 张美珍和赖明洲, 1993 as A. pubescens); 黄山市(陈邦杰和吴鹏程, 1965); 霍山县(Cai, 2002 as A. pubescens)。

\section{小叶苔科 Fossombroniaceae}

\section{小叶苔属 Fossombronia}

176. 日本小叶苔 Fossombronia japonica Schiffn. 芜湖市(程前和师雪芹, 2018)。

\section{南溪苔科 Makinoaceae}

\section{南溪苔属 Makinoa}

177. 南溪苔 Makinoa crispata (Steph.) Miyake 安徽(Piippo, 1990; 张美珍和赖明洲, 1993; 贾渝和何思, 2013); 黄山市(陈邦杰和吴鹏 程, 1965); 霍山县(Cai, 2002); 石台县(郭新弧等, 1990)。

\section{Moerckiaceae}

\section{假带叶苔属 Hattorianthus}


178. 拟带叶苔 Hattorianthus erimonus (Steph.) R. M. Schust. et Inoue 安徽(张美珍和赖明洲, 1993); 霍山县(刘仲苓, 1988; Cai, 2002)。

\section{带叶苔科 Pallaviciniaceae}

\section{带叶苔属 Pallavicinia}

179. 长刺带叶苔 Pallavicinia subciliata (Austin) Steph.

安徽(张美珍和赖明洲, 1993); 霍山县(Cai, 2002 as P. longispina)。

\section{溪苔科 Pelliaceae}

\section{溪苔属 Pellia}

180. 花叶溪苔 Pellia endiviifolia (Dicks.) Dumort.

安徽(Piippo, 1990; 张美珍和赖明洲, 1993); 霍山县(Cai, 2002); 石台县(郭新弧等, 1990)。

181. 溪苔 Pellia epiphylla (L.) Corda

安徽(张美珍和赖明洲, 1993); 霍山县(Cai, 2002)。

\section{瘤冠苔科 Aytoniaceae}

\section{紫背苔属 Plagiochasma}

182. 无纹紫背苔 Plagiochasma intermedium Lindenb. et Gottsche 安徽(Piippo, 1990; 张美珍和赖明洲, 1993); 石台县(郭新弧等, 1990)。

\section{石地钱属 Reboulia}

183. 石地钱 Reboulia hemisphaerica (L.) Raddi

安徽(Piippo, 1990; 张美珍和赖明洲, 1993); 黄山市(陈邦杰和吴鹏程, 1965); 霍山县 (Cai, 2002)。

\section{蛇苔科 Conocephalaceae}

\section{蛇苔属 Conocephalum}

184. 蛇苔 Conocephalum conicum (L.) Dumort.

安徽(Piippo, 1990; 张美珍和赖明洲, 1993); 黄山市(陈邦杰和吴鹏程, 1965); 霍山县 (Cai, 2002); 石台县(郭新弧等, 1990)。

185. 小蛇苔 Conocephalum japonicum (Thunb.) Grolle

安徽(张美珍和赖明洲, 1993); 霍山县(Cai, 2002 as C. supradecompositum)。

\section{毛地钱科 Dumortieraceae}

\section{毛地钱属 Dumortiera}

186. 毛地钱 Dumortiera hirsuta (Sw.) Nees

安徽(Piippo, 1990; 张美珍和赖明洲, 1993); 黄山市(陈邦杰和吴鹏程, 1965); 石台县(郭 新弧等, 1990)。

\section{地钱科 Marchantiaceae}

地钱属 Marchantia

187. 粗裂地钱 Marchantia paleacea Bertol.

石台县(郭新弧等, 1990)。 


\section{单月苔科 Monosoleniaceae}

\section{单月苔属 Monosolenium}

188. 单月苔 Monosolenium tenerum Griff.

宁国市(程前和师雪芹, 2018); 芜湖市(程前和师雪芹, 2018)。

\section{泥炭藓科 Sphagnaceae}

\section{蘚类植物门 Bryophyta}

\section{泥炭蘚属 Sphagnum}

189. 拟尖叶泥炭藓 Sphagnum acutifolioides Warnst.

安徽(张美珍和赖明洲, 1993; 贾渝和何思, 2013); 黄山市(高谦, 1994; Gao et al, 1999)。

190. 泽地泥炭藓 Sphagnum inundatum Russow

安徽(张美珍和赖明洲, 1993 as S. subsecundum var. inundatum; Redfearn et al, 1996 also as

S. subsecundum var. inundatum); 黄山市(Potier de la Varde, 1937 as $S$. inundatum var.

perfibrosum; 陈邦杰和吴鹏程, 1965 as S. inundatum var. perfibrosum)。

191. 暖地泥炭藓 Sphagnum junghuhnianum Dozy et Molk.

安徽(张美珍和赖明洲, 1993; Redfearn et al, 1996); 黄山市(陈邦杰和吴鹏程, 1965); 石台 县(郭新弧等, 1990)。

192. 加萨泥炭藓 Sphagnum khasianum Mitt.

安徽(张美珍和赖明洲, 1993; Redfearn et al, 1996; 贾渝和何思, 2013; 吴明开等, 2010a); 黄山市(陈邦杰和吴鹏程, 1965; 高谦, 1994; Gao et al, 1999)。

193. 中位泥炭藓 Sphagnum magellanicum Brid.

安徽(张美珍和赖明洲, 1993; Redfearn et al, 1996; 贾渝和何思, 2013); 黄山市(高谦, 1994; Gao et al, 1999)。

194. 卵叶泥炭蘚 Sphagnum ovatum Hampe

安徽(张美珍和赖明洲, 1993; Redfearn et al, 1996; 贾渝和何思, 2013); 黄山市(陈邦杰和 黎兴江, 1956; 陈邦杰和吴鹏程, 1965; 高谦, 1994; Gao et al, 1999)。

195. 泥炭藓 Sphagnum palustre L.

安徽(张美珍和赖明洲, 1993; Redfearn et al, 1996 also as S. cymbifolium, also as $S$.

pseudocymbifolium; 吴明开等, 2010a as S. palustre ssp. pseudocymbifolium; 贾渝和何思, 2013); 黄山市(Tchen, 1936 as S. cymbifolium; Potier de la Varde, 1937 as S. cymbifolium; 陈邦杰和黎兴江, 1956 as S. cymbifolium, also as S. pseudocymbifolium; 陈邦杰和吴鹏程, 1965 as S. cymbifolium, also as S. pseudocymbifolium; 高谦, 1994 also as S. palustre ssp. pseudocymbifolium; Gao et al, 1999 also as S. palustre ssp. pseudocymbifolium)。

196. 偏叶泥炭藓 Sphagnum subsecundum Nees 安徽(贾渝和何思, 2013); 黄山市(高谦, 1994; Gao et al, 1999)。

\section{黑蘚科 Andreaeaceae}

\section{黑蘚属 Andreaea}

197. 欧黑藓东亚亚种 Andreaea rupestris ssp. fauriei (Besch.) W. Schultze-Motel 安徽(张美珍和赖明洲, 1993 as A. mamillosula); 黄山市(陈邦杰和万宗玲, 1958 as $A$. mamillosula; 陈邦杰和吴鹏程, 1965 as A. mamillosula; 高谦, 1994 as A. mamillosula; Gao et al, 1999)。 


\section{金发藓科 Polytrichaceae 仙鹤藓属 Atrichum}

198. 狭叶仙鹤蘚 Atrichum angustatum (Brid.) Bruch et Schimp.

安徽(吴明开等, 2010a); 霍山县(Cai, 2002); 黄山市(吴明开等, 2008)。

199. 小仙鹤蘚 Atrichum crispulum Schimp. ex Besch.

安徽(Luo \& Koponen, 1986; 张美珍和赖明洲, 1993; 吴明开等, 2010a); 黄山市(陈邦杰

和吴鹏程, 1965 as $A$. henryi, also as $A$. spinulosum); 霍山县(Cai, 2002 as $A$. henryi, also as

A. spinulosum)。

200. 小胞仙鹤藓 Atrichum rhystophyllum (Müll. Hal.) Paris

安徽(Potier de la Varde, 1918 as Catharinea rhystophylla; Luo \& Koponen, 1986; 张美珍和 赖明洲, 1993; Redfearn et al, 1996 as C. parvirosula, also as C. rhystophylla; 吴明开等,

2010a)。

201. 薄壁仙鹤蘚 Atrichum subserratum (Harv. et Hook. f.) Mitt. 安徽(吴明开等, 2010a); 黄山市(吴明开等, 2008)。

202. 仙鹤藓多龩变种 Atrichum undulatum var. gracilisetum Besch.

安徽(Luo \& Koponen, 1986; 吴明开等, 2010a; 贾渝和何思, 2013); 霍山县(Cai, 2002 as A. obtusulum)。

203. 东亚仙鹤藓 Atrichum yakushimense (Horik.) Mizush. 安徽(吴明开等, 2010a; 贾渝和何思, 2013); 黄山市(Luo \& Koponen, 1986; 吴鹏程和贾 渝, 2004; Wu et al, 2005)。

\section{小金发藓属 Pogonatum}

204. 小金发藓 Pogonatum aloides (Hedw.) P. Beauv.

安徽(Redfearn et al, 1996); 霍山县(Cai, 2002)。

205. 刺边小金发藓褐色亚种 Pogonatum cirratum ssp. fuscatum (Mitt.) Hyvönen 安徽(张美珍和赖明洲, 1993; Redfearn et al, 1996, also as P. spuriocirratum)。

206. 扭叶小金发藓 Pogonatum contortum (Menzies ex Brid.) Lesq. 安徽(张美珍和赖明洲, 1993; Redfearn et al, 1996); 黄山市(陈邦杰和吴鹏程, 1965)。

207. 东亚小金发藓 Pogonatum inflexum (Lindb.) Sande Lac.

安徽(张美珍和赖明洲, 1993; Redfearn et al, 1996; 吴明开等, 2010a；贾渝和何思, 2013); 黄山市(Potier de la Varde, 1937; 陈邦杰和吴鹏程, 1965; 吴鹏程和贾渝, 2004; Wu et al, 2005); 霍山县(Cai, 2002); 勯县(Wu et al, 2005)。

208. 小口小金发藓 Pogonatum microstomum (R. Br. ex Schwägr.) Brid. 安徽(张美珍和赖明洲, 1993; Redfearn et al, 1996)。

209. 硬叶小金发藓 Pogonatum neesii (Müll. Hal.) Dozy 安徽(张美珍和赖明洲, 1993; Redfearn et al, 1996; 吴明开等, 2010a); 石台县(郭新弧等, 1990 as $P$. junghuhnianum)。

210. 苞叶小金发藓 Pogonatum spinulosum Mitt. 安徽(张美珍和赖明洲, 1993; Redfearn et al, 1996; 贾渝和何思, 2013); 黄山市(陈邦杰和 吴鹏程, 1965; 吴鹏程和贾渝, 2004; Wu et al, 2005); 霍山县(Cai, 2002); 青阳县(吴鹏程 和贾渝, 2004); 石台县(郭新弧等, 1990)。

211. 疮小金发藓 Pogonatum urnigerum (Hedw.) P. Beauv. 
安徽(Potier de la Varde, 1918; Reimers, 1931; 张美珍和赖明洲, 1993; Redfearn et al, 1996; 贾渝和何思, 2013); 黄山市(陈邦杰和吴鹏程, 1965; 吴鹏程和贾渝, 2004; Wu et al, 2005); 霍山县(Cai, 2002)。

\section{拟金发蘚属 Polytrichastrum}

212. 台湾拟金发藓 Polytrichastrum formosum (Hedw.) G. L. Sm. 安徽(张美珍和赖明洲, 1993; Redfearn et al, 1996 also as Polytrichum formosum; 吴明开 等, 2010a; 贾渝和何思, 2013); 黄山市(陈邦杰和吴鹏程, 1965 as P. formosum; 吴鹏程和 贾渝, 2004); 霍山县(Cai, 2002 as $P$. formosum); 石台县(郭新弧等, 1990 as $P$. formosum)。

213. 台湾拟金发藓圆齿变种 Polytrichastrum formosum var. densifolium (Hedw.) G. L. Sm. 安徽(Redfearn et al, 1996)。

214. 细叶拟金发藓 Polytrichastrum longisetum (Sw. ex Brid.) G. L. Sm. 安徽(吴明开等, 2010a); 黄山市(吴明开等, 2008)。

\section{金发藓属 Polytrichum}

215. 金发藓 Polytrichum commune Hedw. 安徽(张美珍和赖明洲, 1993; Redfearn et al, 1996; 吴明开等, 2010a；贾渝和何思, 2013); 黄山市(Tchen, 1936; Potier de la Varde, 1937; 陈邦杰和吴鹏程, 1965; Wu et al, 2005)。

\section{短颈藓科 Diphysciaceae}

\section{短颈藓属 Diphyscium}

216. 东亚短颈蘚 Diphyscium fulvifolium Mitt.

安徽(张美珍和赖明洲, 1993; Redfearn et al, 1996; 吴明开等, 2010a；贾渝和何思, 2013); 黄山市(陈邦杰和吴鹏程, 1965; 吴鹏程和贾渝, 2004; Wu et al, 2005)。

\section{葫芦蘚科 Funariaceae}

\section{葫芦蘚属 Funaria}

217. 葫芦蘚 Funaria hygrometrica Hedw. 安徽(张美珍和赖明洲, 1993; Redfearn et al, 1996; 吴明开等, 2010a); 黄山市(陈邦杰和 吴鹏程, 1965); 石台县(郭新弧等, 1990; 黎兴江, 2000; Gao et al, 2003)。

218. 日本葫芦蘚 Funaria japonica Broth. 安徽(吴明开等, 2010a)。

219. 小口葫芦蘚 Funaria microstoma Bruch ex Schimp. 安徽(贾渝和何思, 2013); 黄山市(黎兴江, 2000; Gao et al, 2003)。

\section{立碗蘚属 Physcomitrium}

220. 江岸立碗藓 Physcomitrium courtoisii Paris et Broth. 安徽(Paris, 1911; 张美珍和赖明洲, 1993; Redfearn et al, 1996; 吴明开等, 2010a; 贾渝和 何思, 2013); 黄山市(陈邦杰和吴鹏程, 1965); 桐城市(黎兴江, 2000; Gao et al, 2003); 芜 湖市(Paris, 1909)。

221. 红蒴立碗藓 Physcomitrium eurystomum Sendtn. 安徽(贾渝和何思, 2013); 黄山市(黎兴江, 2000; Gao et al, 2003)。

222. 日本立碗藓 Physcomitrium japonicum (Hedw.) Mitt. 安徽(张美珍和赖明洲, 1993 as P. limbatulum; Redfearn et al, 1996 as P. limbatulum; 贾渝 和何思, 2013); 黄山市(陈邦杰和吴鹏程, 1965 as P. limbatulum; 黎兴江, 2000 also as $P$. 
limbatulum; Gao et al, 2003); 霍山县(黎兴江, 2000 also as P. limbatulum; Gao et al, 2003)。

223. 中华立碗藓 Physcomitrium sinensi-sphaericum Müll. Hal. 安徽(吴明开等, 2010a); 黄山市(吴明开等, 2008)。

224. 立碗藓 Physcomitrium sphaericum (Ludw.) Fürnr. 安徽(吴明开等, 2010a)；黄山市(吴明开等, 2008)。

\section{木衣蘚科 Drummondiaceae}

\section{木衣藓属 Drummondia}

225. 中华木衣藓 Drummondia sinensis Müll. Hal.

安徽(张美珍和赖明洲, 1993; Redfearn et al, 1996; 贾渝和何思, 2013); 黄山市(吴鹏程和 贾渝, 2011; Wu et al, 2011); 霍山县(Cai, 2002; 吴鹏程和贾渝, 2011; Wu et al, 2011); 青 阳县(吴鹏程和贾渝, 2011; Wu et al, 2011)。

\section{虾藓科 Bryoxiphiaceae}

\section{虾蘚属 Bryoxiphium}

226. 虾藓东亚亚种 Bryoxiphium norvegicum ssp. japonicum (Berggr.) Á. Löve et D. Löve 安徽(张美珍和赖明洲, 1993; 吴明开等, 2010a; 贾渝和何思, 2013); 黄山市(黎兴江, 1958 as B. japonicum; 陈邦杰和吴鹏程, 1965 as B. japonicum; 高谦, 1994; Gao et al, 1999)。

\section{缩叶藓科 Ptychomitriaceae}

\section{缩叶藓属 Ptychomitrium}

227. 齿边缩叶藓 Ptychomitrium dentatum (Mitt.) A. Jaeger 安徽(张美珍和赖明洲, 1993; Redfearn et al, 1996; 贾渝和何思, 2013); 黄山市(高谦, 1996); 霍山县(Cai, 2002)。

228. 东亚缩叶蘚 Ptychomitrium fauriei Besch.

安徽(张美珍和赖明洲, 1993; Redfearn et al, 1996; 吴明开等, 2010a；贾渝和何思, 2013); 黄山市(陈邦杰和吴鹏程, 1965; Cao et al, 1995; 高谦, 1996; Li et al, 2001); 石台县(郭新 弧等, 1990)。

229. 多枝缩叶藓 Ptychomitrium gardneri Lesq. 安徽(吴明开等, 2010a as P. polyphylloides); 黄山市(吴明开等, 2008 as $P$. polyphylloides)。

230. 狭叶缩叶藓 Ptychomitrium linearifolium Reimers

安徽(张美珍和赖明洲, 1993; Redfearn et al, 1996; 吴明开等, 2010a; 贾渝和何思, 2013); 黄山市(陈邦杰和吴鹏程, 1965; Cao et al, 1995; 高谦, 1996; Li et al, 2001); 石台县(郭新 弧等, 1990); 霍山县(高谦, 1996; Cai, 2002)。

231. 中华缩叶藓 Ptychomitrium sinense (Mitt.) A. Jaeger 安徽(Paris, 1911; 张美珍和赖明洲, 1993; Redfearn et al, 1996 also as Glyphomitrium sinense; 吴明开等, 2010a)。

232. 威氏缩叶藓 Ptychomitrium wilsonii Sull. et Lesq. 安徽(Potier de la Varde, 1918; Reimers, 1931; 张美珍和赖明洲, 1993; Redfearn et al, 1996; 吴明开等, 2010a; 贾渝和何思, 2013); 黄山市(陈邦杰和吴鹏程, 1965; Cao et al, 1995; 高 
谦, 1996; Li et al, 2001)。

\section{紫蕶藓科 Grimmiaceae}

矮齿蘚属 Bucklandiella

233. 高山矮齿藓 Bucklandiella sudetica (Funck) Bednarek-Ochyra et Ochyra 安徽(Redfearn et al, 1996 as Racomitrium heterostichum var. sudeticum, also as $R$. sudeticum; 吴明开等, 2010a as R. sudeticum)。

\section{无尖藓属 Codriophorus}

234. 黄无尖藓 Codriophorus anomodontoides (Cardot) Bednarek-Ochyra et Ochyra 安徽(张美珍和赖明洲, 1993 as Racomitrium anomodontoides; Redfearn et al, 1996 as $R$. fasciculare var. atroviride, also as R. anomodontoides; 吴明开等, 2010a as $R$. anomodontoides; 贾渝和何思, 2013); 黄山市(陈邦杰和吴鹏程, 1965 as $R$. anomodontoides; 黎兴江, 2000 as R. anomodontoides; Gao et al, 2003 as $R$. anomodontoides); 石台县(郭新弧等, 1990 as R. anomodontoides)。

235. 短柄无尖藓 Codriophorus brevisetus (Lindb.) Bednarek-Ochyra et Ochyra 安徽(吴明开等, 2010a as Racomitrium brevisetum; 贾渝和何思, 2013); 黄山市(黎兴江, 2000 as R. brevisetum; Gao et al, 2003 as R. brevisetum)。

236. 短无尖藓 Codriophorus carinatus (Cardot) Bednarek-Ochyra et Ochyra 安徽(吴明开等, 2010a as Racomitrium carinatum); 歎县(吴明开等, 2008 as $R$. carinatum)。

237. 从枝无尖藓 Codriophorus fasicularis (Hedw.) Bednarek-Ochyra \& Ochyra 安徽(张美珍和赖明洲, 1993 as Racomitrium fasciculare; Redfearn et al, 1996 as $R$. fasciculare; 吴明开等, 2010a as R. fasciculare); 黄山市(陈邦杰和吴鹏程, 1965 as $R$. fasciculare); 霍山县(Cai, 2002)。

\section{紫蕶蘚属 Grimmia}

238. 近缘紫蕶蘚 Grimmia longirostris Hook.

安徽(张美珍和赖明洲, 1993 as G. affinis; Redfearn et al, 1996 as G. affinis; 贾渝和何思, 2013); 黄山市(Cao \& Vitt, 1986 as G. affinis; 黎兴江, 2000 as G. affinis; Gao et al, 2003)。

239. 高山紫萝蘚 Grimmia montana Bruch et Schimp. 安徽(张美珍和赖明洲, 1993; Redfearn et al, 1996; 吴明开等, 2010a；贾渝和何思, 2013); 黄山市(Cao \& Vitt, 1986; 黎兴江, 2000; Gao et al, 2003); 石台县(郭新弧等, 1990)。

240. 卵叶紫葶蘚 Grimmia ovalis (Hedw.) Lindb. 石台县(郭新弧等, 1990 as G. commutata)。

241. 毛尖紫葶蘚 Grimmia pilifera P. Beauv. 安徽(Redfearn et al, 1996; 吴明开等, 2010a; 贾渝和何思, 2013); 黄山市(Cao \& Vitt, 1986; 黎兴江, 2000; Gao et al, 2003); 霍山县(Cai, 2002); 休宁县(Gao et al, 2003)。

\section{长齿蘚属 Niphotrichum}

242. 硬叶长齿蘚 Niphotrichum barbuloides (Cardot) Bednarek-Ochyra et Ochyra 安徽(吴明开等, 2010a as Racomitrium barbuloides); 歇县(吴明开等, 2008 as $R$. barbuloides)。

243. 长齿藓 Niphotrichum canescens (Hedw.) Bednarek-Ochyra et Ochyra 安徽(张美珍和赖明洲, 1993 as Racomitrium canescens; Redfearn et al, 1996 as $R$. 
canescens); 黄山市(陈邦杰和吴鹏程, 1965 as $R$. canescens; Gao et al, 2003 as $R$. canescens); 霍山县(Cai, 2002); 石台县(郭新弧等, 1990 as R. canescens)。

244. 长枝长齿藓 Niphotrichum ericoides (Brid.) Bednarek-Ochyra et Ochyra 安徽(贾渝和何思, 2013); 金寨县(Gao et al, 2003 as R. ericoides)。

245. 东亚长齿藓 Niphotrichum japonicum (Dozy et Molk.) Bednarek-Ochyra et Ochyra 安徽(吴明开等, 2010a as Racomitrium japonicum; 贾渝和何思, 2013); 阜南县(Gao et al, 2003 as R. japonicum); 黄山市(黎兴江, 2000 as $R$. japonicum; Gao et al, 2003 as $R$.

japonicum); 霍山县(黎兴江, 2000 as R. japonicum; Gao et al, 2003 as R. japonicum); 休宁 县(Gao et al, 2003 as $R$. japonicum)。

\section{砂蘚属 Racomitrium}

246. 异枝砂藓 Racomitrium heterostichum (Hedw.) Brid. 安徽(张美珍和赖明洲, 1993; Redfearn et al, 1996; 吴明开等, 2010a); 黄山市(陈邦杰和 吴鹏程, 1965)。

247. 多枝砂藓 Racomitrium laetum Besch. et Cardot 安徽(吴明开等, 2010a; 贾渝和何思, 2013); 撮县(黎兴江, 2000; Gao et al, 2003)。

248. 白毛砂藓 Racomitrium lanuginosum (Hedw.) Brid. 安徽(Redfearn et al, 1996; 贾渝和何思, 2013); 黄山市(黎兴江, 2000; Gao et al, 2003)。

\section{连轴蘚属 Schistidium}

249. 圆蒴连轴蘚 Schistidium apocarpum (Hedw.) Bruch et Schimp. 安徽(张美珍和赖明洲, 1993; Redfearn et al, 1996 also as Grimmia apocarpa); 霍山县(Cai, 2002); 石台县(郭新弧等, 1990 as G. apocarpa)。

250. 粗疮连轴藓 Schistidium strictum (Turner) Loeske ex Martensson 安徽(吴明开等, 2010a); 黄山市(吴明开等, 2008)。

\section{牛毛蘚科 Ditrichaceae}

\section{角齿蘚属 Ceratodon}

251. 角齿藓 Ceratodon purpureus (Hedw.) Brid. 金寨县(Gao et al, 1999)。

\section{牛毛蘚属 Ditrichum}

252. 叉枝牛毛蘚 Ditrichum divaricatum Mitt. 安徽(张美珍和赖明洲, 1993; Redfearn et al, 1996)。

253. 细牛毛蘚 Ditrichum flexicaule (Schwägr.) Hampe 霍山县(Cai, 2002)。

254. 牛毛藓 Ditrichum heteromallum (Hedw.) E. Britton 安徽(张美珍和赖明洲, 1993; 吴明开等, 2010a); 霍山县(Cai, 2002); 青阳县(吴明开等, 2008)。

255. 黄牛毛蘚 Ditrichum pallidum (Hedw.) Hampe 安徽(张美珍和赖明洲, 1993; Redfearn et al, 1996; 吴明开等, 2010a；贾渝和何思, 2013); 石台县(郭新弧等, 1990); 黄山市(陈邦杰和吴鹏程, 1965; 高谦, 1994; Gao et al, 1999); 歌县(Gao et al, 1999)。

\section{丛毛蘚属 Pleuridium}

256. 从毛藓 Pleuridium subulatum (Hedw.) Rabenh. 安徽(张美珍和赖明洲, 1993; Redfearn et al, 1996); 石台县(郭新弧等, 1990)。 


\section{小烛蘚科 Bruchiaceae}

\section{长葫藓属 Trematodon}

257. 长蒴藓 Trematodon longicollis Michx.

安徽(Paris, 1908; 张美珍和赖明洲, 1993; Redfearn et al, 1996 also as T. tonkinensis; 吴明 开等, 2010a; 贾渝和何思, 2013); 黄山市(陈邦杰和吴鹏程, 1965; 高谦, 1994; Gao et al, 1999); 霍山县(Gao et al, 1999)。

\section{小曲尾蘚科 Dicranellaceae}

\section{小曲尾蘚属 Dicranella}

258. 福建小曲尾蘚 Dicranella fukienensis Broth. 安徽(吴明开等, 2010a); 黄山市(吴明开等, 2008)。

259. 多形小曲尾藓 Dicranella heteromalla (Hedw.) Schimp.

安徽(张美珍和赖明洲, 1993; Redfearn et al, 1996; 吴明开等, 2010a; 贾渝和何思, 2013); 黄山市(陈邦杰和吴鹏程, 1965; 高谦, 1994; Gao et al, 1999)。

260. 细叶小曲尾蘚 Dicranella micro-divaricata (Müll. Hal.) Paris 安徽(吴明开等, 2010a); 黄山市(吴明开等, 2008)。

261. 史贝小曲尾藓 Dicranella schreberiana (Hedw.) Hilf. ex H. A. Crum et L. E. Anderson 安徽(吴明开等, 2010a as D. grevilleana)；黄山市(吴明开等, 2008 as D. grevilleana)。

262. 偏叶小曲尾藓 Dicranella subulata (Hedw.) Schimp. 安徽(张美珍和赖明洲, 1993; 贾渝和何思, 2013); 黄山市(高谦, 1994; Gao et al, 1999)。

263. 变形小曲尾藓 Dicranella varia (Hedw.) Schimp. 安徽(张美珍和赖明洲, 1993; Redfearn et al, 1996); 黄山市(陈邦杰和吴鹏程, 1965 as Anisothecium rubra)。

\section{曲背蘚科 Oncophoraceae}

\section{卷毛蘚属 Dicranoweisia}

264. 卷毛藓 Dicranoweisia crispula (Hedw.) Lindb. ex Milde 安徽(张美珍和赖明洲, 1993; 贾渝和何思, 2013); 黄山市(高谦, 1994; Gao et al, 1999); 霍山县(Cai, 2002)。

\section{高领藓属 Glyphomitrium}

265. 短枝高领蘚 Glyphomitrium humillimum (Mitt.) Cardot 安徽(吴明开等, 2010a); 黄山市(吴明开等, 2010b)。

266. 东亚高领蘚 Glyphomitrium warburgii (Broth.) Cardot 安徽(吴明开等, 2010a); 黄山市(吴明开等, 2010b)。

\section{曲背藓属 Oncophorus}

267. 卷叶曲背藓 Oncophorus crispifolius (Mitt.) Lindb. 安徽(张美珍和赖明洲, 1993; Redfearn et al, 1996; 吴明开等, 2010a; 贾渝和何思, 2013); 黄山市(陈邦杰和吴鹏程, 1965; 高谦, 1994; Gao et al, 1999)。

268. 曲背藓 Oncophorus wahlenbergii Brid. 安徽(吴明开等, 2010a)；黄山市(吴明开等, 2008)。

\section{合睫蘚属 Symblepharis}

269. 合睫藓 Symblepharis vaginata (Hook.) Wijk et Margad. 
安徽(Redfearn et al, 1996 also as S. helicophylla；吴明开等, 2010a；贾渝和何思, 2013); 黄山市(Potier de la Varde, 1937 as S. helicophylla；陈邦杰和吴鹏程, 1965 as $S$. helicophylla)。

\section{树生蘚科 Erpodiaceae \\ 钟帽蘚属 Venturiella}

270. 钟帽藓 Venturiella sinensis (Venturi) Müll. Hal.

安徽(张美珍和赖明洲, 1993; Redfearn et al, 1996; 贾渝和何思, 2013); 黄山市(陈邦杰和 吴鹏程, 1965; 吴鹏程和贾渝, 2011; Wu et al, 2011)。

\section{曲尾藓科 Dicranaceae \\ 锦叶藓属 Dicranoloma}

271. 长蒴锦叶藓 Dicranoloma cylindrothecium (Mitt.) Sakura

安徽(张美珍和赖明洲, 1993 as Dicranum subcylindrothecium; Redfearn et al, 1996)。

\section{曲尾藓属 Dicranum}

272. 阿萨姆曲尾蘚 Dicranum assamicum Dixon 安徽(吴明开等, 2010a)；黄山市(吴明开等, 2008)。

273. 鞭枝曲尾藓 Dicranum flagellare Hedw.

霍山县(Cai, 2002)。

274. 线叶曲尾藓(细叶曲尾藓)Dicranum fulvum Hook.

安徽(吴明开等, 2010a); 黄山市(吴明开等, 2008)。

275. 钩叶曲尾蘚 Dicranum hamulosum Mitt.

石台县(郭新弧等, 1990)。

276. 日本曲尾蘚 Dicranum japonicum Mitt.

安徽(张美珍和赖明洲, 1993; Redfearn et al, 1996; 吴明开等, 2010a also as D.

schensianum; 贾渝和何思, 2013); 黄山市(高谦, 1994; Gao et al, 1999)。

277. 多蒴曲尾蘚 Dicranum majus Turner

安徽(张美珍和赖明洲, 1993 also as D. delavayi; Redfearn et al, 1996 also as D. delavayi);

黄山市(Potier de la Varde, 1937; 陈邦杰和吴鹏程, 1965 as D. delavayi)。

278. 东亚曲尾蘚 Dicranum nipponense Besch.

安徽(张美珍和赖明洲, 1993; 吴明开等, 2010a; Redfearn et al, 1996 also as D. rufescens); 黄山市(陈邦杰和吴鹏程, 1965); 霍山县(Cai, 2002)。

279. 脆叶曲尾蘚 Dicranum psathyrum Klazenga

安徽(高谦等, 1993 as Dicranoloma fragile; 张美珍和赖明洲, 1993 as D. fragile; Redfearn et al, 1996 as D. fragile; 贾渝和何思, 2013); 黄山市(高谦, 1994 as D. fragile); 霍山县

(Gao et al, 1999 as D. fragile)。

280. 曲尾藓 Dicranum scoparium Hedw.

安徽(张美珍和赖明洲, 1993; Redfearn et al, 1996; 吴明开等, 2010a; 贾渝和何思, 2013);

黄山市(陈邦杰和吴鹏程, 1965; 高谦, 1994; Gao et al, 1999); 石台县(郭新弧等, 1990)。

\section{苞领藓属 Holomitrium}

281. 柱鞘苞领藓 Holomitrium cylindraceum (P. Beauv.) Wijk et Marg.

霍山县(Cai, 2002)。

282. 密叶苞领藓 Holomitrium densifolium (Wilson) Wijk et Marg. 
安徽(张美珍和赖明洲, 1993; Redfearn et al, 1996 also as H. griffithianum; 吴明开等, 2010a also as H. griffithianum; 贾渝和何思, 2013); 黄山市(陈邦杰和吴鹏程, 1965 as $H$. griffithianum); 霍山县(高谦, 1994; Gao et al, 1999)。

\section{拟白发蘚属 Paraleucobryum}

283. 㽼肋拟白发藓 Paraleucobryum schwarzii (Schimp.) C. Gao et Vitt. 安徽(张美珍和赖明洲, 1993 as Campylopus schwarzii); 石台县(郭新弧等, 1990 as C. schwarzii)。

\section{白发藓科 Leucobryaceae}

\section{白氏藓属 Brothera}

284. 白氏藓 Brothera leana (Sull.) Müll. Hal. 安徽(张美珍和赖明洲, 1993); 黄山市(陈邦杰和吴鹏程, 1965); 霍山县(Cai, 2002)。

\section{曲柄藓属 Campylopus}

285. 长叶曲柄藓 Campylopus atrovirens De Not. 安徽(张美珍和赖明洲, 1993; Redfearn et al, 1996; 吴明开等, 2010a；贾渝和何思, 2013); 黄山市(陈邦杰和吴鹏程, 1965; Frahm, 1992; 高谦, 1994; Gao et al, 1999); 霍山县(Cai, 2002); 青阳县(Frahm, 1992); 石台县(郭新弧等, 1990)。

286. 尾尖曲柄藓 Campylopus comosus (Schwägr.) Bosch et Sande Lac. 安徽(吴明开等, 2010a also as C. caudatus); 歇县(吴明开等, 2008 as C. caudatus)。

287. 毛叶曲柄藓 Campylopus ericoides (Griff.) A. Jaeger 安徽(张美珍和赖明洲, 1993 also as C. involutus; Redfearn et al, 1996 also as C. involutus; 吴明开等, 2010a)。

288. 曲柄藓 Campylopus flexuosus (Hedw.) Brid. 安徽(张美珍和赖明洲, 1993; Redfearn et al, 1996; 吴明开等, 2010a)。

289. 纤枝曲柄藓 Campylopus gracilis (Mitt.) A. Jaeger 安徽(吴明开等, 2010a); 黄山市(吴明开等, 2008)。

290. 疏网曲柄蘚 Campylopus laxitextus Sande Lac. 安徽(吴明开等, 2010a); 歌县(吴明开等, 2008)。

291. 辛氏曲柄蘚 Campylopus schimperi J. Milde 安徽(张美珍和赖明洲, 1993 as C. subulatus var. schimperi; 吴明开等, 2010a as $C$. alpigena, also as C. alpigena var. lamellatus; 贾渝和何思, 2013); 黄山市(高谦, 1994 as C. alpigena var. lamellatus; Gao et al, 1999); 撮县(吴明开等, 2008 as C. alpigena)。

292. 黄曲柄藓 Campylopus schmidii (Müll. Hal.) A. Jaeger 安徽(吴明开等, 2010a also as C. aureus; 贾渝和何思, 2013); 黄山市(吴明开等, 2008 as C. aureus); 歌县(Gao et al, 1999)。

293. 中华曲柄藓 Campylopus sinensis (Müll. Hal.) J. P. Frahm 安徽(张美珍和赖明洲, 1993 as C. japonicus; Redfearn et al, 1996 also as C. japonicus; 吴 明开等, 2010a as C. japonicus; 贾渝和何思, 2013); 石台县(郭新弧等, 1990 as $C$. japonicus)。

294. 拟脆枝曲柄藓 Campylopus subfragilis Renauld et Cardot 安徽(吴明开等, 2010a); 黄山市(吴明开等, 2008)。

295. 台湾曲柄蘚 Campylopus taiwanensis Sakurai 安徽(张美珍和赖明洲, 1993; Redfearn et al, 1996; 吴明开等, 2010a；贾渝和何思， 
2013)。

296. 节茎曲柄藓 Campylopus umbellatus (Arnott) Paris 安徽(张美珍和赖明洲, 1993 also as C. coreensis; Redfearn et al, 1996 also as Thysanomitrion blumei; 吴明开等, 2010a; 贾渝和何思, 2013); 黄山市(陈邦杰和吴鹏程, 1965; Frahm, 1992; 高谦, 1994; Gao et al, 1999); 霍山县(Cai, 2002 as C. richardii); 青阳 县(Frahm, 1992); 檁县(Gao et al, 1999)。

\section{青毛藓属 Dicranodontium}

297. 粗叶青毛藓 Dicranodontium asperulum (Mitt.) Broth. 安徽(Redfearn et al, 1996)。

298. 青毛蘚 Dicranodontium denudatum (Brid.) E. Britton ex Williams 安徽(张美珍和赖明洲, 1993); 石台县(郭新弧等, 1990)。

299. 长叶青毛蘚 Dicranodontium didymodon (Griff.) Paris 安徽(吴明开等, 2010a as Campylopus longigemmatus); 宁国市(吴明开等, 2008 as C. longigemmatus)。

300. 钩叶青毛藓 Dicranodontium uncinatum (Harv.) A. Jaeger 安徽(张美珍和赖明洲, 1993 also as D. blindioides; Redfearn et al, 1996 as D. fleischerianum; 贾渝和何思, 2013); 歌县(Gao et al, 1999)。

\section{白发藓属 Leucobryum}

301. 弯叶白发藓 Leucobryum aduncum Dozy et Molk. 安徽(贾渝和何思, 2013); 黄山市(Gao et al, 1999)。

302. 粗叶白发藓 Leucobryum boninense Sull. et Lesq. 安徽(张美珍和赖明洲, 1993 as L. scaberulum; 吴明开等, 2010a as L. scaberulum); 石台 县(郭新弧等, 1990 as L. scaberulum); 黄山市(吴明开等, 2008 as L. scaberulum)。

303. 狭叶白发藓 Leucobryum bowringii Mitt. 安徽(张美珍和赖明洲, 1993; Redfearn et al, 1996; 吴明开等, 2010a; 贾渝和何思, 2013); 黄山市(Gao et al, 1999); 霍山县(Cai, 2002); 石台县(郭新弧等, 1990)。

304. 绿色白发藓 Leucobryum chlorophyllosum Müll. Hal. 安徽(吴明开等, 2010a); 黄山市(吴明开等, 2008)。

305. 白发藓 Leucobryum glaucum (Hedw.) Aöngström 安徽(张美珍和赖明洲, 1993; Redfearn et al, 1996)。

306. 短枝白发藓 Leucobryum humillimum Cardot 安徽(Redfearn et al, 1996 also as L. galeatum; 贾渝和何思, 2013); 黄山市(陈邦杰和吴鹏 程, 1965 as L. galeatum)。

307. 爪哇白发藓 Leucobryum javense (Brid.) Mitt. 安徽(张美珍和赖明洲, 1993; Redfearn et al, 1996; 贾渝和何思, 2013); 黄山市(陈邦杰和 吴鹏程, 1965; 高谦, 1994; Gao et al, 1999)。

308. 桧叶白发藓 Leucobryum juniperoideum (Brid.) Müll. Hal. 安徽(张美珍和赖明洲, 1993 as L. neilgherrense; 高谦, 1994 as L. neilgherrense; Redfearn et al, 1996 also as L. neilgherrense; 吴明开等, 2010a also as L. neilgherrense); 黄山市 (Potier de la Varde, 1937 as L. neilgherrense; 陈邦杰和吴鹏程, 1965 as L. neilgherrense); 霍山县(Cai, 2002 as L. neilgherrense)。

309. 疮叶白发藓 Leucobryum scabrum Sande Lac.

安徽(Redfearn et al, 1996; 吴明开等, 2010a；贾渝和何思, 2013)；黄山市(高谦, 1994; 
Gao et al, 1999)。

\section{凤尾蘚科 Fissidentaceae \\ 凤尾藓属 Fissidens}

310. 异形凤尾蘚 Fissidens anomalus Mont. 安徽(Redfearn et al, 1996; 吴明开等, 2010a)。

311. 糙蒴凤尾藓 Fissidens capitulatus Nog. 安徽(Redfearn et al, 1996)。

312. 齿叶凤尾藓 Fissidens crenulatus Mitt. 安徽(吴明开等, 2010a); 黄山市(吴明开等, 2008)。

313. 黄叶凤尾蘚 Fissidens crispulus Brid. 安徽(张美珍和赖明洲, 1993 also as F. zippelianus; Redfearn et al, 1996 as F. zippelianus; 贾渝和何思, 2013); 黄山市(陈邦杰和吴鹏程, 1965 as F. auriculatus)。

314. 卷叶凤尾藓 Fissidens dubius P. Beauv. 安徽(Redfearn et al, 1996 also as F. cristatus; 吴明开等, 2010a as F. cristatus; 贾渝和何 思, 2013); 黄山市(Tchen, 1936 as F. cristatus; 陈邦杰和吴鹏程, 1965 as F. cristatus; Iwatsuki, 1980 as F. cristatus; Li, 1985 as F. cristatus; 高谦, 1996 as F. cristatus; Li et al, 2001); 石台县(郭新弧等, 1990 as F. cristatus)。

315. 二形凤尾蘚 Fissidens geminiflorus Dozy et Molk. 安徽(张美珍和赖明洲, 1993 also as F. geminiflorus var. nagasakinus; Redfearn et al, 1996 also as F. geminiflorus var. nagasakinus; 吴明开等, 2010a); 霍山县(Cai, 2002)。

316. 大叶凤尾蘚 Fissidens grandifrons Brid. 安徽(张美珍和赖明洲, 1993; Redfearn et al, 1996; 贾渝和何思, 2013); 黄山市(Potier de la Varde, 1937; 陈邦杰和吴鹏程, 1965)。

317. 裸募风尾蘚 Fissidens gymnogynus Besch. 安徽(张美珍和赖明洲, 1993; 吴明开等, 2010a; 贾渝和何思, 2013); 黄山市(高谦, 1996; Li et al, 2001)。

318. 内卷凤尾蘚 Fissidens involutus Wilson ex Mitt. 安徽(张美珍和赖明洲, 1993 as F. plagiochiloides; Redfearn et al, 1996 as F. plagiochiloides); 霍山县(Cai, 2002 as F. plagiochiloides)。

319. 大凤尾藓 Fissidens nobilis Griff. 安徽(吴明开等, 2010a); 黄山市(吴明开等, 2008)。

320. 粗肋凤尾藓 Fissidens pellucidus Hornsch. 安徽(张美珍和赖明洲, 1993 as F. laxus; 吴明开等, 2010a as F. laxus); 黄山市(吴明开等, 2008 as F. laxus)。

321. 网孔凤尾藓 Fissidens polypodioides Hedw. 安徽(Redfearn et al, 1996)。

322. 鳞叶凤尾蘚 Fissidens taxifolius Hedw. 安徽(张美珍和赖明洲, 1993; Redfearn et al, 1996); 霍山县(Cai, 2002); 石台县(郭新弧等, 1990)。

323. 南京凤尾藓 Fissidens teysmannianus Dozy et Molk. 安徽(张美珍和赖明洲, 1993 as F. adelphinus; Redfearn et al, 1996 as F. adelphinus; 吴明 开等, 2010a as F. adelphinus)。 
324. 拟小凤尾蘚 Fissidens tosaensis Broth. 安徽(吴明开等, 2010a); 黄山市(吴明开等, 2008)。

\section{丛藓科 Pottiaceae}

\section{丛本藓属 Anoectangium}

325. 从本藓 Anoectangium aestivum (Hedw.) Mitt. 安徽(贾渝和何思, 2013); 黄山市(高谦, 1996 as A. euchloron; Li et al, 2001); 倝县(高谦, 1996 as A. euchloron)。

326. 扭叶丛本藓 Anoectangium stracheyanum Mitt. 安徽(贾渝和何思, 2013); 歌县(高谦, 1996; Li et al, 2001)。

327. 卷叶丛本藓 Anoectangium thomsonii Mitt. 安徽(贾渝和何思, 2013); 黄山市(高谦, 1996; Li et al, 2001); 霍山县(Cai, 2002); 檁县( $\mathrm{Li}$ et al, 2001)。

\section{扭口藓属 Barbula}

328. 砂地扭口藓 Barbula arcuata Griff. 安徽(贾渝和何思, 2013); 黄山市(高谦, 1996 as Hydrogonium arcuatum; Li et al, 2001 as H. arcuatum)。

329. 爪哇扭口藓 Barbula javanica Dozy et Molk. 安徽(贾渝和何思, 2013); 滁州市(高谦, 1996 as Hydrogonium consanguineum); 黟县(Li et al, 2001 as $H$. javanicum)。

330. 扭口藓 Barbula unguiculata Hedw. 安徽(张美珍和赖明洲, 1993; 吴明开等, 2010a; 贾渝和何思, 2013); 黄山市(陈邦杰和吴 鹏程, 1965 as B. unguiculata var. trichostomifolia); 芜湖市(高谦, 1996; Li et al, 2001)。

\section{对齿蘚属 Didymodon}

331. 尖叶对齿蘚 Didymodon constrictus (Mitt.) K. Saito 安徽(张美珍和赖明洲, 1993 as Barbula constricta; Redfearn et al, 1996; 吴明开等, 2010a as B. constricta; 贾渝和何思, 2013); 耠县(高谦, 1996 as B. constricta; Li et al, 2001)。

332. 长尖对齿藓 Didymodon ditrichoides (Broth.) X. J. Li et S. He 安徽(Redfearn et al, 1996 as Barbula ditrichoides, also as Didymodon rigidulus var. ditrichoides; 贾渝和何思, 2013); 黄山市(Li et al, 2001); 青阳县(高谦, 1996 as Barbula ditrichoides; Li et al, 2001); 檁县(高谦, 1996 as B. ditrichoides; Li et al, 2001)。

333. 反叶对齿藓 Didymodon ferrugineus (Schimp. ex Besch.) M. O. Hill 安徽(贾渝和何思, 2013); 青阳县(高谦, 1996 as Barbula reflexa; Li et al, 2001)。

334. 黑对齿蘚 Didymodon nigrescens (Mitt.) K. Saito 安徽(吴明开等, 2010a as Barbula nigrescens); 黄山市(吴明开等, 2008 as B. nigrescens)。

335. 硬叶对齿藓 Didymodon rigidulus Hedw. 安徽(张美珍和赖明洲, 1993; 吴明开等, 2010a); 黄山市(吴明开等, 2008)。

336. 短叶对齿藓 Didymodon tectorum (Müll. Hal.) K. Saito 安徽(张美珍和赖明洲, 1993; Redfearn et al, 1996; 吴明开等, 2010a as Barbula tectorum; 贾渝和何思, 2013); 黄山市(陈邦杰和吴鹏程, 1965 as B. tectorum); 檁县(高谦, 1996 as B. tectorum; Li et al, 2001)。

337. 灰土对齿藓 Didymodon tophaceus (Brid.) Lisa 安徽(吴明开等, 2010a); 黄山市(吴明开等, 2008)。 
338. 土生对齿藓 Didymodon vinealis (Brid.) R. H. Zander 安徽(张美珍和赖明洲, 1993 as Barbula subcontorta; Redfearn et al, 1996; 高谦, 1996 as B. subcontorta; 吴明开等, 2010a as B. subcontorta); 霍山县(Cai, 2002 as B. subcontorta)。

\section{立膜藓属 Hymenostylium}

339. 立膜蘚 Hymenostylium recurvirostrum (Hedw.) Dixon 安徽(张美珍和赖明洲, 1993 as Gymnostomum recurvirostrum; 吴明开等, 2010a as G. recurvirostrum); 石台县(郭新弧等, 1990 as G. recurvirostrum)。

\section{湿地藓属 Hyophila}

340. 卷叶湿地藓 Hyophila involuta (Hook.) A. Jaeger 安徽(吴明开等, 2010a); 黄山市(吴明开等, 2008)。

341. 花状湿地藓 Hyophila nymaniana (M. Fleisch.) M. Menzel 安徽(张美珍和赖明洲, 1993 as H. rosea; Redfearn et al, 1996 also as H. rosea; 吴明开等, 2010a also as H. rosea；贾渝和何思, 2013); 黄山市(Li et al, 2001); 潜山市(高谦, 1996 as H. rosea; Li et al, 2001); 㵊县(高谦, 1996 as H. rosea)。

\section{大丛蘚属 Molendoa}

342. 高山大从藓 Molendoa sendtneriana (Bruch et Schimp.) Limpr. 安徽(张美珍和赖明洲, 1993; Redfearn et al, 1996; 贾渝和何思, 2013); 潜山市(高谦, 1996; Li et al, 2001); 歌县(Li et al, 2001)。

343. 高山大从藓云南变种 Molendoa sendtneriana var. yunnanica (Broth.) Györffy 安徽(贾渝和何思, 2013); 歌县(高谦, 1996; Li et al, 2001)。

\section{拟合睫蘚属 Pseudosymblepharis}

344. 狭叶拟合睫藓 Pseudosymblepharis angustata (Mitt.) Hilp. 安徽(张美珍和赖明洲, 1993; Redfearn et al, 1996 also as P. papillosula, also as $P$. subduriuscula; 吴明开等, 2010a also as P. papillosula, also as P. subduriuscula; 贾渝和何 思, 2013); 黄山市(陈邦杰和吴鹏程, 1965 as P. papillosula; 高谦, 1996 as P. papillosula; Li et al, 2001); 青阳县(高谦, 1996; Li et al, 2001); 歌县(高谦, 1996 as P. papillosula, also as P. subduriuscula; $\mathrm{Li}$ et al, 2001); 石台县(郭新弧等, 1990 as P. papillosula)。

\section{舌叶蘚属 Scopelophila}

345. 剑叶舌叶藓 Scopelophila cataractae (Mitt.) Broth. 安徽(张美珍和赖明洲, 1993; 贾渝和何思, 2013); 黄山市(高谦, 1996 as Merceyopsis sikkimensis; Li et al, 2001)。

346. 舌叶藓 Scopelophila ligulata (Spruce) Spruce 安徽(张美珍和赖明洲, 1993; Redfearn et al, 1996 as Merceya ligulata; 贾渝和何思, 2013); 㵊县(高谦, 1996 as M. ligulata; Li et al, 2001)。

\section{赤藓属 Syntrichia}

347. 芽胞赤藓 Syntrichia gemmascens (P. C. Chen) R. H. Zander 安徽(吴明开等, 2010a as Desmatodon gemmascens)。

\section{反纽藓属 Timmiella}

348. 反纽藓 Timmiella anomala (Bruch et Schimp.) Limpr. 安徽(张美珍和赖明洲, 1993 as Rhamphidium crassicostatum; 贾渝和何思, 2013); 青阳县 (高谦, 1996 as R. crassicostatum; Li et al, 2001)。 
安徽(张美珍和赖明洲, 1993; 贾渝和何思, 2013); 潜山市(高谦, 1996; Li et al, 2001)。

\section{纽蘚属 Tortella}

350. 扭蘚(丛叶扭藓)Tortella humilis (Hedw.) Jenn.

安徽(贾渝和何思, 2013); 黄山市(吴明开等, 2010b); 勯县(吴明开等, 2010b)。

351. 长叶扭藓 Tortella tortuosa (Hedw.) Limpr.

安徽(张美珍和赖明洲, 1993; 吴明开等, 2010a; 贾渝和何思, 2013); 霍山县(高谦, 1996;

Cai, 2002; Li et al, 2001)。

\section{墙蘚属 Tortula}

352. 长尖墙藓 Tortula hoppeana (Schultz) Ochyra 安徽(吴明开等, 2010a as T. nankomontana); 黄山市(吴明开等 2008 as $T$. nankomontana)。

353. 泛生墙藓原变种 Tortula muralis Hedw. 安徽(张美珍和赖明洲, 1993; Redfearn et al, 1996; 吴明开等, 2010a); 石台县(郭新弧等, 1990); 芜湖市(Paris, 1909)。

\section{毛口藓属 Trichostomum}

354. 毛口藓 Trichostomum brachydontium Bruch 安徽(张美珍和赖明洲, 1993; Redfearn et al, 1996; 吴明开等, 2010a；贾渝和何思, 2013); 黄山市(陈邦杰和吴鹏程, 1965; 高谦, 1996; Li et al, 2001); 歌县(Li et al, 2001)。

355. 皱叶毛口藓 Trichostomum crispulum Bruch 安徽(吴明开等, 2010a); 黄山市(吴明开等, 2008)。

356. 卷叶毛口藓 Trichostomum hattorianum B. C. Tan et Z. Iwats. 安徽(吴明开等, 2010a as T. involutum); 黄山市(吴明开等, 2008 as T. involutum)。

357. 平叶毛口藓 Trichostomum planifolium (Dixon) R. H. Zander 安徽(张美珍和赖明洲, 1993 as Weissia planifolia; 吴明开等, 2010a as W. planifolia; 贾渝 和何思, 2013); 黄山市(高谦, 1996 as W. planifolia; Li et al, 2001)。

358. 阔叶毛口藓 Trichostomum platyphyllum (Broth. ex Iisiba) P. C. Chen

湌县(高谦, 1996 as Hyophila stenophylla)。

359. 波边毛口藓 Trichostomum tenuirostre (Hook. f. et Taylor) Lindb. 安徽(张美珍和赖明洲, 1993 as Oxystegus cuspidatus, also as O. cylindricus; Redfearn et al, 1996 also as O. cuspidatus, also as O. cylindricus; 吴明开等, 2010a as O. cuspidatus; 贾渝 和何思, 2013); 黄山市(陈邦杰和吴鹏程, 1965 as O. cuspidatus; Li et al, 2001); 金寨县( $\mathrm{Li}$ et al, 2001); 歌县(高谦, 1996 as O. cuspidatus, also as O. cylindricus)。

360. 芒尖毛口藓 Trichostomum zanderi Redf. et B. C. Tan 安徽(吴明开等, 2010a as T. aristatulum); 黄山市(吴明开等, 2008 as T. aristatulum)。

\section{小墙蘚属 Weisiopsis}

361. 褶叶小墙藓 Weisiopsis anomala (Broth. et Paris) Broth. 安徽(张美珍和赖明洲, 1993; Redfearn et al, 1996; 吴明开等, 2010a；贾渝和何思, 2013); 歌县(高谦, 1996; Li et al, 2001)。

\section{小石藓属 Weissia}

362. 短柄小石藓 Weissia breviseta (Thér.) P. C. Chen 安徽(吴明开等, 2010a); 黄山市(吴明开等, 2008)。

363. 小石藓 Weissia controversa Hedw.

安徽(张美珍和赖明洲, 1993 also as W. longidens; Redfearn et al, 1996 also as W. longidens, 
also as W. viridula；吴明开等, 2010a also as W. controversa var. minutissima；贾渝和何思， 2013); 黄山市(陈邦杰和吴鹏程, 1965 as W. longidens, also as W. viridula); 宁国市(高谦, 1996; Li et al, 2001); 歌县(高谦, 1996; Li et al, 2001); 芜湖市(高谦, 1996)。

364. 缺齿小石藓 Weissia edentula Mitt.

安徽(张美珍和赖明洲, 1993; Redfearn et al, 1996; 吴明开等, 2010a also as $W$.

platyphylloides, also as W. semipallida; 贾渝和何思, 2013); 黄山市(吴明开等, 2008 also as W. platyphylloides \& W. semipallida); 金寨县(高谦, 1996; Li et al, 2001); 翖县(高谦, 1996)。

365. 东亚小石藓 Weissia exserta (Broth.) P. C. Chen

安徽(张美珍和赖明洲, 1993; 吴明开等, 2010a; 贾渝和何思, 2013); 霍山县(Cai, 2002);

潜山市(高谦, 1996; Li et al, 2001); 青阳县(高谦, 1996; Li et al, 2001); 石台县(郭新弧等, 1990); 芜湖市(Paris, 1909; 高谦, 1996; Li et al, 2001)。

366. 皱叶小石藓 Weissia longifolia Mitt.

安徽(张美珍和赖明洲, 1993 as W. crispa; Redfearn et al, 1996 as W. crispa; 吴明开等,

2010a as W. crispa); 黄山市(陈邦杰和吴鹏程, 1965 as W. crispa); 霍山县(Cai, 2002 as $W$. crispa; Li et al, 2001); 芜湖市(高谦, 1996 as W. crispa; Li et al, 2001)。

\section{虎尾蘚科 Hedwigiaceae}

\section{虎尾蘚属 Hedwigia}

367. 虎尾藓 Hedwigia ciliata (Hedw.) Ehrh. ex P. Beauv.

安徽(Potier de la Varde, 1918; 张美珍和赖明洲, 1993; Redfearn et al, 1996 also as $H$. albicans; 吴明开等, 2010a); 黄山市(Tchen, 1936 as H. albicans; Potier de la Varde, 1937 as H. albicans; 陈邦杰和吴鹏程, 1965 as H. albicans; 吴鹏程和贾渝, 2011; Wu et al, 2011); 霍山县(Cai, 2002); 金寨县( Wu et al, 2011); 青阳县(吴鹏程和贾渝, 2011; Wu et al, 2011); 石台县(郭新弧等, 1990)。

\section{珠藓科 Bartramiaceae}

珠藓属 Bartramia

368. 亮叶珠藓 Bartramia halleriana Hedw.

安徽(张美珍和赖明洲, 1993; 吴明开等, 2010a; 贾渝和何思, 2013); 黄山市(Li et al, 2007)。

369. 直叶珠藓 Bartramia ithyphylla Brid. 安徽(张美珍和赖明洲, 1993); 黄山市(陈邦杰和吴鹏程, 1965)。

370. 梨蒴珠藓 Bartramia pomiformis Hedw.

安徽(Potier de la Varde, 1918 as B. crispata; 张美珍和赖明洲, 1993 also as B. pomiformis var. elongata; 吴明开等, 2010a; 贾渝和何思, 2013); 黄山市(Potier de la Varde, 1937 as $B$. crispata; 陈邦杰和吴鹏程, 1965 as B. crispata; 黎兴江, 2006; Li et al, 2007); 霍山县(Cai, 2002); 金寨县( $\mathrm{Li}$ et al, 2007)。

371. 毛叶珠藓 Bartramia subpellucida Mitt.

安徽(吴明开等, 2010a); 休宁县(吴明开等, 2008)。

\section{泽蘚属 Philonotis}

372. 偏叶泽藓 Philonotis falcata (Hook.) Mitt. 安徽(吴明开等, 2010a); 黄山市(吴明开等, 2008)。 
373. 泽藓 Philonotis fontana (Hedw.) Brid.

安徽(张美珍和赖明洲, 1993; Redfearn et al, 1996; 贾渝和何思, 2013); 霍山县(Cai, 2002); 金寨县(Li et al, 2007)。

374. 密叶泽藓 Philonotis hastata (Duby) Wijk et Margad. 安徽(吴明开等, 2010a); 黄山市(吴明开等, 2008)。

375. 毛叶泽藓 Philonotis lancifolia Mitt.

安徽(Paris, 1911 as P. courtoisii; 张美珍和赖明洲, 1993; Redfearn et al, 1996 slao as $P$. courtoisii; 贾渝和何思, 2013); 黄山市(陈邦杰和吴鹏程, 1965; 黎兴江, 2006; Li et al, 2007)。

376. 柔叶泽藓 Philonotis mollis (Dozy et Molk.) Mitt. 安徽(吴明开等, 2010a); 金寨县(吴明开等, 2008)。

377. 齿缘泽藓 Philonotis seriata Mitt. 安徽(贾渝和何思, 2013); 青阳县(黎兴江, 2006)。

378. 细叶泽藓 Philonotis thwaitesii Mitt. 安徽(张美珍和赖明洲, 1993 also as P. revoluta; Redfearn et al, 1996 also as P. revoluta, also as P. socia; 吴明开等, 2010a also as P. revoluta; 贾渝和何思, 2013) 黄山市(陈邦杰和吴 鹏程, 1965 as P. socia); 霍山县(Cai, 2002 as P. revolute, also as P. socia); 金寨县( Li et al, 2007); 石台县(郭新弧等, 1990 as P. revolute, also as $P$. socia)。

379. 东亚泽蘚 Philonotis turneriana (Schwägr.) Mitt. 安徽(张美珍和赖明洲, 1993; Redfearn et al, 1996; 吴明开等, 2010a); 黄山市(陈邦杰和 吴鹏程, 1965); 霍山县(Cai, 2002)。

380. 粗尖泽藓 Philonotis yezoana Besch. et Cardot 安徽(贾渝和何思, 2013); 金寨县(Li et al, 2007)。

\section{真蘚科 Bryaceae}

\section{银蘚属 Anomobryum}

381. 金黄银藓 Anomobryum auratum (Mitt.) A. Jaeger 安徽(吴明开等, 2010a; 贾渝和何思, 2013); 黄山市(吴明开等, 2010b)。

382. 芽孢银蘚 Anomobryum gemmigerum Broth. 安徽(吴明开等, 2010a; 贾渝和何思, 2013); 黄山市(吴明开等, 2010b)。

\section{短月藓属 Brachymenium}

383. 纤枝短月蘚 Brachymenium exile (Dozy et Molk.) Bosch et Sande Lac. 安徽(贾渝和何思, 2013); 翖县(黎兴江, 2006; Li et al, 2007)。

384. 多枝短月藓 Brachymenium leptophyllum (Müll. Hal.) A. Jaeger 安徽(吴明开等, 2010a); 黄山市(吴明开等, 2008)。

385. 饰边短月藓 Brachymenium longidens Renauld et Cardot 安徽(吴明开等, 2010a; 贾渝和何思, 2013); 黄山市(黎兴江, 2006); 檁县(Li et al, 2007)。

386. 短月藓 Brachymenium nepalense Hook.

安徽(张美珍和赖明洲, 1993; 吴明开等, 2010a; 贾渝和何思, 2013); 黄山市(Potier de la Varde, 1937; 陈邦杰和吴鹏程, 1965; 黎兴江, 2006); 霍山县(Cai, 2002 also as $B$. nepalense var. clavulum); 石台县(郭新弧等, 1990)。

387. 丛生短月藓 Brachymenium pendulum Mont. 
安徽(吴明开等, 2010a); 黄山市(吴明开等, 2008)。

\section{真藓属 Bryum}

388. 狭网真蘚(钙土真蘚)Bryum algovicum Sendtn. ex Müll. Hal.

安徽(吴明开等, 2010a; 贾渝和何思, 2013); 霍山县(Cai, 2002 as B. angustirete; 黎兴江, 2006; Li et al, 2007)。

389. 高山真藓 Bryum alpinum Huds. ex With.

安徽(吴明开等, 2010a); 黄山市(吴明开等, 2008)。

390. 毛状真藓 Bryum apiculatum Schwägr.

安徽(吴明开等, 2010a)；黄山市(吴明开等, 2008)。

391. 极地真藓 Bryum arcticum (R. Br. bis) Bruch et Schimp.

安徽(Redfearn et al, 1996; 吴明开等, 2010a；贾渝和何思, 2013)。

392. 真藓(银叶真蘚)Bryum argenteum Hedw.

安徽(Potier de la Varde, 1918; 张美珍和赖明洲, 1993; Redfearn et al, 1996; 吴明开等, 2010a); 黄山市(Potier de la Varde, 1937; 陈邦杰和吴鹏程, 1965; 黎兴江, 2006); 霍山县 (Cai, 2002); 青阳县(黎兴江, 2006; Li et al, 2007); 歌县(Li et al, 2007)。

393. 比拉真蘚 Bryum billarderi Schwägr.

安徽(Potier de la Varde, 1918 as B. ramosum; Reimers, 1931 as B. ramosum; 张美珍和赖明 洲, 1993; Redfearn et al, 1996 alao as B. ramosum; 吴明开等, 2010a; 贾渝和何思, 2013); 黄山市(陈邦杰和吴鹏程, 1965 as B. truncorum); 潜山市(黎兴江, 2006; Li et al, 2007); 歇 县( Li et al, 2007)。

394. 卵龩真蘚 Bryum blindii Bruch et Schimp. 安徽(吴明开等, 2010a); 黄山市(吴明开等, 2008)。

395. 从生真蘚 Bryum caespiticium Hedw.

安徽(张美珍和赖明洲, 1993; Redfearn et al, 1996; 吴明开等, 2010a; 贾渝和何思, 2013); 黄山市(黎兴江, 2006); 霍山县(Cai, 2002); 檁县(Li et al, 2007)。

396. 细叶真藓 Bryum capillare Hedw.

安徽(Paris, 1908 as B. courtoisii; 张美珍和赖明洲, 1993; Redfearn et al, 1996 also as $B$. courtoisii; 吴明开等, 2010a; 贾渝和何思, 2013); 黄山市(陈邦杰和吴鹏程, 1965)。

397. 柔叶真蘚 Bryum cellulare Hook.

安徽(Redfearn et al, 1996; 吴明开等, 2010a; 贾渝和何思, 2013)。

398. 圆叶真藓 Bryum cyclophyllum (Schwägr.) Bruch et Schimp.

安徽(张美珍和赖明洲, 1993 as B. tortifolium; Redfearn et al, 1996; 贾渝和何思, 2013);

霍山县(黎兴江, 2006); 金寨县( $\mathrm{Li}$ et al, 2007)。

399. 双色真蘚 Bryum dichotomum Hedw.

安徽(Redfearn et al, 1996; 贾渝和何思, 2013)；黄山市(黎兴江, 2006)；歌县(Li et al， 2007)。

400. 喀什真蘚 Bryum kashmirense Broth.

安徽(吴明开等, 2010a)；黄山市(吴明开等, 2008)。

401. 纤茎真蘚 Bryum leptocaulon Cardot

安徽(张美珍和赖明洲, 1993; Redfearn et al, 1996)。

402. 灰黄真蘚 Bryum pallens Sw.

安徽(张美珍和赖明洲, 1993; Redfearn et al, 1996; 贾渝和何思, 2013); 霍山县(Cai, 2002); 青阳县(黎兴江, 2006; Li et al, 2007)。 
403. 黄色真藓 Bryum pallescens Schleich. ex Schwägr.

安徽(张美珍和赖明洲, 1993; Redfearn et al, 1996; 吴明开等, 2010a；贾渝和何思, 2013); 石台县(郭新弧等, 1990)。

404. 近高山真蘚 Bryum paradoxum Schwägr.

安徽(张美珍和赖明洲, 1993; Redfearn et al, 1996 also as B. pseudoalpinum; 吴明开等, 2010a；贾渝和何思, 2013)。

405. 拟三列真藓(大叶真藓)Bryum pseudotriquetrum (Hedw.) P. Gaertn., B. Mey. et Scherb. 安徽(张美珍和赖明洲, 1993 aslo as B. crispulum, Redfearn et al, 1996; 贾渝和何思, 2013); 霍山县(Cai, 2002; 黎兴江, 2006; Li et al, 2007)。

406. 紫色真藓 Bryum purpurascens (R. Br.) Bruch et Schimp. 安徽(Redfearn et al, 1996; 贾渝和何思, 2013); 霍山县(Cai, 2002)。

407. 弯叶真藓原变种 Bryum recurvulum Mitt. 安徽(张美珍和赖明洲, 1993; Redfearn et al, 1996; 贾渝和何思, 2013)。

408. 拟大叶真蘚 Bryum salakense Cardot 安徽(吴明开等, 2010a); 黄山市(吴明开等, 2008)。

409. 垂蒴真蘚 Bryum uliginosum (Brid.) Bruch et Schimp. 安徽(张美珍和赖明洲, 1993; Redfearn et al, 1996 also as B. cernuum; 吴明开等, 2010a)。 410. 云南真蘚 Bryum yuennanense Broth. 安徽(贾渝和何思, 2013); 黄山市(黎兴江, 2006); 倝县( Li et al, 2007)。

\section{大叶藓属 Rhodobryum}

411. 暖地大叶藓 Rhodobryum giganteum (Schwägr.) Paris 安徽(张美珍和赖明洲, 1993; Redfearn et al, 1996; 吴明开等, 2010a；贾渝和何思, 2013); 黄山市(Potier de la Varde, 1937; 陈邦杰和吴鹏程, 1965; Koponen et al, 1982; 黎兴江, 2006; Li et al, 2007); 霍山县(Cai, 2002); 金寨县( $\mathrm{Li}$ et al, 2007); 石台县(郭新弧等, 1990)。

412. 润边大叶藓 Rhodobryum laxelimbatum (Ochi) Z. Iwats. et T. J. Kop. 安徽(Redfearn et al, 1996; 贾渝和何思, 2013)。

413. 狭边大叶蘚 Rhodobryum ontariense (Kindb.) Paris 安徽(贾渝和何思, 2013); 霍山县(黎兴江, 2006; Li et al, 2007)。

\section{提灯藓科 Mniaceae}

\section{提灯藓属 Mnium}

414. 平肋提灯藓 Mnium laevinerve Cardot 安徽(张美珍和赖明洲, 1993; Redfearn et al, 1996; 吴明开等, 2010a); 霍山县(Cai, 2002)。

415. 长叶提灯藓 Mnium lycopodioides Schwägr. 安徽(Redfearn et al, 1996; 吴明开等, 2010a; 贾渝和何思, 2013)。

416. 具缘提灯藓 Mnium marginatum (With.) P. Beauv. 安徽(张美珍和赖明洲, 1993; Redfearn et al, 1996; 贾渝和何思, 2013)。

417. 偏叶提灯藓 Mnium thomsonii Schimp. 安徽(张美珍和赖明洲, 1993; Redfearn et al, 1996 also as M. lycopodioides ssp. orthorrhynchum, also as M. orthorrhynchum; 贾渝和何思, 2013); 黄山市(黎兴江和藏穆, 1979 also as M. orthorrhynchum; 黎兴江, 2006; Li et al, 2007); 青阳县(黎兴江和藏穆, 
1979 as M. orthorrhynchum)。

\section{立灯蘚属 Orthomnion}

418. 柔叶立灯蘚 Orthomnion dilatatum (Mitt.) P. C. Chen 安徽(张美珍和赖明洲, 1993; Redfearn et al, 1996 also as Orthomniopsis dilatata, also as $O$. japonica; 贾渝和何思, 2013); 黄山市(陈邦杰和吴鹏程, 1965 as O. japonica; 黎兴江和 㶓穆, 1979 as O. japonica; Koponen, 1980; 黎兴江, 2006; Li et al, 2007); 霍山县(Cai, 2002)。

419. 隐缘立灯藓 Orthomnion loheri Broth. 安徽(张美珍和赖明洲, 1993; Redfearn et al, 1996; 贾渝和何思, 2013); 黄山市(陈邦杰和 吴鹏程, 1965; 黎兴江和藏穆, 1979; 黎兴江, 2006; Li et al, 2007)。

\section{匐灯藓属 Plagiomnium}

420. 尖叶匐灯藓 Plagiomnium acutum (Lindb.) T. J. Kop. 安徽(张美珍和赖明洲, 1993; Redfearn et al, 1996 also as Mnium cuspidatum ssp. trichomanes, also as M. trichomanes; 黎兴江, 2006; 吴明开等, 2010a); 黄山市(黎兴江和 藏穆, 1979 as M. cuspidatum ssp. trichomanes; Li et al, 2007)；宁国市(黎兴江和藏穆， 1979 as M. cuspidatum ssp. trichomanes)。

421. 皱叶匐灯蘚 Plagiomnium arbusculum (Müll. Hal.) T. J. Kop. 黄山市(Li et al, 2007); 霍山县(Cai, 2002)。

422. 匐灯藓 Plagiomnium cuspidatum (Hedw.) T. J. Kop. 安徽(张美珍和赖明洲, 1993; Redfearn et al, 1996 also as Mnium cuspidatum; 吴明开等, 2010a); 黄山市(Li et al, 2007); 霍山县(Cai, 2002)。

423. 粗齿匐灯蘚 Plagiomnium drummondii (Bruch et Schimp.) T. J. Kop. 安徽(张美珍和赖明洲, 1993; Redfearn et al, 1996 also as M. drummondii; 贾渝和何思, 2013); 黄山市(黎兴江和藏穆, 1979 as M. drummondii; 黎兴江, 2006; Li et al, 2007); 霍 山县(Cai, 2002)。

424. 全缘匐灯藓 Plagiomnium integrum (Bosch et Sande Lac.) T. J. Kop. 安徽(张美珍和赖明洲, 1993; Redfearn et al, 1996; 吴明开等, 2010a；贾渝和何思, 2013); 黄山市(Li et al, 2007); 霍山县(Cai, 2002)。

425. 日本匐灯藓 Plagiomnium japonicum (Lindb.) T. J. Kop. 安徽(Redfearn et al, 1996; 黎兴江, 2006; 吴明开等, 2010a; 贾渝和何思, 2013); 黄山市 (Li et al, 2007); 霍山县(Cai, 2002)。

426. 侧枝匐灯蘚 Plagiomnium maximoviczii (Lindb.) T. J. Kop. 安徽(张美珍和赖明洲, 1993; Redfearn et al, 1996 also as Mnium rostratum f. micro-ovale, also as M. maximoviczii, also as M. subundulatum; 吴明开等, 2010a；贾渝和何思, 2013); 黄山市(Tchen, 1936 as M. maximoviczii; 陈邦杰和吴鹏程, 1965 as M. maximoviczii, also as M. subundulatum; 黎兴江和㶓穆, 1979 as M. subundulatum, also as M. maximoviczii; 黎 兴江, 2006; Li et al, 2007); 霍山县(Cai, 2002); 石台县(郭新弧等, 1990)。

427. 具喙匐灯藓 Plagiomnium rhynchophorum (Harv.) T. J. Kop. 安徽(吴明开等, 2010a); 黄山市(吴明开等, 2008)。

428. 钝叶匐灯蘚 Plagiomnium rostratum (Schrad.) T. J. Kop.

安徽(张美珍和赖明洲, 1993; Redfearn et al, 1996 also as Mnium rostratum; 吴明开等, 2010a; 贾渝和何思, 2013); 黄山市(Potier de la Varde, 1937 as M. rostratum; 陈邦杰和吴 鹏程, 1965 as M. rostratum; 黎兴江和藏穆, 1979 as M. rostratum; 黎兴江, 2006; Li et al, 
2007); 霍山县(Cai, 2002)。

429. 大叶匐灯藓 Plagiomnium succulentum (Mitt.) T. J. Kop.

安徽(张美珍和赖明洲, 1993; Redfearn et al, 1996 also as Mnium succulentum; 吴明开等, 2010a; 贾渝和何思, 2013); 安庆市(黎兴江, 2006; Li et al, 2007); 铜陵市(黎兴江和藏穆, 1979 as M. succulentum)。

430. 圆叶匐灯蘚 Plagiomnium vesicatum (Besch.) T. J. Kop. 安徽(张美珍和赖明洲, 1993; Redfearn et al, 1996 also as Mnium vesicatum; 贾渝和何思, 2013); 黄山市(黎兴江和㶓穆, 1979 as M. vesicatum; 黎兴江, 2006; Li et al, 2007)。

\section{丝瓜蘚属 Pohlia}

431. 泛生丝瓜蘚 Pohlia cruda (Hedw.) Lindb.

安徽(Redfearn et al, 1996; 黎兴江, 2006; 贾渝和何思, 2013); 霍山县(Cai, 2002)。

432. 丝瓜藓 Pohlia elongata Hedw.

安徽(张美珍和赖明洲, 1993; 吴明开等, 2010a; 贾渝和何思, 2013); 黄山市(黎兴江, 2006); 霍山县(Cai, 2002)。

433. 疮齿丝瓜藓 Pohlia flexuosa Harv.

安徽(贾渝和何思, 2013); 黄山市(黎兴江, 2006; Li et al, 2007)。

434. 南亚丝瓜蘚 Pohlia gedeana (Bosch et Sande Lac.) Gangulee 安徽(吴明开等, 2010a); 黄山市(吴明开等, 2008)。

435. 勒氏丝瓜蘚 Pohlia ludwigii (Schwägr.) Broth.

霍山县(Cai, 2002)。

436. 黄丝瓜藓Pohlia nutans (Hedw.) Lindb.

安徽(吴明开等, 2010a); 黄山市(吴明开等, 2008)。

437. 卵蒴丝瓜蘚 Pohlia proligera (Kindb.) Broth.

安徽(张美珍和赖明洲, 1993; 贾渝和何思, 2013); 黄山市(黎兴江, 2006; Li et al, 2007); 石台县(郭新弧等, 1990)。

\section{毛灯蘚属 Rhizomnium}

438. 毛灯藓 Rhizomnium punctatum (Hedw.) T. J. Kop.

安徽(张美珍和赖明洲, 1993; Redfearn et al, 1996 also as Mnium punctatum; 吴明开等, 2010a; 贾渝和何思, 2013); 黄山市(陈邦杰和吴鹏程, 1965 as M. punctatum; 黎兴江和藏 穆, 1979 as M. punctatum; 黎兴江, 2006; Li et al, 2007); 霍山县(Cai, 2002)。

439. 细枝毛灯藓 Rhizomnium striatulum (Mitt.) T. J. Kop.

安徽(张美珍和赖明洲, 1993; Redfearn et al, 1996; 吴明开等, 2010a；贾渝和何思, 2013); 黄山市(Li et al, 2007)。

\section{病灯藓属 Trachycystis}

440. 疮灯藓 Trachycystis microphylla (Dozy et Molk.) Lindb.

安徽(张美珍和赖明洲, 1993; Redfearn et al, 1996 also as Mnium microphyllum; 吴明开等, 2010a; 贾渝和何思, 2013); 黄山市(陈邦杰和吴鹏程, 1965; 黎兴江和藏穆, 1979 as $M$. microphyllum; Koponen \& Lou, 1982; Li et al, 2007); 霍山县(Cai, 2002); 石台县(郭新弧 等, 1990); 金寨县( $\mathrm{Li}$ et al, 2007); 祁门县( $\mathrm{Li}$ et al, 2007); 㰯县( $\mathrm{Li}$ et al, 2007)。

441. 树形疮灯藓 Trachycystis ussuriensis (Maack et Regel) T. J. Kop. 安徽(张美珍和赖明洲, 1993; Redfearn et al, 1996 also as Mnium immarginatum; 黎兴江, 2006; 贾渝和何思, 2013); 黄山市(陈邦杰和吴鹏程, 1965 as M. immarginatum)。 


\section{木灵蘚科 Orthotrichaceae 直叶藓属 Macrocoma}

442. 细枝直叶藓 Macrocoma sullivantii (Müll. Hal.) Grout 安徽(张美珍和赖明洲, 1993 as Macrocoma tenuis ssp. sullivantii; Redfearn et al, 1996 as Macrocoma tenuis ssp. sullivantii, also as Macromitrium okamurae; 贾渝和何思, 2013); 黄 山市(陈邦杰和吴鹏程, 1965 as Macromitrium okamurae; Wu et al, 2011 as Macrocoma tenuis ssp. sullivantii); 石台县(郭新弧等, 1990 as Macrocoma hymenostoma)。

\section{㝨藓属 Macromitrium}

443. 中华㝨藓 Macromitrium cavaleriei Cardot et Thér.

安徽(Potier de la Varde, 1918 as M. syntrichophyllum; Reimers, 1931 as M. syntrichophyllum; 张美珍和赖明洲, 1993 as M. sinense; Redfearn et al, 1996 as M. syntrichophyllum; 吴明开等, 2010a as M. sinense; 贾渝和何思, 2013); 黄山市(Wu et al, $2011)$; 金寨县(Wu et al, 2011); 青阳县( Wu et al, 2011)。

444. 华东䒾藓 Macromitrium courtoisii Broth. et Paris 安徽(张美珍和赖明洲, 1993; 吴明开等, 2010a)。

445. 福氏蓑藓 Macromitrium ferriei Cardot et Thér. 安徽(张美珍和赖明洲, 1993; Redfearn et al, 1996; 贾渝和何思, 2013); 黄山市(吴鹏程和 贾渝, 2011; Wu et al, 2011); 霍山县(Cai, 2002)。

446. 长枝䒾藓 Macromitrium formosae Cardot 安徽(张美珍和赖明洲, 1993; Redfearn et al, 1996); 黄山市(陈邦杰和吴鹏程, 1965)。

447. 缺齿㝨藓 Macromitrium gymnostomum Sull. et Lesq. 安徽(张美珍和赖明洲, 1993; Redfearn et al, 1996; 吴明开等, 2010a; 贾渝和何思, 2013); 黄山市(陈邦杰和吴鹏程, 1965; 吴鹏程和贾渝, 2011; Wu et al, 2011); 霍 山县(Cai, 2002); 石台县(郭新弧等, 1990)。

448. 钝叶䒾藓 Macromitrium japonicum Dozy et Molk.

安徽(Potier de la Varde, 1918 as M. incurvum; 张美珍和赖明洲, 1993; Redfearn et al, 1996 also as M. incurvum); 霍山县(Cai, 2002); 石台县(郭新弧等, 1990)。

449. 长帽㝨藓 Macromitrium tosae Besch. 安徽(吴明开等, 2010a); 黄山市(吴明开等, 2008)。

450. 乳胞㝨藓 Macromitrium uraiense Nog. 石台县(郭新弧等, 1990)。

\section{木灵藓属 Orthotrichum}

451. 从生木灵藓 Orthotrichum consobrinum Cardot 安徽(Lewinsky, 1992; 张美珍和赖明洲, 1993; Redfearn et al, 1996; 吴明开等, 2010a also as O. courtoisii; 贾渝和何思, 2013); 霍山县(Cai, 2002); 金寨县( Wu et al, 2011); 石台县 (郭新弧等, 1990)。

452. 红叶木灵藓 Orthotrichum erubescens Müll. Hal.

安徽(Redfearn et al, 1996; 贾渝和何思, 2013); 青阳县(Lewinsky, 1992; 吴鹏程和贾渝, 2011; Wu et al, 2011)。

453. 粗柄木灵藓 Orthotrichum subpumilum E. B. Bartram ex Lewinsky 青阳县(Lewinsky, 1992; Redfearn et al, 1996; 吴鹏程和贾渝, 2011; Wu et al, 2011)。

\section{火蘚属 Schlotheimia}


454. 南亚火藓 Schlotheimia grevilleana Mitt. 安徽(吴明开等, 2010a; 贾渝和何思, 2013); 黄山市(吴鹏程和贾渝, 2011; Wu et al, 2011); 金寨县(Wu et al, 2011)。

455. 小火藓 Schlotheimia pungens E. B. Bartram 安徽(张美珍和赖明洲, 1993; Redfearn et al, 1996 also as S. charrieri; 贾渝和何思, 2013); 黄山市(Potier de la Varde, 1937 as S. charrieri; 陈邦杰和吴鹏程, 1965 as S. charrieri; Wu et al, 2011)。

\section{卷叶藓属 Ulota}

456. 卷叶藓 Ulota crispa (Hedw.) Brid. 安徽(贾渝和何思, 2013); 黄山市(吴鹏程和贾渝, 2011; Wu et al, 2011; Wang \& Jia, 2012)。

457. Ulota delicata Q. H. Wang et Y. Jia 黄山市(Wang \& Jia, 2012)。

458. 无齿卷叶藓 Ulota gymnostoma S. L. Guo, Enroth et Virtanen 安徽(贾渝和何思, 2013); 黄山市(Wu et al, 2011; Wang \& Jia, 2012)。

459. 短柄卷叶藓 Ulota perbreviseta Dixon et Sakurai 安徽(贾渝和何思, 2013); 金寨县(Wu et al, 2011)。

\section{桧蘚科 Rhizogoniaceae}

\section{桧蘚属 Pyrrhobryum}

460. 大桧藓 Pyrrhobryum dozyanum (Sande Lac.) Manuel 安徽(Redfearn et al, 1996 also as Rhizogonium dozyanum; 吴明开等, 2010a；贾渝和何思， 2013); 黄山市(陈邦杰和吴鹏程, 1965 as R. dozyanum; 黎兴江, 2006; Li et al, 2007)。

461. 刺叶桧蘚 Pyrrhobryum spiniforme (Hedw.) Mitt. 安徽(张美珍和赖明洲, 1993 as Rhizogonium spiniforme; Redfearn et al, 1996 also as $R$. spiniforme); 石台县(郭新弧等, 1990 as R. spiniforme)。

\section{卷柏藓科 Racopilaceae}

\section{卷柏蘚属 Racopilum}

462. 薄壁卷柏藓 Racopilum cuspidigerum (Schwägr.) Ångström 安徽(张美珍和赖明洲, 1993 as R. aristatum; Redfearn et al, 1996 as R. aristatum; 吴明开 等, 2010a as R. aristatum)。

\section{孔雀蘚科 Hypopterygiaceae 雉尾藓属 Cyathophorum}

463. 短肋雉尾藓 Cyathophorum hookerianum (Griff.) Mitt. 安徽(张美珍和赖明洲, 1993 as Cyathophorella hookeriana; Redfearn et al, 1996 also as C. hookeriana; 吴明开等, 2010a as C. hookeriana); 黄山市(陈邦杰和吴鹏程, 1965 as $C$. hookeriana; 吴鹏程, 2002 as C. hookeriana; $\mathrm{Wu}$ et al, 2002 as C. hookeriana)。

\section{孔雀藓属 Hypopterygium}

464. 黄边孔雀藓 Hypopterygium flavolimbatum Müll. Hal. 安徽(张美珍和赖明洲, 1993 as H. fauriei, also as H. formosanum, also as H. japonicum; Redfearn et al, 1996 as H. fauriei, also as H. formosanum, also as H. japonicum; 吴明开等, 
2010a as H.japonicum; 贾渝和何思, 2013); 黄山市(陈邦杰和吴鹏程, 1965 as $H$. formosanum; 吴鹏程, 2002 as H. japonicum; $\mathrm{Wu}$ et al, 2002 as H. formosanum); 霍山县 (Cai, 2002 as H. japonicum); 祁门县(吴鹏程, 2002 as H. japonicum; Wu et al, 2002 as $H$. japonicum); 石台县(郭新弧等, 1990 as H. fauriei)。

\section{小黄蘚科 Daltoniaceae}

\section{黄蘚属 Distichophyllum}

465. 厚角黄藓宽边变种 Distichophyllum collenchymatosum var. pseudosinense B. C. Tan et P. J.

Lin

安徽(吴明开等, 2010a; 贾渝和何思, 2013); 黄山市(吴明开等, 2010b)。

\section{油蘚科 Hookeriaceae}

\section{油蘚属 Hookeria}

466. 尖叶油藓 Hookeria acutifolia Hook. et Grev.

安徽(张美珍和赖明洲, 1993; Redfearn et al, 1996; 贾渝和何思, 2013); 黄山市(陈邦杰和 吴鹏程, 1965; Wu et al, 2002); 霍山县(Cai, 2002); 石台县(郭新弧等, 1990)。

\section{棉藓科 Plagiotheciaceae}

长灰蘚属 Herzogiella

467. 明角长灰藓 Herzogiella striatella (Brid.) Z. Iwats.

安徽(吴明开等, 2010a; 贾渝和何思, 2013); 石台县(吴鹏程和贾渝, 2004; Wu et al, 2005)。

468. 沼生长灰蘚 Herzogiella turfacea (Lindb.) Z. Iwats.

安徽(张美珍和赖明洲, 1993); 石台县(郭新弧等, 1990)。

\section{小鼠尾蘚属 Myurella}

469. 小鼠尾藓 Myurella julacea (Schwägr.) Bruch et Schimp.

霍山县(Cai, 2002)。

470. 刺叶小鼠尾蘚 Myurella sibirica (Müll. Hal.) Reimers

安徽(张美珍和赖明洲, 1993; Redfearn et al, 1996)。

\section{棉蘚属 Plagiothecium}

471. 圆条棉藓 Plagiothecium cavifolium (Brid.) Z. Iwats.

安徽(张美珍和赖明洲, 1993; Redfearn et al, 1996 also as P. roeseanum; 吴明开等, 2010a; 贾渝和何思, 2013); 霍山县(Cai, 2002; 胡人亮和王幼芳, 2005; Hu et al, 2008); 青阳县 (Hu et al, 2008); 石台县(郭新弧等, 1990)。

472. 圆条棉藓阔叶变种 Plagiothecium cavifolium var. fallax (Cardot et Thér.) Z. Iwats. 安徽(贾渝和何思, 2013); 霍山县(胡人亮和王幼芳, 2005); 青阳县(胡人亮和王幼芳, 2005); 石台县(Cai, 2002)。

473. Plagiothecium enerve (Broth.) Q. Zuo

霍山县(Cai, 2002 as Fabronia enervis)。

474. 直叶棉藓原变种 Plagiothecium euryphyllum (Cardot et Thér.) Z. Iwats.

安徽(吴明开等, 2010a; 贾渝和何思, 2013); 黄山市(胡人亮和王幼芳, 2005; Hu et al, 2008)。

475. 直叶棉藓短尖变种 Plagiothecium euryphyllum var. brevirameum (Cardot) Z. Iwats. 
安徽(Redfearn et al, 1996; 吴明开等, 2010a；贾渝和何思, 2013); 黄山市(Hu et al, 2008); 檁县(胡人亮和王幼芳, 2005; Hu et al, 2008)。

476. 台湾棉藓 Plagiothecium formosicum Broth. et Yasuda 安徽(Redfearn et al, 1996); 霍山县(Cai, 2002)。

477. 台湾棉藓直叶变种 Plagiothecium formosicum var. restiapex D. K. Li 安徽(吴明开等, 2010a); 黄山市(吴明开等, 2008)。

478. 光泽棉蘚 Plagiothecium laetum Bruch et Schimp. 安徽(张美珍和赖明洲, 1993; Redfearn et al, 1996; 吴明开等, 2010a)。

479. 扁平棉藓 Plagiothecium neckeroideum Bruch et Schimp.

安徽(张美珍和赖明洲, 1993; Redfearn et al, 1996; 贾渝和何思, 2013); 黄山市(胡人亮和 王幼芳, 2005; Hu et al, 2008); 宁国市(胡人亮和王幼芳, 2005; Hu et al, 2008); 石台县(郭 新弧等, 1990)。

480. 扁平棉藓宽叶变种 Plagiothecium neckeroideum var. niitakayamae (Toyama) Z. Iwats. 安徽(吴明开等, 2010a; 贾渝和何思, 2013); 黄山市(胡人亮和王幼芳, 2005; Hu et al, 2008); 鹯县(胡人亮和王幼芳, 2005; Hu et al, 2008)。

481. 垂蒴棉藓 Plagiothecium nemorale (Mitt.) A. Jaeger 安徽(张美珍和赖明洲, 1993 also as P. sylvaticum; Redfearn et al, 1996 also as $P$. sylvaticum; 吴明开等, 2010a; 贾渝和何思, 2013); 霍山县(Cai, 2002 as P. sylvaticum, also as P. nemorale f. japonicum; 胡人亮和王幼芳, 2005; Hu et al, 2008); 金寨县(Hu et al, 2008); 宁国市(胡人亮和王幼芳, 2005; Hu et al, 2008); 祁门县(胡人亮和王幼芳, 2005; Hu et al, 2008); 歇县(胡人亮和王幼芳, 2005)。

482. 毛尖棉蘚 Plagiothecium piliferum (Sw.) Schimp. 安徽(Redfearn et al, 1996)。

483. 阔叶棉藓 Plagiothecium platyphyllum Mönk. 安徽(张美珍和赖明洲, 1993; Redfearn et al, 1996; 吴明开等, 2010a; 贾渝和何思, 2013); 霍山县(Cai, 2002; 胡人亮和王幼芳, 2005; Hu et al, 2008)。

484. 长喙棉藓 Plagiothecium succulentum (Wilson) Lindb. 安徽(张美珍和赖明洲, 1993; Redfearn et al, 1996; 吴明开等, 2010a；贾渝和何思, 2013); 黄山市(胡人亮和王幼芳, 2005; Hu et al, 2008); 霍山县(胡人亮和王幼芳, 2005; Hu et al, 2008 ); 祁门县(胡人亮和王幼芳, 2005; Hu et al, 2008); 歌县(胡人亮和王幼芳, 2005; Hu et al, 2008)。

485. 波叶棉藓 Plagiothecium undulatum (Hedw.) Schimp. 安徽(Redfearn et al, 1996)。

\section{牛尾藓属 Struckia}

486. 牛尾蘚 Struckia argentata (Mitt.) Müll. Hal. 安徽(张美珍和赖明洲, 1993; Redfearn et al, 1996)。

\section{硬叶藓科 Stereophyllaceae \\ 拟绢藓属 Entodontopsis}

487. 尖叶拟绢藓 Entodontopsis anceps (Bosch et Sande Lac.) W. R. Buck et Ireland 安徽(张美珍和赖明洲, 1993 as Stereophyllum anceps; Redfearn et al, 1996 also as $S$. anceps; 吴明开等, 2010a)。

488. 狭叶拟绢蘚 Entodontopsis wightii (Mitt.) W. R. Buck et Ireland 
安徽(吴明开等, 2010a); 黄山市(吴明开等, 2008)。

\section{腋苞藓科 Pterigynandraceae \\ 腋苞蘚属 Pterigynandrum}

489. 腋苞藓 Pterigynandrum filiforme Hedw.

安徽(张美珍和赖明洲, 1993; Redfearn et al, 1996); 霍山县(Cai, 2002)。

\section{叉肋藓属 Trachyphyllum}

490. 叉肋藓 Trachyphyllum inflexum (Harv.) A. Gepp

安徽(张美珍和赖明洲, 1993; Redfearn et al, 1996; 贾渝和何思, 2013); 黄山市(胡人亮和

王幼芳, 2005; Hu et al, 2008); 鹯县(胡人亮和王幼芳, 2005; Hu et al, 2008)。

\section{柔齿藓科 Habrodontaceae}

\section{柔齿藓属 Habrodon}

491. 柔齿蘚 Habrodon perpusillus (De Not.) Lindb.

安徽(吴明开等, 2010a)。

\section{万年蘚科 Climaciaceae}

\section{万年藓属 Climacium}

492. 万年藓 Climacium dendroides (Hedw.) F. Weber et D. Mohr 安徽(张美珍和赖明洲, 1993; Redfearn et al, 1996; 贾渝和何思, 2013); 黄山市(Tchen, 1936; Potier de la Varde, 1937; 陈邦杰和吴鹏程, 1965; 吴鹏程和贾渝, 2011; Wu et al, 2011)。

493. 东亚万年藓 Climacium japonicum Lindb.

安徽(张美珍和赖明洲, 1993; Redfearn et al, 1996 also as C. americanum ssp.japonicum; 吴明开等, 2010a; 贾渝和何思, 2013); 黄山市(陈邦杰和吴鹏程, 1965; 吴鹏程和贾渝, 2011; Wu et al, 2011); 霍山县(Cai, 2002 as C. americanum ssp.japonicum); 金寨县(Wu et al, 2011)。

\section{柳叶藓科 Amblystegiaceae \\ 细湿蘚属 Campylium}

494. 黄叶细湿藓 Campylium chrysophyllum (Brid.) Lange

安徽(张美珍和赖明洲, 1993 also as C. courtoisii; Redfearn et al, 1996 also as C. courtoisii; 贾渝和何思, 2013); 霍山县(Cai, 2002; 胡人亮和王幼芳, 2005 as Campyliadelphus chrysophyllus; Hu et al, 2008 as C. chrysophyllus); 芜湖市(Paris, 1909; 胡人亮和王幼芳, 2005 as C. chrysophyllus)。

495. 细湿藓 Campylium hispidulum (Brid.) Mitt.

霍山县(Cai, 2002)。

496. 长肋细湿藓 Campylium polygamum (Schimp.) C. E. O. Jensen 安徽(Redfearn et al, 1996); 霍山县(Cai, 2002); 石台县(郭新弧等, 1990)。

\section{牛角蘚属 Cratoneuron}

497. 牛角蘚 Cratoneuron filicinum (Hedw.) Spruce 安徽(贾渝和何思, 2013); 霍山县( Hu et al, 2008); 歇县(胡人亮和王幼芳, 2005; Hu et al, 2008)。 


\section{镰刀藓属 Drepanocladus}

498. 镰刀藓直叶变种 Drepanocladus aduncus var. kneiffii (Bruch et Schimp.) Mönk.

安徽(贾渝和何思, 2013); 青阳县(胡人亮和王幼芳, 2005; Hu et al, 2008)。

\section{湿柳蘚属 Hygroamblystegium}

499. 水生湿柳蘚 Hygroamblystegium fluviatile (Hedw.) Loeske

安徽(张美珍和赖明洲, 1993 as Amblystegium noterophilum; Redfearn et al, 1996)。

\section{水灰藓属 Hygrohypnum}

500. 扭叶水灰藓 Hygrohypnum eugyrium (Bruch et Schimp.) Loeske

安徽(贾渝和何思, 2013); 黄山市(胡人亮和王幼芳, 2005; Hu et al, 2008); 霍山县(Cai, 2002; 胡人亮和王幼芳, 2005; Hu et al, 2008)。

501. 水灰藓 Hygrohypnum luridum (Hedw.) Jenn.

安徽(张美珍和赖明洲, 1993; Redfearn et al, 1996)。

502. 钝叶水灰蘚 Hygrohypnum smithii (Sw.) Broth.

安徽(张美珍和赖明洲, 1993; Redfearn et al, 1996; 贾渝和何思, 2013)。

\section{薄网蘚属 Leptodictyum}

503. 曲肋薄网藓 Leptodictyum humile (P. Beauv.) Ochyra

安徽(吴明开等, 2010a)。

\section{湿原藓科 Calliergonaceae}

\section{湿原蘚属 Calliergon}

504. 湿原蘚 Calliergon cordifolium (Hedw.) Kindb. 安徽(Redfearn et al, 1996)。

505. 蔓枝湿原蘚 Calliergon sarmentosum (Wahlenb.) Kindb.

安徽(Redfearn et al, 1996 also as Sarmentypnum sarmentosum)。

\section{范氏藓属 Warnstorfia}

506. 范氏藓Warnstorfia exannulata (Bruch et Schimp.) Loeske 霍山县(Cai, 2002 as Drepanocladus exannulatus)。

\section{薄罗蘚科 Leskeaceae}

\section{麻羽藓属 Claopodium}

507. 狭叶麻羽藓 Claopodium aciculum (Broth.) Broth.

安徽(Paris, 1911; 张美珍和赖明洲, 1993; Redfearn et al, 1996 as C. sinicum; 吴明开等, 2010a); 霍山县(Cai, 2002); 石台县(郭新弧等, 1990)。

508. 大麻羽藓 Claopodium assurgens (Sull. et Lesq.) Cardot 安徽(吴明开等, 2010a); 黄山市(吴明开等, 2008)。

509. 偏叶麻羽蘚 Claopodium rugulosifolium S. Y. Zeng 安徽(张美珍和赖明洲, 1993; 吴明开等, 2010a)。

\section{叉羽蘚属 Leptopterigynandrum}

510. 卷叶叉羽藓 Leptopterigynandrum incurvatum Broth.

霍山县(Cai, 2002)。

511. 全缘叉羽蘚 Leptopterigynandrum subintegrum (Mitt.) Broth.

黄山市(吴明开等, 2010a)。

\section{细罗蘚属 Leskeella}




\section{2. 细罗藓 Leskeella nervosa (Brid.) Loeske} 安徽(Redfearn et al, 1996); 霍山县(Cai, 2002 also as Leskea nervosa)。

\section{细枝蘚属 Lindbergia}

513. 细枝蘚 Lindbergia brachyptera (Mitt.) Kindb. 安徽(吴明开等, 2010a); 黄山市(吴明开等, 2008)。

514. 中华细枝蘚 Lindbergia sinensis (Müll. Hal.) Broth. 安徽(张美珍和赖明洲, 1993 also as L. magniretis; Redfearn et al, 1996 also as $L$. magniretis; 吴明开等, 2010a); 霍山县(Cai, 2002)。

\section{瓦叶藓属 Miyabea}

515. 瓦叶藓 Miyabea fruticella (Mitt.) Broth. 安徽(张美珍和赖明洲, 1993; Redfearn et al, 1996; 吴明开等, 2010a; 贾渝和何思, 2013); 黄山市(陈邦杰和吴鹏程, 1965; 吴鹏程, 2002; Wu et al, 2002); 霍山县(Cai, 2002)。

\section{拟草藓属 Pseudoleskeopsis}

516. 拟草藓 Pseudoleskeopsis zippelii (Dozy et Molk.) Broth. 安徽(张美珍和赖明洲, 1993 also as P. serrulata; Redfearn et al, 1996 also as . decurvata, also as P. serrulata; 吴明开等, 2010a; 贾渝和何思, 2013); 黄山市(陈邦杰和吴鹏程, 1965 as P. decurvata); 霍山县(Cai, 2002 as P. decurvata); 金寨县(吴鹏程, 2002; $\mathrm{Wu}$ et al, 2002)。

\section{小绢蘚属 Rozea}

517. 小蒴小绢藓 Rozea fulva Müll. Hal. ex M. Fleisch. 黄山市(吴明开等, 2010a as R. chrysea)。

\section{附干蘚属 Schwetschkea}

518. 中华附干藓 Schwetschkea sinica Broth. et Paris 安徽(Redfearn et al, 1996; 贾渝和何思, 2013); 黄山市(吴鹏程, 2002)。

\section{拟薄罗蘚科 Pseudoleskeaceae}

\section{多毛蘚属 Lescuraea}

519. 密根多毛蘚 Lescuraea radicosa (Mitt.) Mönk. 安徽(张美珍和赖明洲, 1993 as Pseudoleskea radicosa; Redfearn et al, 1996 also as Pseudoleskea radicosa)。

\section{假细罗蘚科 Pseudoleskeellaceae 假细罗蘚属 Pseudoleskeella}

520. 假细罗藓 Pseudoleskeella catenulata (Brid. ex Schrad.) Kindb. 安徽(张美珍和赖明洲, 1993; Redfearn et al, 1996); 霍山县(Cai, 2002)。

521. 瓦叶假细罗藓 Pseudoleskeella tectorum (Brid.) Kindb. 安徽(吴明开等, 2010a); 黄山市(吴明开等, 2008)。

\section{羽藓科 Thuidiaceae}

\section{毛羽藓属 Bryonoguchia}

522. 毛羽蘚 Bryonoguchia molkenboeri (Sande Lac.) Z. Iwats. et Inoue 霍山县(Cai, 2002)。

\section{小羽藓属 Haplocladium}


523. 狭叶小羽蘚 Haplocladium angustifolium (Hampe et Müll. Hal.) Broth. 安徽(张美珍和赖明洲, 1993; Redfearn et al, 1996 also as H. macropilum; 吴明开等, 2010a); 黄山市(陈邦杰和吴鹏程, 1965); 霍山县(Cai, 2002)。

524. 细叶小羽蘚 Haplocladium microphyllum (Hedw.) Broth.

安徽(张美珍和赖明洲, 1993; Redfearn et al, 1996 also as H. capillatum; 吴明开等, 2010a); 黄山市(陈邦杰和吴鹏程, 1965 also as H. capillatum); 霍山县(Cai, 2002)。

525. 东亚小羽藓 Haplocladium strictulum (Cardot) Reimers 安徽(Redfearn et al, 1996 also as H. fauriei；吴明开等, 2010a)。

\section{细羽藓属 Cyrto-hypnum}

526. 多毛细羽藓 Cyrto-hypnum vestitissimum (Besch.) W. R. Buck et H. A. Crum 安徽(张美珍和赖明洲, 1993; Redfearn et al, 1996 also as Thuidium lepidoziaceum)。

\section{鹤嘴藓属 Pelekium}

527. 纤枝鹤嘴藓 Pelekium bonianum (Besch.) A. Touw 安徽(Redfearn et al, 1996 as Thuidium lejeuneoides, also as Cyrto-hypnum bonianum; 吴明 开等, 2010a as C. bonianum)。

528. 糙柄鹤嘴藓 Pelekium minutulum (Hedw.) A. Touw ${ }^{3}$ 安徽(Redfearn et al, 1996 as Cyrto-hypnum minutulum, also as Thuidium minutulum)。

529. 多疮鹤嘴藓 Pelekium pygmaeum (Schimp.) A. Touw 安徽(吴明开等, 2010a as Cyrto-hypnum pygmaeum); 黄山市(吴明开等, 2008 as C. pygmaeum)。

\section{羽藓属 Thuidium}

530. 绿羽藓 Thuidium assimile (Mitt.) A. Jaeger 安徽(张美珍和赖明洲, 1993 as T. pycnothallum; Redfearn et al, 1996 as T. philibertii, also as T. pycnothallum); 黄山市(陈邦杰和吴鹏程, 1965 as T. pycnothallum)。

531. 大羽藓 Thuidium cymbifolium (Dozy et Molk.) Dozy et Molk. 安徽(张美珍和赖明洲, 1993; Redfearn et al, 1996; 吴明开等, 2010a; 贾渝和何思, 2013); 黄山市(陈邦杰和吴鹏程, 1965; 吴鹏程, 2002; Wu et al, 2002); 霍山县(Cai, 2002)。

532. 细枝羽蘚 Thuidium delicatulum (Hedw.) Schimp. 安徽(张美珍和赖明洲, 1993; Redfearn et al, 1996; 吴明开等, 2010a); 黄山市(陈邦杰和 吴鹏程, 1965); 霍山县(Cai, 2002)。

533. 拟灰羽蘚 Thuidium glaucinoides Broth. 安徽(Redfearn et al, 1996; 吴明开等, 2010a); 霍山县(Cai, 2002); 石台县(郭新弧等, 1990)。

534. 短肋羽藓 Thuidium kanedae Sakurai 安徽(张美珍和赖明洲, 1993; Redfearn et al, 1996; 吴明开等, 2010a；贾渝和何思, 2013); 霍山县(Cai, 2002); 金寨县(Wu et al, 2002); 石台县(郭新弧等, 1990)。

535. 毛尖羽藓 Thuidium plumulosum (Dozy et Molk.) Dozy et Molk. 安徽(Redfearn et al, 1996 also as T. meyenianum)。

536. 灰羽蘚 Thuidium pristocalyx (Müll. Hal.) A. Jaeger 安徽(张美珍和赖明洲, 1993 as T. glaucinum; Redfearn et al, 1996 as T. glaucinum; 吴明开 等, 2010a); 黄山市(陈邦杰和吴鹏程, 1965 as T. glaucinum; 吴明开等, 2008); 石台县(郭 新弧等, 1990 as T. glaucinum)。

\footnotetext{
3 贾渝和何思 (2013) 未记载该种
} 
537. 钩叶羽藓 Thuidium recognitum (Hedw.) Lindb.

安徽(Redfearn et al, 1996 also as T. recognitum var. delicatulum; 贾渝和何思, 2013); 黄山 市(Tchen, 1936)。

538. 亚灰羽蘚 Thuidium subglaucinum Cardot

安徽(张美珍和赖明洲, 1993; Redfearn et al, 1996)。

539. 短枝羽蘚 Thuidium submicropteris Cardot 安徽(张美珍和赖明洲, 1993; Redfearn et al, 1996; 吴明开等, 2010a)。

540. 羽藓 Thuidium tamariscinum (Hedw.) Bruch et Schimp. 安徽(张美珍和赖明洲, 1993; Redfearn et al, 1996; 吴明开等, 2010a); 石台县(郭新弧等, 1990); 黄山市(Tchen, 1936)。

\section{异枝蘚科 Heterocladiaceae}

\section{粗病藓属 Fauriella}

541. 小粗疮蘚 Fauriella tenerrima Broth.

安徽(Gao \& Cao, 1992; 张美珍和赖明洲, 1993; Redfearn et al, 1996; 吴明开等, 2010a; 贾渝和何思, 2013); 黄山市(陈邦杰和吴鹏程, 1965; 吴鹏程, 2002; Wu et al, 2002); 霍山 县(Cai, 2002)。

542. 粗病藓 Fauriella tenuis (Mitt.) Cardot 安徽(Gao \& Cao, 1992; 张美珍和赖明洲, 1993; Redfearn et al, 1996; 吴明开等, 2010a; 贾渝和何思, 2013); 黄山市(陈邦杰和吴鹏程, 1965; 吴鹏程, 2002; Wu et al, 2002)。

\section{异齿蘚科 Regmatodontaceae}

\section{异齿蘚属 Regmatodon}

543. 异齿藓 Regmatodon declinatus (Hook.) Brid. 安徽(张美珍和赖明洲, 1993; Redfearn et al, 1996)。

\section{青蘚科 Brachytheciaceae}

气蘚属 Aerobryum

544. 气藓Aerobryum speciosum Dozy et Molk.

黄山市(吴明开等, 2010a); 休宁县(吴明开等, 2010a)。

\section{青藓属 Brachythecium}

545. 灰白青蘚 Brachythecium albicans (Hedw.) Bruch et Schimp. 安徽(张美珍和赖明洲, 1993; 吴明开等, 2010a)。

546. 密枝青蘚 Brachythecium amnicola Müll. Hal.

领县(吴明开等, 2008)。

547. 勃氏青藓 Brachythecium brotheri Paris 安徽(张美珍和赖明洲, 1993); 霍山县(Cai, 2002)。

548. 多褶青藓 Brachythecium buchananii (Hook.) A. Jaeger 安徽(张美珍和赖明洲, 1993; 吴明开等, 2010a; 贾渝和何思, 2013); 霍山县(Cai, 2002; 胡人亮和王幼芳, 2005; Hu et al, 2008); 石台县(郭新弧等, 1990)。

549. 斜枝青藓 Brachythecium campylothallum Müll. Hal.

安徽(吴明开等, 2010a); 霍山县(Cai, 2002)。

550. 尖叶青藓Brachythecium coreanum Cardot 
安徽(吴明开等, 2010a; 贾渝和何思, 2013); 黄山市(胡人亮和王幼芳, 2005; Hu et al, 2008)。

551. 多枝青藓 Brachythecium fasciculirameum Müll. Hal. 安徽(吴明开等, 2010a); 黄山市(吴明开等, 2008)。

552. 台湾青蘚 Brachythecium formosanum Takaki 安徽(张美珍和赖明洲, 1993; 吴明开等, 2010a; 贾渝和何思, 2013); 黄山市(陈邦杰和吴 鹏程, 1965; 胡人亮和王幼芳, 2005; Hu et al, 2008); 桐城市(Hu et al, 2008)。

553. 圆枝青藓 Brachythecium garovaglioides Müll. Hal. 安徽(张美珍和赖明洲, 1993 as B. wichurae); 黄山市(陈邦杰和吴鹏程, 1965 as $B$. wichurae)。

554. 冰川青藓 Brachythecium glaciale Bruch et Schimp. 安徽(张美珍和赖明洲, 1993; 贾渝和何思, 2013); 霍山县(Cai, 2002; 胡人亮和王幼芳, 2005; Hu et al, 2008); 歌县(Hu et al, 2008)。

555. 石地青藓 Brachythecium glareosum (Spruce) Bruch et Schimp. 安徽(吴明开等, 2010a); 黄山市(吴明开等, 2008)。

556. 平枝青藓 Brachythecium helminthocladum Broth. et Paris 安徽(贾渝和何思, 2013); 歎县(胡人亮和王幼芳, 2005; Hu et al, 2008)。

557. 同枝青蘚 Brachythecium homocladum Müll. Hal. 安徽(吴明开等, 2010a); 黄山市(吴明开等, 2008)。

558. 皱叶青藓 Brachythecium kuroishicum Besch. 安徽(张美珍和赖明洲, 1993; 吴明开等, 2010a); 霍山县(Cai, 2002)。

559. 柔叶青藓 Brachythecium moriense Besch. 安徽(吴明开等, 2010a; 贾渝和何思, 2013); 黄山市(陈邦杰和吴鹏程, 1965); 霍山县(钱 琳和蔡空辉, 1989; Cai, 2002)。

560. 苍白青藓 Brachythecium pallescens Dixon et Thér. 安徽(贾渝和何思, 2013); 霍山县(钱琳和蔡空辉, 1989; Cai, 2002)。

561. 悬垂青藓 Brachythecium pendulum Takaki 安徽(贾渝和何思, 2013); 歎县(胡人亮和王幼芳, 2005; Hu et al, 2008)。

562. 小青蘚 Brachythecium perminusculum Müll. Hal. 安徽(吴明开等, 2010a); 霍山县(胡人亮和王幼芳, 2005); 翖县(Hu et al, 2008)。

563. 毛尖青藓 Brachythecium piligerum Cardot 安徽(张美珍和赖明洲, 1993; 吴明开等, 2010a; 贾渝和何思, 2013); 黄山市(胡人亮和王 幼芳, 2005; Hu et al, 2008); 霍山县(Cai, 2002; 胡人亮和王幼芳, 2005; Hu et al, 2008); 勯县(胡人亮和王幼芳, 2005; Hu et al, 2008)。

564. 华北青藓 Brachythecium pinnirameum Müll. Hal. 安徽(吴明开等, 2010a; 贾渝和何思, 2013); 黄山市(胡人亮和王幼芳, 2005; Hu et al, 2008)。

565. 羽枝青蘚 Brachythecium plumosum (Hedw.) Schimp. 安徽(张美珍和赖明洲, 1993 also as B. pygmaeum; 吴明开等, 2010a；贾渝和何思, 2013); 黄山市(胡人亮和王幼芳, 2005; Hu et al, 2008); 霍山县(Cai, 2002 as B. pygmaeum; 胡人 亮和王幼芳, 2005; Hu et al, 2008); 石台县(郭新弧等, 1990)。

566. 长肋青藓 Brachythecium populeum (Hedw.) Schimp. 安徽(张美珍和赖明洲, 1993; 吴明开等, 2010a; 贾渝和何思, 2013); 黄山市(胡人亮和王 
幼芳, 2005; Hu et al, 2008); 㪘县(胡人亮和王幼芳, 2005; Hu et al, 2008)。

567. 匐枝青蘚 Brachythecium procumbens (Mitt.) A. Jaeger 安徽(张美珍和赖明洲, 1993; 吴明开等, 2010a; 贾渝和何思, 2013); 歇县(胡人亮和王幼 芳, 2005; Hu et al, 2008)。

568. 羽状青藓 Brachythecium propinnatum Redf., B. C. Tan et S. He 安徽(张美珍和赖明洲, 1993 as B. pinnatum; 吴明开等, 2010a; 贾渝和何思, 2013); 黄山 市(陈邦杰和吴鹏程, 1965 as B. pinnatum; 胡人亮和王幼芳, 2005; Hu et al, 2008)。

569. 青藓 Brachythecium pulchellum Broth. et Paris 安徽(张美珍和赖明洲, 1993 as B. rhynchostegielloides); 霍山县(Cai, 2002 as B. rhynchostegielloides)。

570. 弯叶青蘚 Brachythecium reflexum (Starke) Bruch et Schimp. 安徽(张美珍和赖明洲, 1993; 吴明开等, 2010a; 贾渝和何思, 2013); 霍山县(Cai, 2002; 胡人亮和王幼芳, 2005; Hu et al, 2008); 倝县(胡人亮和王幼芳, 2005; Hu et al, 2008)。

571. 溪边青蘚 Brachythecium rivulare Bruch et Schimp. 安徽(张美珍和赖明洲, 1993; 吴明开等, 2010a; 贾渝和何思, 2013); 霍山县(Cai, 2002; 胡人亮和王幼芳, 2005; Hu et al, 2008); 晾县(胡人亮和王幼芳, 2005; Hu et al, 2008)。

572. 卵叶青藓 Brachythecium rutabulum (Hedw.) Bruch et Schimp. 安徽(张美珍和赖明洲, 1993; 吴明开等, 2010a; 贾渝和何思, 2013); 霍山县(Cai, 2002; 胡人亮和王幼芳, 2005; Hu et al, 2008); 㵊县(胡人亮和王幼芳, 2005; Hu et al, 2008)。

573. 褶叶青蘚 Brachythecium salebrosum (F. Weber et D. Mohr) Bruch et Schimp. 安徽(吴明开等, 2010a); 黄山市(吴明开等, 2008)。

574. 林地青蘚 Brachythecium starkii (Brid.) Bruch et Schimp. 安徽(张美珍和赖明洲, 1993; 吴明开等, 2010a); 霍山县(Cai, 2002)。

575. 钩叶青藓 Brachythecium uncinifolium Broth. et Paris 安徽(张美珍和赖明洲, 1993; Redfearn et al, 1996 as Cratoneurella uncinifolia; 贾渝和何 思, 2013); 霍山县(Cai, 2002; 胡人亮和王幼芳, 2005; Hu et al, 2008)。

576. 线叶青藓 Brachythecium velutinum (Hedw.) Bruch et Schimp. 安徽(张美珍和赖明洲, 1993; 吴明开等, 2010a; 贾渝和何思, 2013); 霍山县(Cai, 2002; 胡人亮和王幼芳, 2005; Hu et al, 2008); 㔊县(胡人亮和王幼芳, 2005; Hu et al, 2008)。

\section{燕尾蘚属 Bryhnia}

577. 短枝燕尾蘚 Bryhnia brachycladula Cardot 安徽(吴明开等, 2010a; 贾渝和何思, 2013); 黄山市(胡人亮和王幼芳, 2005; Hu et al, 2008); 霍山县(胡人亮和王幼芳, 2005; Hu et al, 2008)。

578. 短尖燕尾藓 Bryhnia hultenii E. B. Bartram 安徽(吴明开等, 2010a); 黄山市(吴明开等, 2008)。

579. 燕尾蘚 Bryhnia novae-angliae (Sull. et Lesq.) Grout 安徽(张美珍和赖明洲, 1993 also as B. sublaevifolia; Redfearn et al, 1996 as B. higoensis; 吴明开等, 2010a; 贾渝和何思, 2013); 黄山市(陈邦杰和吴鹏程, 1965 also as $B$. sublaevifolia); 霍山县(Cai, 2002 also as B. sublaevifolia; 胡人亮和王幼芳, 2005; Hu et al, 2008)。

580. 毛尖燕尾藓 Bryhnia trichomitria Dixon et Thér. 安徽(吴明开等, 2010a; 贾渝和何思, 2013); 霍山县(胡人亮和王幼芳, 2005; Hu et al, 2008)。 


\section{斜龩蘚属 Camptothecium}

581. 斜蒴藓(黄斜龩藓)Camptothecium lutescens (Hedw.) Bruch et Schimp. 安徽(张美珍和赖明洲, 1993); 石台县(郭新弧等, 1990 as Homalothecium lutescens)。

\section{毛尖藓属 Cirriphyllum}

582. 毛尖藓 Cirriphyllum piliferum (Hedw.) Grout 安徽(张美珍和赖明洲, 1993; Redfearn et al, 1996; 贾渝和何思, 2013); 黄山市(陈邦杰和 吴鹏程, 1965; 胡人亮和王幼芳, 2005; Hu et al, 2008); 霍山县(胡人亮和王幼芳, 2005; Hu et al, 2008)。

\section{美喙蘚属 Eurhynchium}

583. 短尖美喙藓 Eurhynchium angustirete (Broth.) T. J. Kop. 安徽(Redfearn et al, 1996; 吴明开等, 2010a)。

584. 疮柄美剝藓 Eurhynchium asperisetum (Müll. Hal.) E. B. Bartram 安徽(张美珍和赖明洲, 1993; Redfearn et al, 1996; 贾渝和何思, 2013); 黄山市(陈邦杰和 吴鹏程, 1965)。

585. 狭叶美喙藓 Eurhynchium coarctum Müll. Hal. 安徽(吴明开等, 2010a); 歌县(吴明开等, 2008)。

586. 尖叶美喙藓 Eurhynchium eustegium (Besch.) Dixon 安徽(Redfearn et al, 1996); 霍山县(Cai, 2002)。

587. 宽叶美喙蘚 Eurhynchium hians (Hedw.) Sande Lac. 安徽(吴明开等, 2010a); 黄山市(吴明开等, 2008)。

588. 扭尖美喙藓 Eurhynchium kirishimense Takaki 安徽(吴明开等, 2010a); 黄山市(吴明开等, 2008)。

589. 疏网美喙蘚 Eurhynchium laxirete Broth.

安徽(张美珍和赖明洲, 1993; Redfearn et al, 1996; 吴明开等, 2010a；贾渝和何思, 2013); 霍山县(Cai, 2002; 胡人亮和王幼芳, 2005; Hu et al, 2008)。

590. 羽枝美喙蘚 Eurhynchium longirameum (Müll. Hal.) Y. F. Wang et R. L. Hu 安徽(吴明开等, 2010a)；黄山市(吴明开等, 2008)。

591. 密叶美喙蘚 Eurhynchium savatieri Schimp. ex Besch. 安徽(张美珍和赖明洲, 1993; Redfearn et al, 1996 also as Oxyrrhynchium savatieri; 吴明开 等, 2010a; 贾渝和何思, 2013); 霍山县(Cai, 2002 白马尖 as Eurhynchium polystictum); 㰯县(胡人亮和王幼芳, 2005; Hu et al, 2008)。

\section{同蒴蘚属 Homalothecium}

592. 无疮同蒴蘚 Homalothecium laevisetum Sande Lac. 安徽(张美珍和赖明洲, 1993; Redfearn et al, 1996 also as H. tokiadense; 吴明开等, 2010a; 贾渝和何思, 2013); 黄山市(陈邦杰和吴鹏程, 1965; 胡人亮和王幼芳, 2005; Hu et al, 2008); 霍山县(Cai, 2002; 胡人亮和王幼芳, 2005; Hu et al, 2008)。

593. 白色同蒴藓 Homalothecium leucodonticaule (Müll. Hal.) Broth. 安徽(张美珍和赖明洲, 1993; Redfearn et al, 1996; 贾渝和何思, 2013); 霍山县(Cai, 2002 as H. perimbricatum); 㪘县(胡人亮和王幼芳, 2005; Hu et al, 2008)。

\section{异叶藓属 Kindbergia}

594. 树状异叶藓 Kindbergia arbuscula (Broth.) Ochyra 安徽(吴明开等, 2010a as Eurhynchium arbuscula); 黄山市(吴明开等, 2008 as E. arbuscula)。 


\section{鼠尾蘚属 Myuroclada}

595. 鼠尾蘚 Myuroclada maximowiczii (G. G. Borshch.) Steere et W. B. Schofield 安徽(Paris, 1908; 张美珍和赖明洲, 1993; Redfearn et al, 1996 also as Myuroclada concinna; 吴明开等, 2010a); 黄山市(Tchen, 1936 as Myuroclada concinna; 陈邦杰和吴 鹏程, 1965; Hu et al, 2008); 霍山县(Cai, 2002); 休宁县(Hu et al, 2008)。

\section{褶蘚属 Okamuraea}

596. 短枝褶蘚 Okamuraea brachydictyon (Cardot) Nog. 安徽(张美珍和赖明洲, 1993; Redfearn et al, 1996)。

597. 长枝褶藓 Okamuraea hakoniensis (Mitt.) Broth. 安徽(张美珍和赖明洲, 1993; Redfearn et al, 1996; 吴明开等, 2010a；贾渝和何思, 2013); 黄山市(陈邦杰和吴鹏程, 1965; 吴鹏程, 2002; Wu et al, 2002); 霍山县(Cai, 2002); 金寨 县(吴鹏程, 2002; Wu et al, 2002)。

\section{褶叶藓属 Palamocladium}

598. 深绿褶叶藓 Palamocladium euchloron (Müll. Hal.) Wijk et Margad. 安徽(张美珍和赖明洲, 1993; Redfearn et al, 1996; 吴明开等, 2010a; 贾渝和何思, 2013); 霍山县(Cai, 2002; 胡人亮和王幼芳, 2005; Hu et al, 2008)。

599. 褶叶藓 Palamocladium leskeoides (Hook.) E. Britton 安徽(张美珍和赖明洲, 1993 as P. nilgheriense, also as P. macrostegium; Redfearn et al, 1996 also as $P$. nilgheriense f. luzonense, also as $P$. nilgheriense, also as $P$. macrostegium, also as Pleuropus nilgheriensis f. luzonensis; 吴明开等, 2010a as Palamocladium nilgheriense; 贾渝和何思, 2013); 黄山市(陈邦杰和吴鹏程, 1965 as Pleuropus nilgheriensis f. luzonensis; 胡人亮和王幼芳, 2005 as Palamocladium nilgheriense; Hu et al, 2008); 石台县(郭新弧等, 1990 as Palamocladium nilgheriense)。

\section{细嗀藓属 Rhynchostegiella}

600. 细肋细喙藓 Rhynchostegiella leptoneura Dixon et Thér. 安徽(张美珍和赖明洲, 1993; Redfearn et al, 1996); 霍山县(Cai, 2002)。

\section{长喙藓属 Rhynchostegium}

601. 缩叶长喙藓 Rhynchostegium contractum Cardot 安徽(张美珍和赖明洲, 1993; Redfearn et al, 1996; 贾渝和何思, 2013); 霍山县(钱琳和蔡 空辉, 1989; 胡人亮和王幼芳, 2005; Hu et al, 2008)。

602. 狭叶长喙藓 Rhynchostegium fauriei Cardot 安徽(Redfearn et al, 1996; 贾渝和何思, 2013); 霍山县(钱琳和蔡空辉, 1989; 胡人亮和王 幼芳, 2005; Hu et al, 2008)。

603. 斜枝长喙藓 Rhynchostegium inclinatum (Mitt.) A. Jaeger 安徽(Redfearn et al, 1996; 贾渝和何思, 2013); 霍山县(胡人亮和王幼芳, 2005; Hu et al, 2008); 金寨县(Hu et al, 2008)。

604. 淡叶长喙藓 Rhynchostegium pallidifolium (Mitt.) A. Jaeger 安徽(张美珍和赖明洲, 1993; Redfearn et al, 1996; 吴明开等, 2010a; 贾渝和何思, 2013); 霍山县(Cai, 2002; 胡人亮和王幼芳, 2005; Hu et al, 2008); 舒县(胡人亮和王幼芳, 2005; Hu et al, 2008)。

605. 水生长喙蘚(圆叶美喙蘚)Rhynchostegium riparioides (Hedw.) Cardot 安徽(张美珍和赖明洲, 1993 as Eurhynchium riparioides; Redfearn et al, 1996 as E. riparioides, also as Platyhypnidium riparioides, also as P. rusciforme); 黄山市(陈邦杰和吴 
鹏程, 1965 as P. rusciforme); 霍山县(Cai, 2002 as P. riparioides)。

606. 泛生长喙蘚 Rhynchostegium vagans A. Jaeger

安徽(张美珍和赖明洲, 1993; Redfearn et al, 1996; 贾渝和何思, 2013); 石台县(郭新弧等, 1990)。

\section{蔓藓科 Meteoriaceae}

\section{灰气藓属 Aerobryopsis}

607. 芒叶灰气藓 Aerobryopsis aristifolia X. J. Li, S. H. Wu et D. C. Zhang 安徽(吴明开等, 2010a); 黄山市(吴明开等, 2008)。

608. 大灰气蘚 Aerobryopsis subdivergens (Broth.) Broth. 安徽(张美珍和赖明洲, 1993; 吴明开等, 2010a)。

609. 大灰气藓长尖亚种 Aerobryopsis subdivergens ssp. scariosa (E. B. Bartram) Nog. 安徽(吴明开等, 2010a; 贾渝和何思, 2013); 黄山市(陈邦杰和吴鹏程, 1965 as A. horrida; 吴鹏程和贾渝, 2011; Wu et al, 2011)。

610. 灰气藓 Aerobryopsis wallichii (Brid.) M. Fleisch.

安徽(张美珍和赖明洲, 1993; 吴明开等, 2010a as Aerobryidium wallichii); 黄山市(吴明 开等, 2008)。

\section{悬蘚属 Barbella}

611. 狭叶悬藓 Barbella linearifolia S. H. Lin 安徽(张美珍和赖明洲, 1993 as Pseudobarbella angustifolia; Redfearn et al, 1996 as $P$. angustifolia)。

\section{拟悬藓属 Barbellopsis}

612. 拟悬藓 Barbellopsis trichophora (Mont.) W. R. Buck 安徽(张美珍和赖明洲, 1993 as Barbella cubensis; Redfearn et al, 1996 as B. enervis, also as B. trichophora, also as Dicladiella cubensis; 贾渝和何思, 2013); 黄山市(陈邦杰和吴鹏程, 1965 as Barbella determesii; 吴鹏程和贾渝, 2011 as Dicladiella trichophora; Wu et al, 2011)。

\section{垂藓属 Chrysocladium}

613. 垂藓 Chrysocladium retrorsum (Mitt.) M. Fleisch. 安徽(张美珍和赖明洲, 1993; Redfearn et al, 1996 as C. retrorsum var. kiusiuense; 吴明开 等, 2010a); 黄山市(陈邦杰和吴鹏程, 1965; Wu et al, 2011); 金寨县(Wu et al, 2011)。

\section{隐松萝藓属 Cryptopapillaria}

614. 隐松萝藓 Cryptopapillaria fuscescens (Hook.) M. Menzel 安徽(贾渝和何思, 2013); 黄山市(吴明开等, 2010b as Papillaria fuscescens)。

\section{绿锯藓属 Duthiella}

615. 美绿锯藓 Duthiella speciosissima Broth. ex Cardot 安徽(Redfearn et al, 1996; 贾渝和何思, 2013); 霍山县(Cai, 2002); 倝县(吴鹏程和贾渝, 2011; Wu et al, 2011)。

\section{丝带藓属 Floribundaria}

616. 丝带藓 Floribundaria floribunda (Dozy et Molk.) M. Fleisch.

黄山市(吴明开等, 2010a)。

617. 四川丝带藓 Floribundaria setschwanica Broth.

黄山市(吴明开等, 2010a)。 


\section{粗暮藓属 Meteoriopsis}

618. 反叶粗蔓藓 Meteoriopsis reclinata (Müll. Hal.) M. Fleisch. 安徽(张美珍和赖明洲, 1993; Redfearn et al, 1996)。

619. 粗蔓藓 Meteoriopsis squarrosa (Hook. ex Harv.) M. Fleisch. 安徽(张美珍和赖明洲, 1993; Redfearn et al, 1996); 黄山市(Potier de la Varde, 1937; 陈邦 杰和吴鹏程, 1965)。

\section{蔓藓属 Meteorium}

620. 川滇蔓藓 Meteorium buchananii (Brid.) Broth. 安徽(张美珍和赖明洲, 1993; Redfearn et al, 1996 also as M. buchananii ssp. helminthocladulum, also as M. helminthocladulum; 吴明开等, 2010a); 黄山市(陈邦杰和吴 鹏程, 1965 as $M$. helminthocladulum; 吴鹏程和贾渝, 2011); 霍山县(Cai, 2002 also as $M$. helminthocladulum; 吴鹏程和贾渝, 2011)。

621. 细枝蔓藓 Meteorium papillarioides Nog. 安徽(Noguchi, 1976; 张美珍和赖明洲, 1993; Redfearn et al, 1996); 黄山市(陈邦杰和吴 鹏程, 1965)。

622. 蔓藓 Meteorium polytrichum Dozy et Molk. 安徽(张美珍和赖明洲, 1993 as M. miquelianum; Redfearn et al, 1996 as M. miquelianum; 吴明开等, 2010a as M. miquelianum; 贾渝和何思, 2013); 黄山市(Potier de la Varde, 1937 as M. miquelianum; 陈邦杰和吴鹏程, 1965 as M. miquelianum; 吴鹏程和贾渝, 2011; Wu et al, 2011)。

623. 粗枝蔓藓 Meteorium subpolytrichum (Besch.) Broth. 安徽(张美珍和赖明洲, 1993 also as M. latiphyllum; Redfearn et al, 1996 also as $M$. helminthocladum, also as M. latiphyllum; 吴明开等, 2010a also as M. ciliaphyllum); 黄山 市(陈邦杰和吴鹏程, 1965 as M. helminthocladum; 吴明开等, 2008 also as $M$. ciliaphyllum)。

\section{新丝蘚属 Neodicladiella}

624. 新丝藓 Neodicladiella pendula (Sull.) W. R. Buck 安徽(Li, 1985 as Barbella pendula; 张美珍和赖明洲, 1993 as B. pendula; Redfearn et al, 1996; 吴明开等, 2010a as B. pendula；贾渝和何思, 2013); 黄山市(陈邦杰和吴鹏程, 1965 as B. pendula; 吴鹏程和贾渝, 2011; Wu et al, 2011); 石台县(郭新弧等, 1990 as $B$. pendula)。

\section{假悬藓属 Pseudobarbella}

625. 短尖假悬藓 Pseudobarbella attenuata (Thwaites et Mitt.) Nog. 安徽(Redfearn et al, 1996)。

626. 假悬藓 Pseudobarbella levieri (Renauld et Cardot) Nog. 安徽(张美珍和赖明洲, 1993; Redfearn et al, 1996; 吴明开等, 2010a also as Aerobryidium levieri); 黄山市(陈邦杰和吴鹏程, 1965; Wu et al, 2011)。

\section{多痘藓属 Sinskea}

627. 小多疮藓 Sinskea flammea (Mitt.) W. R. Buck

安徽(张美珍和赖明洲, 1993 as Chrysocladium flammeum; Redfearn et al, 1996 also as C. flammeum); 石台县(郭新弧等, 1990 as C.flammeum)。

\section{拟扭叶藓属 Trachypodopsis}

628. 疏耳拟扭叶藓 Trachypodopsis laxoalaris Broth. 
安徽(贾渝和何思, 2013); 黄山市(吴鹏程和贾渝, 2011; Wu et al, 2011)。

\section{扭叶藓属 Trachypus}

629. 扭叶藓 Trachypus bicolor Reinw. et Hornsch.

安徽(张美珍和赖明洲, 1993; Redfearn et al, 1996 also as T. bicolor var. pilifer; 吴明开等, 2010a; 贾渝和何思, 2013); 黄山市(Potier de la Varde, 1937 as T. bicolor var. pilifer; 陈邦 杰和吴鹏程, 1965; 吴鹏程和贾渝, 2011); 霍山县(Cai, 2002); 金寨县(Wu et al, 2011); 石 台县(郭新弧等, 1990)。

630. 小扭叶藓 Trachypus humilis Lindb. 安徽(张美珍和赖明洲, 1993; Redfearn et al, 1996; 吴明开等, 2010a); 黄山市(陈邦杰和 吴鹏程, 1965); 霍山县(Cai, 2002); 石台县(郭新弧等, 1990)。

631. 小扭叶藓细叶变种 Trachypus humilis var. tenerrimus (Herzog) Zanten 安徽(Redfearn et al, 1996; 贾渝和何思, 2013); 黄山市(吴鹏程和贾渝, 2011; Wu et al, 2011)。

\section{灰蘚科 Hypnaceae}

\section{扁灰藓属 Breidleria}

632. 阔叶扁灰藓 Breidleria erectiuscula (Sull. et Lesq.) Hedenäs 安徽(张美珍和赖明洲, 1993 as Hypnum erectiusculum; Redfearn et al, 1996 also as $H$. erectiusculum, also as H. homaliaceum)。

\section{偏龩藓属 Ectropothecium}

633. 淡叶偏蒴蘚 Ectropothecium dealbatum (Reinw. et Hornsch.) A. Jaeger 安徽(吴明开等, 2010a); 黄山市(吴明开等, 2008)。

634. 平叶偏蒴藓 Ectropothecium zollingeri (Müll. Hal.) A. Jaeger 安徽(张美珍和赖明洲, 1993; Redfearn et al, 1996; 吴明开等, 2010a；贾渝和何思, 2013); 黄山市(吴鹏程和贾渝, 2004; Wu et al, 2005); 霍山县(Cai, 2002)。

\section{粗枝蘚属 Gollania}

635. 长蒴粗枝藓 Gollania cylindricarpa (Mitt.) Broth. 安徽(吴明开等, 2010a); 休宁县(吴明开等, 2008)。

636. 平肋粗枝蘚 Gollania neckerella (Müll. Hal.) Broth. 安徽(张美珍和赖明洲, 1993; Redfearn et al, 1996; 吴明开等, 2010a; 贾渝和何思, 2013); 黄山市(Potier de la Varde, 1937; 陈邦杰和吴鹏程, 1965)。

637. 大粗枝藓 Gollania robusta Broth. 安徽(Redfearn et al, 1996; 吴明开等, 2010a; 贾渝和何思, 2013); 黄山市(Higuchi, 1985; 吴鹏程和贾渝, 2004; Wu et al, 2005)。

638. 刍皮叶粗枝藓 Gollania ruginosa (Mitt.) Broth. 安徽(张美珍和赖明洲, 1993; Redfearn et al, 1996; 吴明开等, 2010a；贾渝和何思, 2013); 黄山市(陈邦杰和吴鹏程, 1965; 吴鹏程和贾渝, 2004; Wu et al, 2005); 霍山县(Cai, 2002)。

639. 中华粗枝蘚 Gollania sinensis Broth. et Paris 安徽(Potier de la Varde, 1918; Redfearn et al, 1996; 吴明开等, 2010a)。

640. 多变粗枝藓 Gollania varians (Mitt.) Broth. 安徽(吴明开等, 2010a)。

\section{灰蘚属 Hypnum}


641. 钙生灰蘚 Hypnum calcicola Ando 安徽(张美珍和赖明洲, 1993; Redfearn et al, 1996; 吴明开等, 2010a)。

642. 尖叶灰蘚 Hypnum callichroum Brid. 安徽(张美珍和赖明洲, 1993; Redfearn et al, 1996)。

643. 灰藓 Hypnum cupressiforme Hedw. 安徽(张美珍和赖明洲, 1993; Redfearn et al, 1996; 贾渝和何思, 2013); 黄山市(Potier de la Varde, 1937; 吴鹏程和贾渝, 2004; Wu et al, 2005); 霍山县(Cai, 2002); 石台县(郭新弧 等, 1990)。

644. 东亚灰藓 Hypnum fauriei Cardot 安徽(吴明开等, 2010a); 黄山市(吴明开等, 2008)。

645. 多蒴灰蘚 Hypnum fertile Sendtn. 安徽(张美珍和赖明洲, 1993; Redfearn et al, 1996)。

646. 长喙灰藓 Hypnum fujiyamae (Broth.) Paris 安徽(吴明开等, 2010a); 黄山市(吴明开等, 2008)。

647. 弯叶灰藓 Hypnum hamulosum Schimp. 安徽(张美珍和赖明洲, 1993; Redfearn et al, 1996; 吴明开等, 2010a; 贾渝和何思, 2013); 黄山市(吴鹏程和贾渝, 2004; Wu et al, 2005)。

648. 美灰藓 Hypnum leptothallum (Müll. Hal.) Paris 安徽(张美珍和赖明洲, 1993 as Eurohypnum leptothallum; Redfearn et al, 1996 as Erythrodontium leptothallum, also as Eurohypnum leptothallum var. tereticaule, also as Erythrodontium leptothallum f. tereticaule; 吴明开等, 2010a as Eurohypnum leptothallum; 贾渝和何思, 2013); 黄山市(陈邦杰和吴鹏程, 1965 as Homomallium leptothallum, also as Homomallium leptothallum var. tereticaule; 吴鹏程和贾渝, 2004 as Eurohypnum leptothallum; $\mathrm{Wu}$ et al, 2005 as Eurohypnum leptothallum); 霍山县(Cai, 2002 as Eurohypnum leptothallum); 石台县(郭新弧等, 1990 as Eurohypnum leptothallum)。

649. 长蒴灰蘚 Hypnum macrogynum Besch. 安徽(吴明开等, 2010a)；黄山市(吴明开等, 2008)。

650. 南亚灰藓 Hypnum oldhamii (Mitt.) A. Jaeger 安徽(张美珍和赖明洲, 1993; Redfearn et al, 1996; 吴明开等, 2010a; 贾渝和何思, 2013); 黄山市(陈邦杰和吴鹏程, 1965; 吴鹏程和贾渝, 2004; Wu et al, 2005); 霍山县(Cai, 2002); 石台县(郭新弧等, 1990)。

651. 黄灰藓 Hypnum pallescens (Hedw.) P. Beauv. 安徽(张美珍和赖明洲, 1993; Redfearn et al, 1996; 吴明开等, 2010a)。

652. 大灰藓 Hypnum plumaeforme Wilson 安徽(张美珍和赖明洲, 1993; Redfearn et al, 1996; 吴明开等, 2010a; 贾渝和何思, 2013); 黄山市(陈邦杰和吴鹏程, 1965; 吴鹏程和贾渝, 2004; Wu et al, 2005); 霍山县(Cai, 2002); 石台县(郭新弧等, 1990)。

653. 卷叶灰藓 Hypnum revolutum (Mitt.) Lindb. 安徽(张美珍和赖明洲, 1993; Redfearn et al, 1996); 霍山县(Cai, 2002); 石台县(郭新弧等, 1990)。

654. 湿地灰蘚 Hypnum sakuraii (Sakurai) Ando 安徽(张美珍和赖明洲, 1993; Redfearn et al, 1996; 贾渝和何思, 2013); 黄山市(陈邦杰和 吴鹏程, 1965; 吴鹏程和贾渝, 2004; Wu et al, 2005)。 
655. 温带灰藓强弯亚种 Hypnum subimponens ssp. ulophyllum (Müll. Hal.) Ando 安徽(吴明开等, 2010a); 黄山市(吴明开等, 2008)。

656. 直叶灰蘚 Hypnum vaucheri Lesq. 安徽(吴明开等, 2010a); 休宁县(吴明开等, 2008)。

\section{拟鳞叶藓属 Pseudotaxiphyllum}

657. 东亚拟鳞叶藓 Pseudotaxiphyllum pohliaecarpum (Sull. et Lesq.) Z. Iwats. 安徽(张美珍和赖明洲, 1993 as Isopterygium pohliaecarpum; Redfearn et al, 1996; 吴明开 等, 2010a; 贾渝和何思, 2013); 黄山市(吴鹏程和贾渝, 2004; Wu et al, 2005); 石台县(郭 新弧等, 1990 as I. textorii)。

\section{拟硬叶蘚属 Stereodontopsis}

658. 拟硬叶藓 Stereodontopsis pseudorevoluta (Reimers) Ando 安徽(张美珍和赖明洲, 1993; Redfearn et al, 1996 also as Hypnum pseudorevolutum; 贾渝 和何思, 2013); 黄山市(陈邦杰和吴鹏程, 1965 as H. pseudorevolutum)。

\section{鳞叶藓属 Taxiphyllum}

659. 针头鳞叶藓 Taxiphyllum arcuatum (Bosch et Sande Lac.) S. He 安徽(张美珍和赖明洲, 1993 as T. subarcuatum; 吴明开等, 2010a as T. subarcuatum); 黄 山市(吴明开等, 2008 as T. subarcuatum)。

660. 凸尖鳞叶藓 Taxiphyllum cuspidifolium (Cardot) Z. Iwats. 安徽(Redfearn et al, 1996; 吴明开等, 2010a); 霍山县(Cai, 2002)。

661. 陕西鳞叶藓 Taxiphyllum giraldii (Müll. Hal.) M. Fleisch. 安徽(张美珍和赖明洲, 1993; Redfearn et al, 1996; 吴明开等, 2010a); 霍山县(Cai, 2002)。

662. 鳞叶藓 Taxiphyllum taxirameum (Mitt.) M. Fleisch. 安徽(张美珍和赖明洲, 1993; Redfearn et al, 1996; 吴明开等, 2010a；贾渝和何思, 2013); 黄山市(吴鹏程和贾渝, 2004; Wu et al, 2005); 霍山县(Cai, 2002); 青阳县(吴鹏程和贾渝, 2004; Wu et al, 2005); 石台县(郭新弧等, 1990)。

\section{明叶蘚属 Vesicularia}

663. 长尖明叶藓 Vesicularia reticulata (Dozy et Molk.) Broth. 安徽(张美珍和赖明洲, 1993; Redfearn et al, 1996); 霍山县(Cai, 2002)。

\section{金灰藓科 Pylaisiaceae 大湿原蘚属 Calliergonella}

664. 大湿原藓 Calliergonella cuspidata (Hedw.) Loeske 安徽(Potier de la Varde, 1918 as Acrocladium cuspidata, Redfearn et al, 1996)。

665. 弯叶大湿原蘚 Calliergonella lindbergii (Mitt.) Hedenäs 安徽(张美珍和赖明洲, 1993 as Hypnum lindbergii; Redfearn et al, 1996 also as $H$. lindbergii; 贾渝和何思, 2013); 霍山县(Cai, 2002 as H. lindbergii); 噏县(胡人亮和王幼 芳, 2005; Hu et al.2008)。

\section{毛灰藓属 Homomallium}

666. 东亚毛灰藓 Homomallium connexum (Cardot) Broth. 安徽(张美珍和赖明洲, 1993; Redfearn et al, 1996 also as H. hwangshanense; 吴明开等, 2010a; 贾渝和何思, 2013); 黄山市(陈邦杰和吴鹏程, 1965 as H. hwangshanense); 青阳 县(吴鹏程和贾渝, 2004; Wu et al, 2005)。 


\section{金灰藓属 Pylaisia}

667. 大金灰藓 Pylaisia cristata Cardot 安徽(Potier de la Varde, 1918 as Pylaisiella robusta; Redfearn et al, 1996 as Pylaisiella robusta, also as Pylaisia robusta)。

668. 金灰藓 Pylaisia polyantha (Hedw.) Bruch et Schimp. 安徽(吴明开等, 2010a also as Pylaisiella polyantha; 贾渝和何思, 2013); 黄山市(吴鹏程 和贾渝, 2004); 霍山县(吴鹏程和贾渝, 2004; Wu et al, 2005); 歇县(Wu et al, 2005)。

\section{毛锦蘚科 Pylaisiadelphaceae}

\section{小锦蘚属 Brotherella}

669. 赤茎小锦藓 Brotherella erythrocaulis (Mitt.) M. Fleisch.

霍山县(Cai, 2002)。

670. 弯叶小锦藓 Brotherella falcata (Dozy et Molk.) M. Fleisch. 安徽(张美珍和赖明洲, 1993; 吴明开等, 2010a); 黄山市(吴明开等, 2008)。

671. 东亚小锦藓 Brotherella fauriei (Cardot) Broth. 安徽(张美珍和赖明洲, 1993; 吴明开等, 2010a; 贾渝和何思, 2013); 黄山市(吴鹏程和贾 渝, 2004; Wu et al, 2005); 石台县(郭新弧等, 1990)。

672. 南方小锦蘚 Brotherella henonii (Duby) M. Fleisch. 安徽(张美珍和赖明洲, 1993; 吴明开等, 2010a)。

673. 垂蒴小锦藓 Brotherella nictans (Mitt.) Broth. 安徽(张美珍和赖明洲, 1993; 吴明开等, 2010a)。

\section{腐木蘚属 Heterophyllium}

674. 腐木藓 Heterophyllium affine (Hook.) M. Fleisch. 安徽(张美珍和赖明洲, 1993 as H. nemorosum); 石台县(郭新弧等, 1990 as $H$. foliolatum)。

\section{同叶藓属 Isopterygium}

675. 淡色同叶藓 Isopterygium albescens (Hook.) A. Jaeger 安徽(张美珍和赖明洲, 1993; Redfearn et al, 1996); 霍山县(Cai, 2002)。

676. 南亚同叶藓 Isopterygium bancanum (Sande Lac.) A. Jaeger 安徽(Redfearn et al, 1996; 吴明开等, 2010a); 黄山市(吴明开等, 2008)。

677. 华东同叶藓 Isopterygium courtoisii Broth. et Paris 安徽(吴明开等, 2010a; 贾渝和何思, 2013)。

678. 刘氏同叶藓 Isopterygium lioui Thér. et P. de la Varde 安徽(张美珍和赖明洲, 1993; Redfearn et al, 1996; 贾渝和何思, 2013); 黄山市(Potier de la Varde, 1937; 陈邦杰和吴鹏程, 1965)。

679. 纤枝同叶藓 Isopterygium minutirameum (Müll. Hal.) A. Jaeger 安徽(张美珍和赖明洲, 1993; Redfearn et al, 1996)。

680. 石生同叶藓 Isopterygium saxense R. S. Williams 安徽(吴明开等, 2010a); 宁国市(吴明开等, 2008)。

681. 齿边同叶藓 Isopterygium serrulatum M. Fleisch. 安徽(贾渝和何思, 2013); 檁县(吴鹏程和贾渝, 2004; Wu et al, 2005)。

682. 柔叶同叶藓 Isopterygium tenerum (Sw.) Mitt. 安徽(贾渝和何思, 2013); 石台县(吴鹏程和贾渝, 2004; Wu et al, 2005)。 


\section{毛锦蘚属 Pylaisiadelpha}

683. 弯叶毛锦蘚 Pylaisiadelpha tenuirostris (Bruch et Schimp. ex Sull.) W. R. Buck 安徽(Redfearn et al, 1996; 吴明开等, 2010a; 贾渝和何思, 2013); 黄山市(吴鹏程和贾渝, 2004; Wu et al, 2005)。

684. 暗绿毛锦藓 Pylaisiadelpha tristoviridis (Broth.) Afonina, H. Tsubota et Ignatova 安徽(张美珍和赖明洲, 1993 as Hypnum tristoviride); 石台县(郭新弧等, 1990 as $H$. tristoviride)。

685. 短叶毛锦藓 Pylaisiadelpha yokohamae (Broth.) W. R. Buck 安徽(张美珍和赖明洲, 1993 as Brotherella yokohamae; Redfearn et al, 1996); 霍山县(Cai, 2002 as B. yokohamae)。

\section{麻锦藓属 Taxithelium}

686. 南亚麻锦藓 Taxithelium instratum (Brid.) Broth. 安徽(张美珍和赖明洲, 1993; Redfearn et al, 1996; 贾渝和何思, 2013)。

\section{刺枝蘚属 Wijkia}

687. 角状刺枝藓 Wijkia hornschuchii (Dozy et Molk) H. A. Crum 黄山市(吴明开等, 2010a)。

\section{锦藓科 Sematophyllaceae 顶胞藓属 Acroporium}

688. 顶胞藓粗枝变种 Acroporium stramineum var. turgidum (Mitt.) B. C. Tan 安徽(张美珍和赖明洲, 1993 as A. turgidum; Redfearn et al, 1996 also as A.turgidum)。

\section{锦蘚属 Sematophyllum}

689. 婆罗锦藓 Sematophyllum borneense (Broth.) P. Câmara 安徽(张美珍和赖明洲, 1993 as Glossadelphus nitidus; Redfearn et al, 1996 as G. nitidus, also as Taxiphyllum nitidum)。

690. 矮锦藓 Sematophyllum subhumile (Müll. Hal.) M. Fleisch. 安徽(张美珍和赖明洲, 1993 as S. pulchellum, also as S. henryi; Redfearn et al, 1996 also as Rhaphidostegium japonicum, also as Sematophyllum henryi, also as S. japonicum, also as $S$. pulchellum, also as S. subhumile ssp. japonicum; 吴明开等, 2010a; 贾渝和何思, 2013); 霍 山县(Cai, 2002); 青阳县(吴鹏程和贾渝, 2004); 石台县(郭新弧等, 1990 as $S$. pulchellum)。

691. 锦藓 Sematophyllum subpinnatum (Brid.) E. Britton 安徽(吴明开等, 2010a); 霍山县(Cai, 2002 as S. robustulum); 黄山市(吴明开等, 2008)。

\section{塔蘚科 Hylocomiaceae 梳蘚属 Ctenidium}

692. 柔枝梳藓 Ctenidium andoi N. Nishim.

安徽(张美珍和赖明洲, 1993; Redfearn et al, 1996; 吴明开等, 2010a；贾渝和何思, 2013); 黄山市(Nishimura, 1985; 吴鹏程和贾渝, 2004; Wu et al, 2005); 檁县(吴鹏程和贾渝, 2004; Wu et al, 2005)。

693. 毛叶梳藓 Ctenidium capillifolium (Mitt.) Broth. 安徽(张美珍和赖明洲, 1993; Redfearn et al, 1996 also as C. robusticaule; 吴明开等, 2010a; 贾渝和何思, 2013); 黄山市(陈邦杰和吴鹏程, 1965; 吴鹏程和贾渝, 2004; Wu et 
$\mathrm{al}, 2005)$; 霍山县(Cai, 2002); 石台县(郭新弧等, 1990)。

694. 戟叶梳藓 Ctenidium hastile (Mitt.) Lindb.

安徽(Redfearn et al, 1996; 贾渝和何思, 2013); 歌县(吴鹏程和贾渝, 2004; Wu et al, 2005)。

695. 平叶梳藓 Ctenidium homalophyllum Broth. et Yasuda ex Ihsiba 安徽(贾渝和何思, 2013); 晾县(吴鹏程和贾渝, 2004; Wu et al, 2005)。

696. 梳藓 Ctenidium molluscum (Hedw.) Mitt.

安徽(Redfearn et al, 1996; 吴明开等, 2010a); 霍山县(Cai, 2002)。

697. 齿叶梳藓 Ctenidium serratifolium (Cardot) Broth.

安徽(吴明开等, 2010a; 贾渝和何思, 2013); 黄山市(吴明开等, 2008); 檁县(吴鹏程和贾 渝, 2004; Wu et al, 2005)。

\section{假蔓蘚属 Loeskeobryum}

698. 假蔓藓 Loeskeobryum brevirostre (Brid.) M. Fleisch. ex Broth. 安徽(贾渝和何思, 2013); 黄山市(吴鹏程和贾渝, 2004; Wu et al, 2005)。

699. 船叶假蔓藓 Loeskeobryum cavifolium (Sande Lac.) M. Fleisch. ex Broth.

安徽(张美珍和赖明洲, 1993 as Hylocomium brevirostre var. cavifolium; Redfearn et al, 1996 also as H. brevirostre var. cavifolium, also as H. cavifolium; 吴明开等, 2010a; 贾渝和 何思, 2013); 黄山市(陈邦杰和吴鹏程, 1965; 吴鹏程和贾渝, 2004); 金寨县(Wu et al, 2005); 霍山县(Cai, 2002 as H. cavifolium)。

\section{南木蘚属 Macrothamnium}

700. 南木藓 Macrothamnium macrocarpum (Reinw. et Hornsch.) M. Fleisch. 安徽(张美珍和赖明洲, 1993; 贾渝和何思, 2013); 霍山县(Cai, 2002; 吴鹏程和贾渝, 2004; Wu et al, 2005)。

\section{小蔓蘚属 Meteoriella}

701. 小蔓藓 Meteoriella soluta (Mitt.) S. Okamura 安徽(张美珍和赖明洲, 1993; Redfearn et al, 1996; 吴明开等, 2010a；贾渝和何思, 2013); 黄山市(陈邦杰和吴鹏程, 1965; 吴鹏程和贾渝, 2011); 金寨县(Wu et al, 2011); 石台县 (郭新弧等, 1990)。

\section{新船叶蘚属 Neodolichomitra}

702. 新船叶藓 Neodolichomitra yunnanensis (Besch.) T. J. Kop. 安徽(Redfearn et al, 1996 also as N. robusta; 吴明开等, 2010a); 霍山县(Cai, 2002 as $N$. robusta)。

\section{赤茎蘚属 Pleurozium}

703. 赤茎藓 Pleurozium schreberi (Brid.) Mitt. 安徽(张美珍和赖明洲, 1993; Redfearn et al, 1996; 吴明开等, 2010a); 霍山县(Cai, 2002)。

\section{拟垂枝蘚属 Rhytidiadelphus}

704. 仰尖拟垂枝藓 Rhytidiadelphus japonicus (Reimers) T. J. Kop. 安徽(张美珍和赖明洲, 1993; Redfearn et al, 1996)。

705. 拟垂枝藓 Rhytidiadelphus squarrosus (Hedw.) Warnst. 安徽(张美珍和赖明洲, 1993; Redfearn et al, 1996); 霍山县(Cai, 2002)。

706. 大拟垂枝藓 Rhytidiadelphus triquetrus (Hedw.) Warnst. 安徽(张美珍和赖明洲, 1993; Redfearn et al, 1996)。 


\section{绢藓科 Entodontaceae 绢蘚属 Entodon}

707. 暖地绢藓 Entodon calycinus Cardot 安徽(Redfearn et al, 1996 also as E. brevisetus; 贾渝和何思, 2013); 霍山县(钱琳和蔡空 辉, 1989 as E. brevisetus)。

708. 柱蒴绢藓 Entodon challengeri (Paris) Cardot 安徽(张美珍和赖明洲, 1993 as E. compressus; Redfearn et al, 1996 as E. compressus; 吴明 开等, 2010a as E. compressus; 贾渝和何思, 2013); 黄山市(吴明开等, 2008 as $E$. compressus); 霍山县(Cai, 2002 as E. compressus; 胡人亮和王幼芳, 2005 as $E$. compressus; Hu et al, 2008); 倝县(胡人亮和王幼芳, 2005 as E. compressus; Hu et al, 2008)。

709. 高原绢藓 Entodon chloropus Renauld et Cardot 安徽(Redfearn et al, 1996)。

710. 绢藓 Entodon cladorrhizans (Hedw.) Müll. Hal. 安徽(张美珍和赖明洲, 1993; Redfearn et al, 1996; 吴明开等, 2010a；贾渝和何思, 2013); 霍山县(Cai, 2002; 胡人亮和王幼芳, 2005; Hu et al, 2008); 撮县(胡人亮和王幼芳, 2005; Hu et al, 2008)。

711. 舀叶绢蘚 Entodon conchophyllus Cardot 安徽(张美珍和赖明洲, 1993; Redfearn et al, 1996; 贾渝和何思, 2013); 黄山市(陈邦杰和 吴鹏程, 1965)。

712. 厚角绢藓 Entodon concinnus (De Not.) Paris 安徽(张美珍和赖明洲, 1993; Redfearn et al, 1996 also as E. serpentinus, also as E. caliginosus; 贾渝和何思, 2013); 黄山市(陈邦杰和吴鹏程, 1965); 㔊县(胡人亮和王幼芳, 2005; Hu et al, 2008)。

713. 长帽绢藓 Entodon dolichocucullatus S. Okamura 安徽(张美珍和赖明洲, 1993; Redfearn et al, 1996; 贾渝和何思, 2013); 倝县(胡人亮和王 幼芳, 2005; Hu et al, 2008)。

714. 广叶绢藓 Entodon flavescens (Hook.) A. Jaeger 安徽(张美珍和赖明洲, 1993; Redfearn et al, 1996 also as E. rubicundus; 吴明开等, 2010a; 贾渝和何思, 2013); 黄山市(陈邦杰和吴鹏程, 1965 as E. rubicundus; 胡人亮和王幼芳, 2005; Hu et al, 2008); 勯县(胡人亮和王幼芳, 2005; Hu et al, 2008)。

715. 长叶绢蘚 Entodon longifolius (Müll. Hal.) A. Jaeger 安徽(吴明开等, 2010a); 黄山市(吴明开等, 2008)。

716. 深绿绢藓 Entodon luridus (Griff.) A. Jaeger 安徽(张美珍和赖明洲, 1993; Redfearn et al, 1996; 贾渝和何思, 2013); 霍山县(Cai, 2002; 胡人亮和王幼芳, 2005; Hu et al, 2008); 晾县(胡人亮和王幼芳, 2005; Hu et al, 2008)。

717. 长柄绢藓 Entodon macropodus (Hedw.) Müll. Hal. 安徽(张美珍和赖明洲, 1993; Redfearn et al, 1996 also as E. angustifolius, also as E. drummondii; 吴明开等, 2010a; 贾渝和何思, 2013); 黄山市(陈邦杰和吴鹏程, 1965 as $E$. drummondii); 霍山县(Cai, 2002; 胡人亮和王幼芳, 2005; Hu et al, 2008); 石台县(郭新弧 等, 1990)。

718. 短柄绢藓 Entodon micropodus Besch. 
安徽(张美珍和赖明洲, 1993; 贾渝和何思, 2013); 檁县(胡人亮和王幼芳, 2005; Hu et al, 2008)。

719. 钝叶绢蘚 Entodon obtusatus Broth.

安徽(吴明开等, 2010a; 贾渝和何思, 2013)。

720. 皱叶绢藓 Entodon plicatus Müll. Hal.

安徽(张美珍和赖明洲, 1993; Redfearn et al, 1996; 贾渝和何思, 2013); 黄山市(胡人亮和

王幼芳, 2005; Hu et al, 2008); 歇县(胡人亮和王幼芳, 2005; Hu et al, 2008)。

721. 横生绢蘚 Entodon prorepens (Mitt.) A. Jaeger

安徽(张美珍和赖明洲, 1993; Redfearn et al, 1996; 贾渝和何思, 2013); 歌县(胡人亮和王 幼芳, 2005; Hu et al, 2008)。

722. 薄叶绢藓 Entodon scariosus Renauld et Cardot 安徽(吴明开等, 2010a; 贾渝和何思, 2013); 㵊县(胡人亮和王幼芳, 2005; Hu et al, 2008)。

723. 陕西绢蘚 Entodon schensianus Müll. Hal.

霍山县(Cai, 2002)。

724. 亮叶绢藓 Entodon schleicheri (Schimp.) Demet.

安徽(张美珍和赖明洲, 1993 as E. aeruginosus; Redfearn et al, 1996 as E. aeruginosus; 吴 明开等, 2010a as E. aeruginosus; 贾渝和何思, 2013); 顽县(胡人亮和王幼芳, 2005 as $E$. aeruginosus; $\mathrm{Hu}$ et al, 2008 as E. aeruginosus)。

725. 中华绢蘚 Entodon smaragdinus Paris et Broth.

安徽(Paris, 1909; Hu, 1983; 张美珍和赖明洲, 1993; Redfearn et al, 1996; 吴明开等, 2010a; 贾渝和何思, 2013); 宁国市(胡人亮和王幼芳, 2005); 歎县(胡人亮和王幼芳, 2005)。

726. 亚美绢蘚原变种 Entodon sullivantii (Müll. Hal.) Lindb.

安徽(张美珍和赖明洲, 1993; Redfearn et al, 1996; 吴明开等, 2010a; 贾渝和何思, 2013); 黄山市(胡人亮和王幼芳, 2005; Hu et al, 2008); 霍山县(Cai, 2002; 胡人亮和王幼芳, 2005; Hu et al, 2008); 晾县(胡人亮和王幼芳, 2005; Hu et al, 2008)。

727. 亚美绢藓多色变种 Entodon sullivantii var. versicolor (Besch.) Mizush.

安徽(张美珍和赖明洲, 1993; Redfearn et al, 1996; 吴明开等, 2010a；贾渝和何思, 2013); 黄山市( $\mathrm{Hu}, 1983$; 胡人亮和王幼芳, 2005; Hu et al, 2008); 霍山县(Cai, 2002; 胡人亮和 王幼芳, 2005; Hu et al, 2008)。

728. 宝岛绢藓 Entodon taiwanensis C. K. Wang et S. H. Lin 安徽(Redfearn et al, 1996; 吴明开等, 2010a; 贾渝和何思, 2013); 㵊县(胡人亮和王幼芳, 2005; Hu et al, 2008)。

729. 绿叶绢藓 Entodon viridulus Cardot 安徽(张美珍和赖明洲, 1993; Redfearn et al, 1996; 吴明开等, 2010a; 贾渝和何思, 2013); 倝县(胡人亮和王幼芳, 2005; Hu et al, 2008)。

\section{赤齿蘚属 Erythrodontium}

730. 穗枝赤齿藓 Erythrodontium julaceum (Schwägr.) Paris 安徽(张美珍和赖明洲, 1993; Redfearn et al, 1996); 黄山市(Hu et al, 2008); 石台县(郭新 弧等, 1990)。

\section{斜齿藓属 Mesonodon}

731. 黄色斜齿藓 Mesonodon flavescens (Hook.) W. R. Buck 
安徽(张美珍和赖明洲, 1993; Redfearn et al, 1996 also as Campylodontium flavescens; 贾 渝和何思, 2013); 勯县(胡人亮和王幼芳, 2005; Hu et al, 2008)。

\section{螺叶藓属 Sakuraia}

732. 螺叶藓 Sakuraia conchophylla (Cardot) Nog. 安徽(Redfearn et al, 1996; 贾渝和何思, 2013); 黄山市(Hu, 1983 as Entodon conchophyllus; 胡人亮和王幼芳, 2005; Hu et al, 2008); 歌县(Hu et al, 2008)。

\section{隐葫藓科 Cryphaeaceae \\ 毛枝藓属 Pilotrichopsis}

733. 毛枝藓 Pilotrichopsis dentata (Mitt.) Besch.

安徽(张美珍和赖明洲, 1993; Redfearn et al, 1996; 吴明开等, 2010a; 贾渝和何思, 2013); 黄山市(陈邦杰和吴鹏程, 1965; 吴鹏程和贾渝, 2011; Wu et al, 2011); 金寨县(Wu et al, 2011)。

\section{白齿藓科 Leucodontaceae}

\section{白齿藓属 Leucodon}

734. 鞭枝白齿蘚 Leucodon flagelliformis Müll. Hal. 安徽(张美珍和赖明洲, 1993); 石台县(郭新弧等, 1990)。

735. 垂悬白齿蘚 Leucodon pendulus Lindb. 安徽(张美珍和赖明洲, 1993; Redfearn et al, 1996); 霍山县(Cai, 2002)。

736. 白齿蘚 Leucodon sciuroides (Hedw.) Schwägr. 安徽(张美珍和赖明洲, 1993; Redfearn et al, 1996; 吴明开等, 2010a); 霍山县(Cai， 2002)。

737. 偏叶白齿蘚 Leucodon secundus (Harv.) Mitt. 安徽(张美珍和赖明洲, 1993; Redfearn et al, 1996; 贾渝和何思, 2013); 黄山市(陈邦杰和 吴鹏程, 1965; 吴鹏程和贾渝, 2011; Wu et al, 2011); 霍山县(Cai, 2002)。

738. 中华白齿蘚 Leucodon sinensis Thér. 安徽(张美珍和赖明洲, 1993; Redfearn et al, 1996; 贾渝和何思, 2013); 霍山县(Cai, 2002); 石台县(吴鹏程和贾渝, 2011; Wu et al, 2011)。

\section{拟白齿蘚属 Pterogoniadelphus}

739. 拟白齿藓 Pterogoniadelphus esquirolii (Thér.) Ochyra et Zijlstra 安徽(吴明开等, 2010a as Leucodon esquirolii); 休宁县(吴明开等, 2008 as L. esquirolii)。

\section{莶蘚科 Pterobryaceae}

耳平藓属 Calyptothecium

740. 急尖耳平藓 Calyptothecium hookeri (Mitt.) Broth. 安徽(张美珍和赖明洲, 1993; Redfearn et al, 1996)。

\section{偋藓属 Pterobryon}

741. 树形彍藓 Pterobryon arbuscula Mitt. 安徽(Redfearn et al, 1996)。

\section{平藓科 Neckeraceae}


742. 拟隐蒴残齿藓 Forsstroemia cryphaeoides Cardot 安徽(贾渝和何思, 2013); 黄山市(吴鹏程和贾渝, 2011; Wu et al, 2011)。

743. 短齿残齿蘚 Forsstroemia yezoana (Besch.) S. Olsson, Enroth et D. Quandt 安徽(张美珍和赖明洲, 1993; Redfearn et al, 1996 as Neckera yezoana); 霍山县(Cai, 2002 as N. yezoana)。

\section{扁枝蘚属 Homalia}

744. 扁枝藓 Homalia trichomanoides (Hedw.) Brid. 安徽(张美珍和赖明洲, 1993; Redfearn et al, 1996); 霍山县(Cai, 2002)。

\section{拟扁枝藓属 Homaliadelphus}

745. 拟扁枝藓 Homaliadelphus targionianus (Mitt.) Dixon et P. de la Varde 安徽(张美珍和赖明洲, 1993; Redfearn et al, 1996; 贾渝和何思, 2013); 黄山市(陈邦杰和 吴鹏程, 1965; Wu et al, 2011); 霍山县(Cai, 2002); 金寨县(Wu et al, 2011); 石台县(郭新 弧等, 1990)。

\section{树平藓属 Homaliodendron}

746. 舌叶树平藓 Homaliodendron Iigulaefolinm (Mitt.) M. Fleisch. 安徽(Redfearn et al, 1996; 贾渝和何思, 2013)。

747. 台湾树平藓 Homaliodendron opacum Nog. 安徽(Redfearn et al, 1996); 黄山市(陈邦杰和吴鹏程, 1965)。

748. 疮叶树平蘚 Homaliodendron papillosum Broth. 安徽(张美珍和赖明洲, 1993 also as Porotrichum perplexans; Redfearn et al, 1996 as $P$. perplexans; 吴明开等, 2010a; 贾渝和何思, 2013); 黄山市(陈邦杰和吴鹏程, 1965); 勯县 (吴鹏程和贾渝, 2011; Wu et al, 2011)。

749. 刀叶树平藓 Homaliodendron scalpellifolium (Mitt.) M. Fleisch.

安徽(Paris, 1911; 张美珍和赖明洲, 1993; 吴明开等, 2010a; 贾渝和何思, 2013); 黄山市 (陈邦杰和吴鹏程, 1965 also as H. scalpellifolium var. angustifolium; Wu et al, 2011); 霍山 县(Cai, 2002); 金寨县( $\mathrm{Wu}$ et al, 2011); 石台县(郭新弧等, 1990)。

\section{平蘚属 Neckera}

750. 曲枝平藓 Neckera flexiramea Cardot 安徽(贾渝和何思, 2013); 金寨县(吴鹏程和贾渝, 2011; Wu et al, 2011); 霍山县(Cai, 2002)。

751. 矮平蘚 Neckera humilis Mitt. 安徽(贾渝和何思, 2013); 黄山市(吴鹏程和贾渝, 2011; Wu et al, 2011)。

752. 八列平蘚 Neckera konoi Broth. 安徽(贾渝和何思, 2013); 黄山市(吴鹏程和贾渝, 2011; Wu et al, 2011)。

753. 平藓 Neckera pennata Hedw. 安徽(张美珍和赖明洲, 1993; Redfearn et al, 1996; 吴明开等, 2010a); 黄山市(陈邦杰和 吴鹏程, 1965); 霍山县(Cai, 2002); 石台县(郭新弧等, 1990)。

754. 多枝平藓 Neckera polyclada Müll. Hal. 安徽(张美珍和赖明洲, 1993; Redfearn et al, 1996 also as Neckeradelphus menziesii); 霍山 县(Cai, 2002 as N. menziesii); 黄山市(陈邦杰和吴鹏程, 1965 as N. menziesii)。

\section{木藓属 Thamnobryum}

755. 木藓 Thamnobryum alopecurum (Hedw.) Nieuwl. ex Gangulee 安徽(Redfearn et al, 1996; 吴明开等, 2010a)。 
756. 褶叶木藓 Thamnobryum plicatulum (Sande Lac.) Z. Iwats.

安徽(张美珍和赖明洲, 1993; Redfearn et al, 1996; 吴明开等, 2010a; 贾渝和何思, 2013); 石台县(郭新弧等, 1990)。

757. 匙叶木藓 Thamnobryum subseriatum (Mitt. ex Sande Lac.) B. C. Tan 安徽(张美珍和赖明洲, 1993; Redfearn et al, 1996 also as T. sandei; 吴明开等, 2010a also as T. sandei; 贾渝和何思, 2013); 霍山县(Cai, 2002 as T. sandei); 金寨县(Wu et al, 2011); 石台县(郭新弧等, 1990 as T. sandei)。

758. 南亚木藓 Thamnobryum subserratum (Hook.) Nog. et Z. Iwats. 安徽(张美珍和赖明洲, 1993 as T. laevinerve; Redfearn et al, 1996 also as T. laevinerve; 吴 明开等, 2010a as T. laevinerve); 黄山市(Potier de la Varde, 1937 as T. laevinerve; 陈邦杰 和吴鹏程, 1965 as T. laevinerve)。

\section{船叶蘚科 Lembophyllaceae}

船叶藓属 Dolichomitra

759. 船叶藓 Dolichomitra cymbifolia (Lindb.) Broth.

安徽(张美珍和赖明洲, 1993; Redfearn et al, 1996; 贾渝和何思, 2013); 黄山市(陈邦杰和 吴鹏程, 1965; 吴鹏程和贾渝, 2011; Wu et al, 2011); 霍山县(Cai, 2002); 金寨县(Wu et al, 2011)。

\section{拟船叶藓属 Dolichomitriopsis}

760. 尖叶拟船叶藓 Dolichomitriopsis diversiformis (Mitt.) Nog. 安徽(张美珍和赖明洲, 1993; Redfearn et al, 1996 also as D. diversiformis var. longiseta; 吴明开等, 2010a; 贾渝和何思, 2013); 黄山市(陈邦杰和吴鹏程, 1965 as D. diversiformis var. longiseta; 吴鹏程和贾渝, 2011; Wu et al, 2011)。

\section{猫尾蘚属 Isothecium}

761. 猫尾蘚 Isothecium alopecuroides (Lam. ex Dubois) Isov. 安徽(Redfearn et al, 1996 also as I. myurum)。

762. 异猫尾蘚 Isothecium subdiversiforme Broth. 安徽(张美珍和赖明洲, 1993; Redfearn et al, 1996)。

\section{金毛蘚科 Myuriaceae}

\section{拟金毛蘚属 Eumyurium}

763. 拟金毛藓 Eumyurium sinicum (Mitt.) Nog. 安徽(张美珍和赖明洲, 1993; Redfearn et al, 1996 also as Myuriopsis sinica)。

\section{红毛蘚属 Oedicladium}

764. 脆叶红毛蘚 Oedicladium fragile Cardot 安徽(贾渝和何思, 2013); 黄山市(吴明开等, 2010b)。

\section{栅孔蘚属 Palisadula}

765. 小叶栅孔藓 Palisadula katoi (Broth.) Z. Iwats. 安徽(张美珍和赖明洲, 1993 as Clastobryum katoi; Redfearn et al, 1996 also as C. katoi); 黄山市(陈邦杰和吴鹏程, 1965 as C. katoi)。

\section{牛舌蘚科 Anomodontaceae}

牛舌蘚属 Anomodon 
766. 单疮牛舌藓 Anomodon abbreviatus Mitt. 安徽(张美珍和赖明洲, 1993); 霍山县(Cai, 2002)。

767. 尖叶牛舌蘚 Anomodon giraldii Müll. Hal. 安徽(张美珍和赖明洲, 1993; 吴明开等, 2010a; 贾渝和何思, 2013); 黄山市(Potier de la Varde, 1937; 陈邦杰和吴鹏程, 1965; 吴鹏程, 2002; Wu et al, 2002); 霍山县(Cai, 2002)。

768. 小牛舌藓 Anomodon minor (Hedw.) Lindb. 安徽(张美珍和赖明洲, 1993 also as A. minor ssp. integerrimus); 黄山市(陈邦杰和吴鹏程, 1965 as A. integerrimus)。

769. 皱叶牛舌藓 Anomodon rugelii (Müll. Hal.) Keissl. 安徽(张美珍和赖明洲, 1993); 黄山市(陈邦杰和吴鹏程, 1965); 霍山县(Cai, 2002)。

770. 碎叶牛舌藓 Anomodon thraustus Müll. Hal. 安徽(Redfearn et al, 1996)。

771. 牛舌藓 Anomodon viticulosus (Hedw.) Hook. et Taylor 安徽(Iwatsuki, 1963; Redfearn et al, 1996); 石台县(郭新弧等, 1990)。

\section{多枝蘚属 Haplohymenium}

772. 鞭枝多枝藓 Haplohymenium flagelliforme L. I. Savicz 安徽(吴明开等, 2010a); 黄山市(吴明开等, 2008); 霍山县(Cai, 2002)。

773. 长肋多枝藓 Haplohymenium longinerve (Broth.) Broth. 安徽(张美珍和赖明洲, 1993; Redfearn et al, 1996; 吴明开等, 2010a; 贾渝和何思, 2013); 黄山市(陈邦杰和吴鹏程, 1965 also as H. longinerve f. piliferum; 吴鹏程, 2002; Wu et al, 2002)。

774. 拟多枝藓 Haplohymenium pseudo-triste (Müll. Hal.) Broth. 安徽(张美珍和赖明洲, 1993; Redfearn et al, 1996; 吴明开等, 2010a); 金寨县(Wu et al, 2002); 石台县(郭新弧等, 1990)。

775. 暗绿多枝藓 Haplohymenium triste (Ces.) Kindb. 安徽(Noguchi, 1957; 张美珍和赖明洲, 1993; Redfearn et al, 1996 also as H. microphyllum, also as H. formosanum; 吴明开等, 2010a also as H. formosanum; 贾渝和何思, 2013); 黄 山市(陈邦杰和吴鹏程, 1965; 吴鹏程, 2002; Wu et al, 2002)。

\section{羊角藓属 Herpetineuron}

776. 羊角藓 Herpetineuron toccoae (Sull. et Lesq.) Cardot 安徽(张美珍和赖明洲, 1993; Redfearn et al, 1996; 吴明开等, 2010a；贾渝和何思, 2013); 黄山市(陈邦杰和吴鹏程, 1965; 吴鹏程, 2002; Wu et al, 2002); 霍山县(Cai, 2002)。

\section{拟附干藓属 Schwetschkeopsis}

777. 拟附干藓 Schwetschkeopsis fabronia (Schwägr.) Broth. 安徽(张美珍和赖明洲, 1993; Redfearn et al, 1996 also as $S$. denticulata, also as $S$. japonica); 黄山市(陈邦杰和吴鹏程, 1965 as S. denticulate, also as S. japonica); 霍山县 (Cai, 2002 also as S. japonica)。

\section{存疑种 4}

Doubtful species of bryophytes

1. 中华无轴蘚 Archidium ohioense Schimp. ex Müll. Hal.

\footnotetext{
4 存疑种主要是一些文献和名录中记载安徽有分布, 但是没有引用凭证标本或者无法追溯到凭证标本的种, 也包括个别没有注明采集号和馆藏地点的种。
} 
安徽(张美珍和赖明洲, 1993)。

2. 小扭口藓 Barbula indica (Hook.) Spreng.

铜陵市(赵传海和张朝晖, 2006 as Semibarbula orientalis)。

3. 钝叶扭口藓 Barbula williamsii (P. C. Chen) Z. Iwats. et B. C. Tan

铜陵市(赵传海和张朝晖, 2006 as Hydrogonium williamsii)。

4. 壶苞苔 Blasia pusilla $\mathrm{L}$.

安徽(张美珍和赖明洲, 1993)。

5. 中华短月藓 Brachymenium sinense Cardot et Thér.

安徽(张美珍和赖明洲, 1993; 黎兴江, 2006; 贾渝和何思, 2013)。

6. 田野青蘚 Brachythecium campestre (Müll. Hal.) Schimp.

安徽(刘仲苓等, 1989; 张美珍和赖明洲, 1993)。

7. 撒氏青藓 Brachythecium sakuraii Broth.

安徽(贾渝和何思, 2013)。

8. 南方小锦藓弯叶变种 Brotherella henonii var. falcatula (Broth.) B. C. Tan et Y. Jia 安徽(张美珍和赖明洲, 1993 as Brotherella falcatula)。

9. 刺叶真蘚 Bryum lonchocaulon Müll. Hal.

安徽(张美珍和赖明洲, 1993)。

10. 多枝毛柄藓刺齿亚种 Calyptrochaeta ramosa ssp. spinosa (Nog.) P. J. Lin et B. C. Tan 安徽(张美珍和赖明洲, 1993 as Eriopus spinosus)。

11. 淡色裂颌苔 Chiloscyphus pallescens (Ehrh.) Dumort. 安徽(张美珍和赖明洲, 1993)。

12. 齿叶麻羽藓 Claopodium prionophyllum (Müll. Hal.) Broth. 安徽(张美珍和赖明洲, 1993; Redfearn et al, 1996)。

13. 阔瓣疮鳞苔 Cololejeunea latilobula (Herzog) Tixier 安徽(朱瑞良和王幼芳, 1992)。

14. Cryptolophocolea compacta (Mitt.) L. Söderstr.

安徽(刘仲苓等, 1989 as Lophocolea compacta; 张美珍和赖明洲, 1993 as Chiloscyphus japonicus)。

15. 粗齿雉尾蘚 Cyathophorum adiantum (Griff.) Mitt. 安徽(贾渝和何思, 2013)。

16. 鳞叶筒蕓苔 Cylindrocolea kiaeri (Austin) Váňa 安徽(张美珍和赖明洲, 1993 as Cephaloziella kiaeri; 吴德邻和张力, 2013 as Cephaloziella kiaeri)。

17. 华南小曲尾藓 Dicranella austro-sinensis Herzog et Dixon 铜陵市(赵传海和张朝晖, 2006)。

18. 南亚小曲尾藓 Dicranella coarctata (Müll. Hal.) Bosch et Sande Lac. 铜陵市(赵传海和张朝晖, 2006)。

19. 细叶对齿蘚 Didymodon perobtusus Broth. 铜陵市(赵传海和张朝晖, 2006 as Barbula perobtusa)。

20. 对叶藓 Distichium capillaceum (Hedw.) Bruch et Schimp. 安徽(黎兴江, 1985; 白学良, 2010)。

21. 细叶牛毛藓 Ditrichum pusillum (Hedw.) Hampe 铜陵市(赵传海和张朝晖, 2006)。 
22. 四川拟绢藓 Entodontopsis setschwanica (Broth.) W. R. Buck et Ireland 安徽(Redfearn et al, 1996)。

23. 纤细梨蒴藓 Entosthodon gracilis Hook. f. et Wilson 铜陵市(赵传海和张朝晖, 2006 as Funaria gracilis)。

24. 北方紫䔅藓 Grimmia decipiens (Schultz) Lindb. 安徽(张美珍和赖明洲, 1993)。

25. 锐裂全苧苔 Gymnomitrion commutatum (Limpr.) Schiffn. 安徽(张美珍和赖明洲, 1993 as Marsupella commutata)。

26. 类全蕓苔 Gymnomitrion revolutum (Nees) H.Philib. 安徽(刘仲苓等, 1989 as Marsupella revoluta; 高谦和曹同, 2000 as M. revoluta; 高谦和赖 明洲, 2003 as M. revoluta)。

27. 净口藓 Gymnostomum calcareum Nees et Hornsch. 铜陵市(赵传海和张朝晖, 2006)。

28. 夏氏拟扁枝藓 Homaliadelphus sharpii (R. S. Williams) Sharp 安徽(Hu \& Wang, 1987; Redfearn et al, 1996)。

29. 夏氏拟扁枝藓圆叶变种 Homaliadelphus sharpii var. rotundatus (Nog.) Z. Iwats. 安徽(张美珍和赖明洲, 1993)。

30. 小树平藓 Homaliodendron exiguum (Bosch et Sande Lac.) M. Fleisch. 安徽(吴鹏程等, 2012; 吴鹏程等, 2018 as Circulifolium exiguum)。

31. 芽狍湿地藓 Hyophila propagulifera Broth. 安徽(张美珍和赖明洲, 1993)。

32. 湿生细鳞苔 Lejeunea aquatica Horik. 安徽(贾渝和何思, 2013)。

33. 长叶细鳞苔 Lejeunea discreta Lindenb. 安徽(贾渝和何思, 2013)。

34. 指叶苔 Lepidozia reptans (L.) Dumort. 安徽(Mizutani \& Chang, 1986; 刘仲苓等, 1989; Piippo, 1990; 张美珍和赖明洲, 1993; 高 谦和赖明洲, 2003; 高谦, 2003; 吴鹏程等, 2012; 贾渝和何思, 2013; 吴德邻和张力, 2013; 吴鹏程等, 2018)。

35. 硬指叶苔 Lepidozia vitrea Steph. 安徽(张美珍和赖明洲, 1993)。

36. 粗肋薄罗藓 Leskea scabrinervis Broth. et Paris 六安市(闵运江, 1997)。

37. 偏叶白齿蘚硬叶变种 Leucodon secundus var. strictus (Harv.) H. Akiy. 安徽(贾渝和何思, 2013)。

38. 楔瓣地钱 Marchantia emarginata Reinw. 安徽(张美珍和赖明洲, 1993)。

39. 粗裂地钱风兒亚种 Marchantia paleacea ssp. diptera (Nees et Mont.) Inoue 安徽(张美珍和赖明洲, 1993; 吴德邻和张力, 2013)。

40. 地钱 Marchantia polymorpha $\mathrm{L}$. 安徽(张美珍和赖明洲, 1993; 吴鹏程等, 2012; 吴鹏程等, 2018)。

41. 东亚蔓藓 Meteorium atrovariegatum Cardot et Thér. 安徽(Redfearn et al, 1996; 贾渝和何思, 2013)。 
42. 林氏叉苔 Metzgeria lindbergii Schiffn. 安徽(贾渝和何思, 2013)。

43. 疏叶纤鳞苔 Microlejeunea ulicina (Taylor) Steph. 安徽(朱瑞良和王幼芳, 1992; 贾渝和何思, 2013 as Lejeunea ulicina; 吴德邻和张力, 2013 as L. ulicina)。

44. 刺叶提灯藓 Mnium spinosum (Voit) Schwägr. 安徽(吴鹏程等, 2012; 吴鹏程等, 2018)。

45. 鞭枝新丝蘚 Neodicladiella flagellifera (Cardot) Huttunen et D. Quandt 安徽(张美珍和赖明洲, 1993 as Barbella flagellifera)。

46. 带叶苔 Pallavicinia lyellii (Hook.) Gray 安徽(张美珍和赖明洲, 1993)。

47. 平蒴藓 Plagiobryum zierii (Dicks. ex Hedw.) Lindb. 铜陵市(赵传海和张朝晖, 2006)。

48. 紫背苔 Plagiochasma cordatum Lehm. et Lindenb. 安徽(张美珍和赖明洲, 1993)。

49. 小孔紫背苔 Plagiochasma rupestre (J. R. Forst. et G. Forst.) Steph. 安徽(Piippo, 1990; 张美珍和赖明洲, 1993; 贾渝和何思, 2013)。

50. 羽苔 Plagiochila asplenioides (L.) Dumort. 安徽(张美珍和赖明洲, 1993)。

51. 加萨羽苔 Plagiochila khasiana Mitt. 安徽(高谦和赖明洲, 2003)。

52. 多蒴匐灯藓 Plagiomnium medium (Bruch et Schimp.) T. J. Kop. 安徽(张美珍和赖明洲, 1993; Redfearn et al, 1996; 贾渝和何思, 2013)。

53. 瘤柄匐灯蘚 Plagiomnium venustum (Mitt.) T. J. Kop. 安徽(Redfearn et al, 1996; 贾渝和何思, 2013)。

54. 尖叶丛毛藓 Pleuridium acuminatum Lindb. 安徽(张美珍和赖明洲, 1993)。

55. 全缘小金发蘚 Pogonatum perichaetiale (Mont.) A. Jaeger 安徽(张美珍和赖明洲, 1993)。

56. 多齿光苛苔 Porella campylophylla (Lehm. et Lindenb.) Trevis. 安徽(张美珍和赖明洲, 1993)。

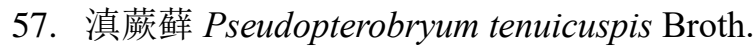
安徽(张美珍和赖明洲, 1993)。

58. 拟木毛藓 Pseudospiridentopsis horrida (Cardot) M. Fleisch. 安徽(张美珍和赖明洲, 1993)。

59. 弯叶金灰蘚 Pylaisia falcata Schimp. 安徽(张美珍和赖明洲, 1993 as Pylaisiella falcata)。

60. 北方金灰藓 Pylaisia selwynii Kindb. 安徽(Potier de la Varde, 1918 as Pylaisia schimperi, Redfearn et al, 1996 as Pylaisiella selwynii)。

61. 叠叶金灰藓 Pylaisia subimbricata Broth. et Paris 安徽(Potier de la Varde, 1918, Redfearn et al, 1996 also as Pylaisiella subimbricata; 贾渝和 何思, 2013)。 
62. 微齿粗石藓 Rhabdoweisia crispata (Dicks. ex With.) Lindb. 铜陵市(赵传海和张朝晖, 2006)。

63. 长喙蘚 Rhynchostegium confertum (Dicks.) Schimp. 安徽(贾渝和何思, 2013)。

64. 叉钱苔 Riccia fluitans L. 安徽(张美珍和赖明洲, 1993; 吴鹏程等, 2012; 吴鹏程等, 2018)。

65. 钱苔 Riccia glauca L. 安徽(张美珍和赖明洲, 1993; 吴鹏程等, 2012; 吴鹏程等, 2018)。

66. 肥果钱苔 Riccia sorocarpa Bisch. 安徽(吴鹏程等, 2012; 吴鹏程等, 2018)。

67. 浮苔 Ricciocarpos natans (L.) Corda 安徽(吴鹏程等, 2012; 吴鹏程等, 2018)。

68. 短合叶苔 Scapania curta (Mart.) Dumort. 安徽(吴鹏程等, 2012; 吴鹏程等, 2018)。

69. 小合叶苔 Scapania parvifolia Warnst. 安徽(吴鹏程等, 2012; 吴鹏程等, 2018)。

70. 高山连轴蘚 Schistidium agassizii Sull. et Lesq. 安徽(张美珍和赖明洲, 1993; Redfearn et al, 1996)。

71. 短枝附干藓 Schwetschkea brevipes (Broth. et Paris) Broth. 安徽(张美珍和赖明洲, 1993; Redfearn et al, 1996)。

72. 异边管口苔 Solenostoma heterolimbatum (Amakawa) Váňa et D. G. Long 安徽(高谦和吴玉环, 2010 as Jungermannia heterolimbata)。

73. 密叶泥炭藓 Sphagnum compactum Lam. et de Cand. 安徽(贾渝和何思, 2013)。

74. 拟宽叶泥炭蘚 Sphagnum platyphylloides Warnst. 安徽(贾渝和何思, 2013)。

75. 希氏赤藓 Syntrichia fragilis (Taylor) Ochyra 铜陵市(赵传海和张朝晖, 2006 as Tortula schmidii)。

76. 日本网蘚 Syrrhopodon japonicus (Besch.) Broth. 安徽(张美珍和赖明洲, 1993)。

77. 筒萼对耳苔 Syzygiella autumnalis (DC.) K. Feldberg, Váňa, Hentschel et Heinrichs 安徽(刘仲苓等, 1989 as Jamesoniella autumnalis; 张美珍和赖明洲, 1993 as J. autumnalis; Zhu \& So, 2001 as J. autumnalis)。

78. 墙蘚 Tortula subulata Hedw. 铜陵市(赵传海和张朝晖, 2006)。

\section{排除出安徽的荅蘚植物}

Excluded species of bryophytes in Anhui Province

1. Atrichum undulatum (Hedw.) P. Beauv. Paris(1909)、陈邦杰和吴鹏程(1965)、郭新弧等(1990) 和 Cai(2002)记录安徽有该种的分布，但是根据 Lou \& Koponen (1986), 该种在中国没有 可靠的凭证标本，所有的标本都是变种 “Atrichum undulatum var. gracilisetum”，故将该 种排除出安徽。

2. Cheilolejeunea mariana (Gottsche) B. M. Thiers et Gradst. 安徽无该种(师雪芹等, 2018)。 
3. Clastobryum glabrescens (Z. Iwats.) B. C. Tan, Z. Iwats. \& D. H. Norris 根据吴鹏程和贾渝 (2004), 将该种排除出安徽。

4. Cololejeunea floccosa (Lehm. et Lindenb.) Schiffn. 安徽无该种(师雪芹等, 2018)。

5. Cololejeunea stylosa (Steph.) Steph. ex Mizut. 安徽无该种(师雪芹等, 2018)。

6. Drepanolejeunea subacuta (Mitt.) Miller et al. 安徽无该种(师雪芹等, 2018)。

7. Frullania densiloba Steph. ex A. Evans 陈邦杰和吴鹏程(1965)记载了该种, Hattori \& Lin (1985) 认为该种鉴定为 “ $F$. punctata” 更合适。

8. Homaliodendron flabellatum (Sm.) M. Fleisch. Redfearn et al(1996)记载安徽有该种分布, 查阅其引用的文献，均未记载该种，故将该种排除出安徽。

9. Lejeunea planiloba A. Evans 安徽无该种(师雪芹等, 2018)。

10. Metalejeunea cucullata (Reinw. et al.) Grolle 安徽无该种(师雪芹等, 2018)。

11. Oedicladium rufescens (Reinw. et Hornsch.) Mitt. Redfearn et al(1996)基于陈邦杰(1978)和 陈邦杰和吴鹏程(1965)记录该种，查阅两篇文献均未发现有该种的记录，故将该种排除 出安徽。

12. Pelekium contortulum (Mitt.) A. Touw Redfearn et al(1996)基于陈邦杰(1978)中 “Thuidium tamariscellum ”确定安徽有该种，经过查证，该种的分布仅记载了云南，故将该种排除出 安徽。

13. Porella pinnata L. Cai (2002)以及张美珍和赖明洲(1993)记载该种在安徽有分布, 根据 Bai et al (2020), 在我国广泛分布的 P. pinnata 被证实在亚洲是错误鉴定，故将该种排除 出安徽。

14. Radula boryana (F. Weber) Nees ex Mont. 张美珍和赖明洲(1993)记载该种在安徽有分布, 根据 Yamada (1979)该种在中国无分布，建议排除该种在安徽的分布。

15. Radula brunnia Steph.Cai (2002)记录该种在安徽有分布，并错误拼写为“Radula brunnea”。 但根据 Yamada (1979), R. brunnea 仅分布于日本和斯里兰卡，故该种在中国的分布需要 进一步研究。

16. Rhodobryum roseum (Hedw.) Limpr. Tchen(1936)记载该种在黄山有分布, 陈邦杰和吴鹏 程(1965)检查该种凭证标本，认为这份标本应该是 “ $R$. giganteum”，张美珍和赖明洲 (1993)也收录该种, 但是不能确认文献来源, 故将该种排除出安徽。

17. Spruceanthus marianus (Gott.) Mizut. 安徽无该种(师雪芹等, 2018)。

18. Trichosteleum mammosum (Müll. Hal.) A.Jaeger 根据吴鹏程和贾渝(2004), 中国目前无该 种的分布。

\section{参考文献}

Bai XL (2010) Helan Mountain Bryophytes. Ningxia People Publisher, Yinchuan. (in Chinese) [白 学良 (2010) 贺兰山苔藓植物. 宁夏人民出版社, 银川.]

Bai Y, Qian K, Xiang YL, Yang ZW, Sulayman M, Li W, Shu L, Zhu RL (2020) Porella pinnata (Porellaceae) excluded from the liverwort flora of Asia. Nova Hedwigia, 150, 193-200.

Cai KH (2002) A list of the bryophytes of Mt. Baimajian Houshan county, Anhui Province, SE China. Chenia, 7, 149-159.

Cao T, Gao C, Vitt DH (1995) A taxonomic revision of the genus Ptychomitrium (Bryopsida: Ptychomitriaceae) in China. Harvard Papers in Botany, 6, 75-96.

Cao T, Vitt DH (1986) A taxonomic revision and phylogenetic analysis of Grimmia and Schistidium (Bryopsida: Grimmiaceae) in China. Journal of the Hattori Botanical Laboratory, 61, 123-247. 
Chen PC, Wan TL (1958) A preliminary study of Chinese Andreaea. Acta Phytotaxonomica Sinica, 7, 91-104. (in Chinese with English abstract) [陈邦杰, 万宗玲 (1958) 中国黑藓属植物初 步观察. 植物分类学报, 7, 91-104.]

Chen PC, Lee SC (1956) A preliminary study of the Chinese Sphagnum. Acta Phytotaxonomica Sinica, 5, 165-203. (in Chinese with English abstract) [陈邦杰, 黎兴江 (1956) 中国泥炭藓 属植物的初步观察. 植物分类学报, 5, 165-203.]

Chen PC, Wu PC (1965). The preliminary study of the bryophytes of Mt. Hwangshan. In: Observationes ad Florulam Hwangshanicum (eds Chen PC, Wu PC, Qiu PX, Xu BS, Zhou JL), pp. 1-59. Science and Technology Press, Shanghai. (in Chinese with English abstract) [陈邦 杰, 吴鹏程 (1965) 黄山苔藓植物的初步研究. 见: 黄山植物的研究 (陈邦杰, 吴鹏程, 装佩喜, 徐炳声, 周纪纶主编), 1-59页. 科学技术出版社, 上海.]

Chen PC ed. (1978) Genera Muscorum Sinicorum. Science Press, Beijing. (in Chinese) [陈邦杰主 编 (1978) 中国藓类植物属志(下册). 科学出版社, 北京.]

Cheng Q, Shi XQ (2018) New records of liverwort from Anhui Province. Guihaia, 38, 1229-1233. (in Chinese with English abstract) [程前, 师雪芹 (2018) 安徽省苔类植物新资料. 广西植 物, 38, 1229-1233.]

Cheng Q, Shi XQ (2019) Haplomitriaceae, a new recorded family in Anhui Province. Journal of Biology, 36(2), 59-60. (in Chinese with English abstract) [程前, 师雪芹 (2019) 裸蕂苔科 一安徽新记录科. 生物学杂志, 36(2), 59-60.]

Frahm JP (1992) A revision of the East-Asian species of Campylopus. Journal of the Hattori Botanical Laboratory, 71, 133-164.

Gao C ed. (1994) Flora Bryophytarum Sinicorum, Vol. 1. Science Press, Beijing. (in Chinese) [高 谦主编 (1994) 中国苔藓志(第1卷). 科学出版社, 北京.]

Gao C ed. (1996) Flora Bryophytarum Sinicorum, Vol. 2. Science Press, Beijing. (in Chinese) [高 谦主编 (1996) 中国苔蘚志(第2卷). 科学出版社, 北京.]

Gao C ed. (2003) Flora Bryophytarum Sinicorum, Vol. 9. Science Press, Beijing. (in Chinese) [高 谦主编 (2003) 中国苔藓志(第9卷). 科学出版社, 北京.]

Gao C, Bai XL (2001) A synoptic revision of family Jungermanniaceae (Hepaticae) in China including some taxa nova. Philippine Scientist, 38, 111-170.

Gao C, Cao T (1992) Studies of Chinese bryophytes (4). The family Theliaceae (Musci). Journal of the Hattori Botanical Laboratory, 71, 367-375.

Gao C, Cao T, Fu X (1993) Some moss species new to China. Chenia, 1, 7-9. (in Chinese with English abstract) [高谦，曹同，傅星 (1993) 中国藓类植物新记录. Chenia, 1, 7-9.]

Gao C, Crosby MR, He S (1999) Moss Flora of China, English Version, Vol. 1. SphagnaceaeLeucobryaceae. Science Press \& Missouri Botanical Garden, Beijing, New York \& St. Louis.

Gao C, Crosby MR, He S (2003) Moss Flora of China, English Version, Vol. 3. GrimmiaceaeTetraphidaceae. Science Press \& Missouri Botanical Garden, Beijing, New York \& St. Louis.

Gao C, Lai MZ ed. (2003) Illustrations of Bryophytes of China. SMC Publishing Inc., Taipei. (in Chinese) [高谦，赖明洲主编（2003）中国苔藓植物图鉴. 南天书局，台北.]

Gao C, Wu YH ed. (2008) Flora Bryophytarum Sinicorum, Vol. 10. Science Press, Beijing. (in Chinese) [高谦，吴玉环主编 (2008) 中国苔藓志(第10卷). 科学出版社，北京.]

Gao C, Wu YH ed. (2010) Genera Hepaticopsida et Anthocerotopsida Sinicorum. Science Press, Beijing. (in Chinese) [高谦, 吴玉环主编 (2010) 中国苔纲和角苔纲植物属志. 科学出版 
社, 北京.]

Guo XH, Liu ZL, Hu RL, Wang YF (1990) The bryophytes of Guniujiang Natrual Conservation. In: Science Investigation in Natural Conservation of Guniujiang (ed Han YL), pp. 247-260, 414-420. China Prospect Press, Beijing. (in Chinese) [郭新弧, 刘仲苓, 胡人亮, 王幼芳 (1990) 牯牛降苔蘚植物. 见: 牯牛降科学考察集 (韩也良主编), 247-260, 414-420页. 中 国展望出版社, 北京.]

Hattori S (1967) Studies of the Asiatic species of the genus Porella (Hepaticae). I. Some new or little know Asiatic species of Porella. Journal of the Hattori Botanical Laboratory, 30, 129151.

Hattori S (1969) Studies of the Asiatic species of the genus Porella (Hepaticae). II. Journal of the Hattori Botanical Laboratory, 32, 319-359.

Hattori S (1970) Studies of the Asian species of the genus Porella (Hepaticae). III. Journal of the Hattori Botanical Laboratory, 33, 41-87.

Hattori S, Lin PJ (1985) A preliminary study of Chinese Frullania flora. Journal of the Hattori Botanical Laboratory, 59, 123-169.

Higuchi M (1985) A taxonomic revision of the genus Gollania (Musci). Journal of the Hattori Botanical Laboratory, 59, 1-77.

Hu RL (1983) A revision of the Chinese species of Entodon (Musci, Entodontaceae). The Bryologist, 86, 193-233.

Hu RL, Wang YF (1987) A review of the moss flora of east China. Memoirs of The New York Botanical Garden, 45, 455-465.

Hu RL, Wang YF ed. (2005) Flora Bryophytarum Sinicorum, Vol. 7. Science Press, Beijing. (in Chinese) [胡人亮, 王幼芳主编 (2005) 中国苔藓志(第7卷). 科学出版社, 北京.]

Hu RL, Wang YF, Crosby MR, He S (2008) Moss Flora of China, English Version, Vol. 7. Amblystegiaceae-Plagiotheciaceae. Science Press \& Missouri Botanical Garden, Beijing, New York \& St. Louis.

Iwatsuki Z (1963) A revision of the East Asiatic species of the genus Anomodon. Journal of the Hattori Botanical Laboratory, 26, 27-62.

Iwatsuki Z (1980) A preliminary study of Fissidens in China. Journal of the Hattori Botanical Laboratory, 48, 171-186.

Jia Y, He S (2013) Species Catalogue of China, Vol. 1. Plants: Bryophytes. Science Press, Beijing. (in Chinese) [贾渝, 何思 (2013) 中国生物物种名录第一卷・植物: 苔藓植物. 科学出版 社, 北京.]

Koponen T (1980) A synopsis of Mniaceae (Bryophyta). II. Orthomnion. Acta Botanica Fennica, $17,35-55$.

Koponen T, Li XJ, Zang M (1982) A synopsis of Rhodobryum (Musci, Bryaceae) in China. Acta Botanica Fennica, 19, 75-80.

Koponen T, Lou JS (1982) Miscellaneous notes on Mniaceae (Bryophyta). XII. Revision of specimens in the Institute of Botany, Academia Sinica, Beijing, China. Acta Botanica Fennica, 19, 67-72.

Lee SC (1958) The genus Bryoxiphium in China. Acta Phytotaxonomica Sinica, 7, 253-263. (in Chinese with English abstract) [黎兴江 (1958) 中国的虾藓. 植物分类学报, 7, 253-263.]

Lewinsky J (1992) The genus Orthotrichum Hedw. (Orthotrichaceae, Musci) in Southeast Asia. A taxonomic revision. Journal of the Hattori Botanical Laboratory, 72, 1-88. 
Li XJ ed. (1985) Bryoflora of Xizang. Science Press, Beijing. (in Chinese) [黎兴江主编 (1985) 西藏苔藓植物志. 科学出版社, 北京.]

Li XJ ed. (2000) Flora Bryophytarum Sinicorum, Vol. 3. Science Press, Beijing. (in Chinese) [黎 兴江主编 (2000) 中国苔藓志(第3卷). 科学出版社, 北京.]

Li XJ ed. (2006) Flora Bryophytarum Sinicorum, Vol. 4. Science Press, Beijing. (in Chinese) [黎 兴江主编 (2006) 中国苔藓志(第4卷). 科学出版社, 北京.]

Li XJ, Crosby MR, He S (2001) Moss Flora of China, English Version, Vol. 2. FissidentaceaePtychomitriaceae. Science Press \& Missouri Botanical Garden, Beijing, New York \& St. Louis.

Li XJ, Crosby MR, He S (2007) Moss Flora of China, English Version, Vol. 4. BryaceaeTimmiaceae. Science Press \& Missouri Botanical Garden, Beijing, New York \& St. Louis.

Li XJ, Zang M (1979) Studies on the Chinese Mniaceae. Acta Botanica Yunnanica, 1, 32-80. (in Chinese with English abstract) [黎兴江, 藏穆 (1979) 中国提灯藓科的研究. 云南植物研 究, 1, 32-80.]

Li ZH (1985) A revision of the Chinese species of Fissidens (Musci, Fissidentaceae). Acta Botanica Fennica, 129, 1-65.

Liu ZL (1988) Genus Hattorianthus (Pallaviciniaceae), a new record to China. Acta Botanica Yunnanica, 10, 193-194. (in Chinese with English abstract) [刘仲苓 (1988) 中国苔类植物 一新纪录属一假带叶苔属. 云南植物研究, 10, 193-194.]

Liu ZL, Guo XH, Hu RL (1988) Investigation on the epiphyllous liverworts from southern part of Anhui Prov., East China. Journal of East China Normal University (Natural Science), 4, 8996. (in Chinese with English abstract) [刘仲苓, 郭新弧, 胡人亮 (1988) 皖南叶附生苔研 究. 华东师范大学学报(自然科学版), 4, 89-96.]

Liu ZL, Li DK, Gao CH (1989) Mosses and liverworts. In: Cryptogamic Flora of the Yangtze Delta and Adjacent Region (ed. Xu BS), pp. 267-413. Scientistific \& Technical Publishers, Shanghai. (in Chinese) [刘仲苓, 李登科, 高彩华 (1989) 苔藓. 见: 长江三角洲及邻近 地区孢子植物志 (徐炳声主编), 267-413页. 科学技术出版社, 上海.]

Luo JX, Koponen T (1986) A revision of Atrichum (Musci, Polytrichaceae) in China. Annales Botanici Fennici, 23, 33-47.

Min YJ (1997) Research of bryophyta of common epixylia and their indicating effect to air pollution in the urban district of Lu'an City. Urban Environment \& Urban Ecology. 10(4), 31-33. (in Chinese with English abstract) [闵运江 (1997) 六安市区常见树附生苔藓植物及其对大气 污染的指示作用研究. 城市环境与城市生态, 10(4), 31-33.

Mizutani M, Chang KC (1986) A preliminary study of Chinese Lepidoziaceae flora. Journal of the Hattori Botanical Laboratory, 60, 419-437.

Nishimura N (1985) A revision of the genus Ctenidium (Musci). Journal of the Hattori Botanical Laboratory, 58, 1-82.

Noguchi A (1957) A revision of the genus Haplohymenium Doz. et Molk. (Musci). Kumamoto Journal of Science, Series B: Section 2, 3, 20-31.

Noguchi A (1976) A taxonomic revision of the family Meteoriaceae of Asia. Journal of the Hattori Botanical Laboratory, 41, 231-357.

Paris EG (1908) Muscinées de l'Asie orientale. 7. Revue Bryologique, 35, 40-55.

Paris EG (1909) Muscinées de l'Asie Orientale. 9. Revue Bryologique, 36, 8-13.

Paris EG (1911) Mousses de l'Asie orientale. 12. Revue Bryologique, 38, 53-60.

Peng T, Li F, Liu XX, Tang LY, Li TT, Jiang Y, Xia HX, Zhou XP (2018) Provincial new records 
for from Anhui and Guizhou - Megaceros flagellaris. Journal of Guizhou Normal University (Natural Sciences), 36(5), 65-68. (in Chinese with English abstract) [彭涛, 李飞, 刘行行, 唐 录艳, 李婷婷, 蒋娅, 夏红霞, 周徐平 (2018) 安徽和贵州的省级分布新记录种一东亚 大角苔Megaceros flagellaris. 贵州师范大学学报(自然科学版), 36(5), 65-68.]

Piippo S (1990) Annotated catalogue of Chinese Hepaticae and Anthocerotae. Journal of the Hattori Botanical Laboratory, 68, 1-192.

Potier de la Varde RAL (1918) Sur trois mousses inedites de la Chine orientale. Revue Générale de Botanique, 30, 346-354.

Potier de la Varde RAL (1937) Contribution a la flore bryologique de la Chine. Revue Bryologique et Lichénologique, 10, 136-145.

Qian L, Tsai KH (1989) Some bryophytes new to China found in Anhui, China. Bulletin of Botanical Research, 9(1), 81-84. (in Chinese with English abstract) [钱琳, 蔡空辉 (1989) 安 徽产苔藓植物新记录种. 植物研究, 9(1), 81-84.]

Redfearn Jr PL, Tan BC, He S (1996) A newly updated and annotated checklist of Chinese mosses. Journal of the Hattori Botanical Laboratory, 79, 163-357.

Reimers H (1931) Beiträge zur moosflora Chinas I. Hedwigia, 71, 1-77.

Shi XQ, Tang X, Wei YM, Wang J (2018) Study and investigation of Lejeuneaceae species diversity in Anhui Province. Journal of East China Normal University (Natural Science), 4, 138-146. (in Chinese with English abstract) [师雪芹, 唐霞, 韦玉梅, 王健 (2018) 安徽省细鳞苔科 植物物种多样性调查与研究. 华东师范大学学报(自然科学版), 4, 138-146.]

So ML (2001) Plagiochila (Hepaticae, Plagiochilaceae) in China. Systematic Botany Monographs, $60,1-214$.

So ML, Zhu RL (1998) on six species of the genus Lejeunea in China, including one new species. The Bryologist, 101, 137-143.

Tchen PT (1936) Note preliminaire, sur les bryophytes de Chine. Contributions from the Institute of Botany, National Academy of Peiping, 4, 301-336.

Wang J, Zhu RL, Gradstein SR (2016) Taxonomic revision of Lejeuneaceae subfamily Ptychanthoideae (Marchantiophyta) in China. Bryophytorum Bibliotheca, 65, 1-141.

Wang QH, Jia Y (2012) A taxonomic revision of the Asian species of Ulota Mohr (Orthotrichaceae). The Bryologist, 115, 412-443.

Wu DL, Zhang L ed. (2013). Bryophyte Flora of Guangdong. Guangdong Provincial Publishing Group, Guangzhou. (in Chinese) [吴德邻, 张力主编 (2013) 广东苔藓志. 广东省出版集团, 广州.]

Wu MK, Cao T, Zhang XP (2008) Study on moss flora of Anhui Province, China. Acta Botanica Yunnanica, 30, 645-654. (in Chinese with English abstract) [吴明开, 张小平, 曹同 (2008) 安徽藓类植物区系. 云南植物研究, 30, 645-654.]

Wu MK, Cao T, Zhang XP (2010a) Investigation on mosses of Anhui Province, China. Journal of Anhui Agricultural University, 37, 735-743. (in Chinese with English abstract) [吴明开, 曹 同, 张小平 (2010a) 安徽藓类植物调查研究. 安徽农业大学学报, 37, 735-743.]

Wu MK, Zhang XP, Cao T (2010b). Newly recorded genera and species of Musci in Anhui Province. Journal of Anhui Agricultural Sciences, 38, 1650-1651. (in Chinese with English abstract) [ 吴 明开, 张小平, 曹同 (2010b) 安徽藓类植物地理分布新纪录. 安徽农业科学, 38, 16501651.] 
Wu PC ed. (2002) Flora Bryophytarum Sinicorum, Vol. 6. Science Press, Beijing. (in Chinese) [吴 鹏程主编 (2002) 中国苔藓志(第6卷). 科学出版社, 北京.]

Wu PC, Crosby MR, He S (2002) Moss Flora of China, English Version, Vol. 6. HookeriaceaeThuidiaceae. Science Press \& Missouri Botanical Garden, Beijing, New York \& St. Louis.

Wu PC, Crosby MR, He S (2005) Moss Flora of China, English Version, Vol. 8. Sematophyllaceae—Polytrichaceae. Science Press \& Missouri Botanical Garden, Beijing, New York \& St. Louis.

Wu PC, Crosby MR, He S (2011) Moss Flora of China, English Version, Vol. 5. ErpodiaceaeClimaciaceae. Science Press \& Missouri Botanical Garden, Beijing, New York \& St. Louis.

Wu PC, Guo XH (1986) A report on the epiphyllous liverworts in Anhui Province, China. Acta Phytotaxonomica Sinica, 24, 136-138. (in Chinese with English abstract) [ 吴鹏程, 郭新弧 (1986) 安徽叶附生苔植物初报. 植物分类学报, 24, 136-138.]

Wu PC, Jia Y ed. (2004) Flora Bryophytarum Sinicorum, Vol. 8. Science Press, Beijing. (in Chinese) [吴鹏程，贾渝主编 (2004) 中国苔藓志(第8卷). 科学出版社，北京.]

Wu PC, Jia Y ed. (2011) Flora Bryophytarum Sinicorum, Vol. 5. Science Press, Beijing. (in Chinese) [吴鹏程，贾渝主编 (2011) 中国苔藓志(第5卷). 科学出版社, 北京.]

Wu PC, Jia Y, Wang QH, Yu NN, He Q (2018) Chinese Illustrated Bryophytes. China Forestry Press, Beijing. (in Chinese) [吴鹏程，贾渝，王庆华，于宁宁，何强 (2018) 中国苔藓图鉴. 中国林业出版社，北京.]

Wu PC, Jia Y, Zhang L ed. (2012) Higher Plants of China, Vol. 1. Bryophyta. Qingdao Press, Qingdao. (in Chinese) [吴鹏程，贾渝，张力主编 (2012) 中国高等植物第一卷. 苔藓植物 门. 青岛出版社, 青岛.]

Yamada K (1979) A revision of Asian taxa of Radula, Hepaticae. Journal of the Hattori Botanical Laboratory, 45, 201-322.

Yamada K (1982) Some new records on Radula collections from China. Miscellanea Bryologica et Lichenologica, 9, 129-131.

Zhang MZ, Lai MZ ed. (1993) Checklist of Plants of Five Provinces and One City in Eastern China. Shanghai Popular Science Press, Shanghai. (in Chinese) [张美珍, 赖明洲主编（1993) 华东 五省一市植物名录. 科学普及出版社, 上海.]

Zhao CH, Zhang ZH (2006) Studies on bryophytes in the Shizishan copper mine of Tongling City, Anhui. Journal of Guizhou Normal University (Natural Sciences), 24(2), 7-12. (in Chinese with English abstract) [赵传海, 张朝晖 (2006) 安徽铜陵狮子山铜矿苔蘚植物研究. 贵州 师范大学学报(自然科学版), 24(2), 7-12.]

Zhou LP, Zhang L, Xing FW (2012) Taxonomical review of Bazzania (Lepidoziaceae, Marchantiophyta) in China. Journal of Fairylake Botanical Garden, 11(2), 1-62. (in Chinese with English abstract) [周兰平, 张力, 刑福武 (2012) 中国鞭苔属植物的分类学研究. 仙 湖, 11(2), 1-62.]

Zhu RL (1995) Notes on some species of the genus Cololejeunea (Lejeuneaceae, Hepaticae) in China. Journal of the Hattori Botanical Laboratory, 78, 83-109.

Zhu RL, Gradstein SR (2005) Monograph of Lopholejeunea (Lejeuneaceae, Hepaticae) in Asia. Systematic Botany Monographs, 74, 1-98.

Zhu RL, Grolle R (2001) Notes on the taxonomy and distribution of Acanthocoleus yoshinaganus and Lejeunea papilionacea (Hepaticae, Lejeuneaceae). Annales Botanici Fennici, 38, 329-336.

Zhu RL, So ML (1999) Additions of Lejeuneaceae taxa to the hepatic flora of Yunnan, China. 
Annales Botanici Fennici, 36, 219-229.

Zhu RL, So ML (2000) Additions and correction for Chinese Lejeuneaceae (Hepaticae). Botanical Bulletin of Academia Sinica, 41, 243-250.

Zhu RL, So ML (2001) Epiphyllous liverworts of China. Nova Hedwigia Beiheft, 121, 1-418.

Zhu RL, So ML, Wang YF (2002) The genus Cheilolejeunea (Hepaticae, Lejeuneaceae) in China. Nova Hedwigia, 75, 387-408.

Zhu RL, Wang YF (1992) A preliminary revision of epiphyllous liverworts from Dinghushan. Journal of East China Normal University (Natural Science), 2(2), 90-97. (in Chinese with English abstract) [朱瑞良, 王幼芳 (1992) 鼎湖山叶附生苔类植物的初步研究. 华东师范 大学学报(自然科学版), 2(2), 90-97.] 